University of San Diego

Digital USD

2021-05-16

\title{
Expanding Consciousness Across Disruptions: Developmental Leadership Coaches Growing Together Through Action Inquiry
}

Ilaria Distefano

University of San Diego

Follow this and additional works at: https://digital.sandiego.edu/dissertations

Part of the Leadership Studies Commons

\section{Digital USD Citation}

Distefano, llaria, "Expanding Consciousness Across Disruptions: Developmental Leadership Coaches Growing Together Through Action Inquiry" (2021). Dissertations. 188.

https://digital.sandiego.edu/dissertations/188 


\title{
EXPANDING CONSCIOUSNESS ACROSS DISRUPTIONS
}

\section{DEVELOPMENTAL LEADERSHIP COACHES GROWING TOGETHER} THROUGH ACTION INQUIRY

\author{
by \\ Ilaria Distefano \\ A dissertation submitted in partial fulfillment \\ of the requirements for the degree of \\ Doctor of Philosophy
}

May 2021

Dissertation Committee

Cheryl Getz, EdD, Chair

Antonio Jiménez-Luque, $\mathrm{PhD}$, Member

René Molenkamp, PhD, Member

University of San Diego 
(C) Copyright by Ilaria Distefano

All Rights Reserved 2021 


\section{University of San Diego School of Leadership and Education Sciences}

CANDIDATE'S NAME: Ilaria Distefano

TITLE OF DISSERTATION: EXPANDING CONSCIOUSNESS ACROSS DISRUPTIONS: DEVELOPMENTAL LEADERSHIP COACHES GROWING TOGETHER THROUGH ACTION INQUIRY

APPROVAL:

, Chair

$$
\text { Cheryl Getz, EdD }
$$
, Member

Antonio Jiménez-Luque, $\mathrm{PhD}$ , Member

René Molenkamp, PhD

DATE: December 11, 2020 


\begin{abstract}
The planetary, societal, and personal challenges of our times call for the expansion of leaders' consciousness. More comprehensive and integrated ways of making meaning of self and systems are required to navigate the current levels of complexity. Based on constructive-developmental theory, developmental leadership coaching supports leaders in this evolution.

The literature on developmental coaching converges on the relevance of the coach's meaning-making to coaching outcomes and processes. The purpose of this study was to explore how seven developmental leadership coaches, including the researcher, could evolve their consciousness, capacities and skills using action inquiry. Seven meetings were held, and knowledge and development were generated through ongoing self- and mutual inquiry among individual co-inquirers, and with the whole system of participants. The context of the global COVID-19 pandemic and of systemic racism profoundly marked the experience and the learnings of the co-inquirers.

Data were collected through video-recording of the meetings, post-meeting questionnaires, e-mail exchanges among co-inquirers, analytical memos, and individual post-co-inquiry interviews with each participant. Also, each co-inquirer's meaningmaking was assessed through the Leadership Maturity Assessment Profile. Data analysis was based on coding and inductive categorization of the emerging themes.

Findings demonstrated individual and collective developmental movements that emerged throughout the study. Key learnings included the potential of action inquiry as a methodology supporting growth through disruption. Growth was evident for each coinquirer as a whole self, as a self in relationship with others, and as part of the Whole.
\end{abstract}


This was conducive to expanded capacity for presence, integration, and (personal, mutual and systemic) regeneration. At the group level, the following factors emerged as impacting growth: (1) intentionality, (2) open and secure container, (3) leadership as hosting, (4) co-leadership, and (5) the space between and beyond. Three meta-insights about the expansion of consciousness through disruption highlighted the importance of dwelling within the lived experience of systemic complexity, growing together with others, and re-training unitive consciousness across the developmental spectrum.

This study contributes to the understanding of developmental leadership coaching, and to the theory and practice of action inquiry as a method for personal, mutual and systemic growth across disruptions. 


\section{DEDICATION}

To Elias, Francesco, and Alessandro Ottolini, whose love made this possible. 


\section{ACKNOWLEDGMENTS}

This dissertation contains the love, the light, and the dedication of many fellow human beings across time and space. It purely is a participatory accomplishment.

I am infinitely grateful to:

My six co-inquirers, for their generosity of heart and energy, and for their commitment to the expansion of consciousness.

Cheryl Getz, my beacon of light throughout the doctoral program, for meeting me in vulnerability and exploration, and for showing me beautiful ways to "teach love."

René Molenkamp, for his compassion, insightfulness, and spaciousness, and the revelations catalyzed on the path of this dissertation.

Toni Jiménez-Luque, for his ever-flowing energy and support, and his generous sharing of his experience since our first class together.

Hilary Bradbury and Toni Petrinovich, for their luminous, unwavering guidance.

Susanne Cook-Greuter, for her insights into my/our developmental unfolding.

Shakiyla Smith, for her foundational example.

Ryosuke Watanabe and Sanket Patel, for their developmental friendship since our first steps in the doctoral program.

My teachers, mentors, colleagues, and clients, for their presence on the journey.

My family and friends all over the world, for being with me, always.

My husband Elias Ottolini, for his loving, unconditional support and the sacrifices he made so that I could walk this road. And our children, Francesco and Alessandro, who constantly light my way. 


\section{TABLE OF CONTENTS}

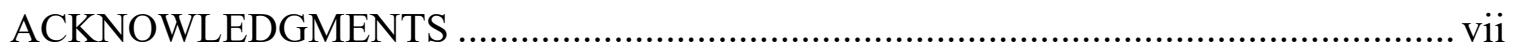

TABLE OF CONTENTS ................................................................................ viii

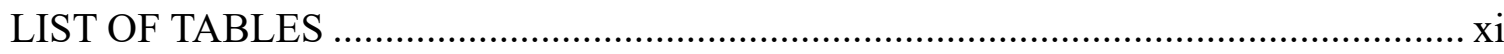

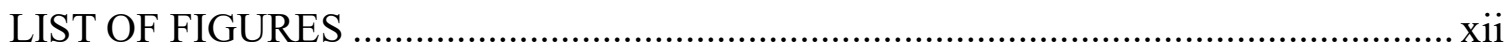

CHAPTER ONE BACKGROUND ........................................................................... 1

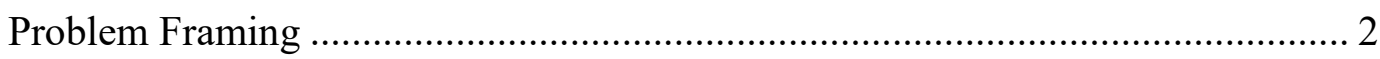

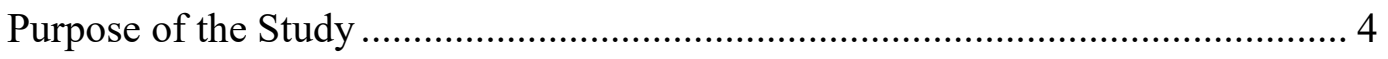

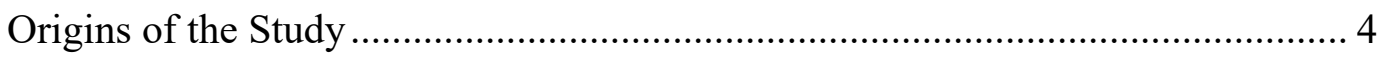

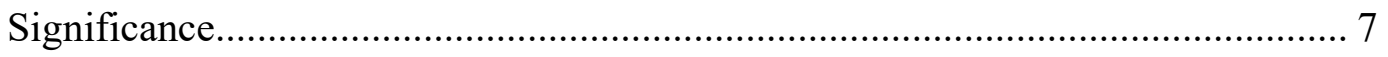

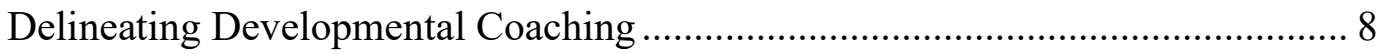

Coaches' Making Meaning of Developmental Coaching. ............................. 12

CHAPTER TWO LITERATURE REVIEW ............................................................. 21

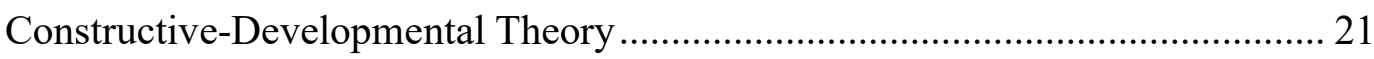

The Complexity (and Ineffability?) of the Developmental Unfolding: Critiques

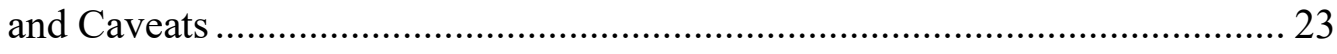

Constructive-Developmental Models ....................................................... 28

Post-Conventional Consciousness and Leadership.......................................... 42

Post-Conventional Leadership Capacities ................................................. 44

Possible Post-Conventional Mistakes ........................................................ 52

Leadership Theories Conceptualizing Post-conventional Awareness and

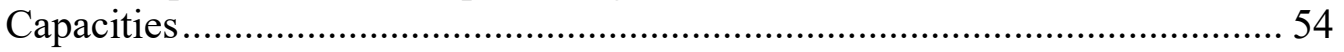

Coaching and Developmental Levels ......................................................... 58

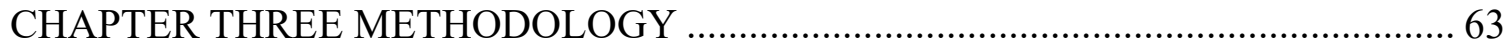

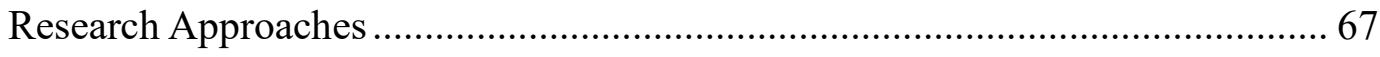

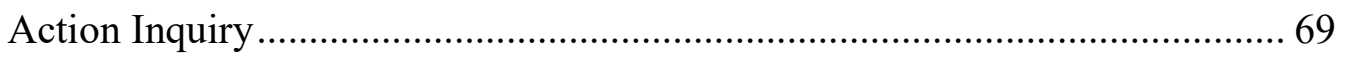

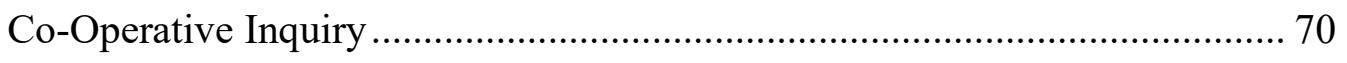

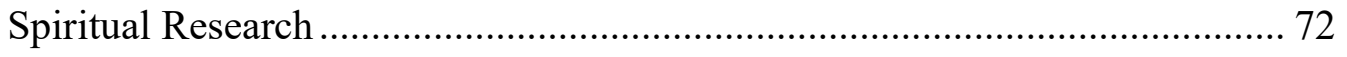




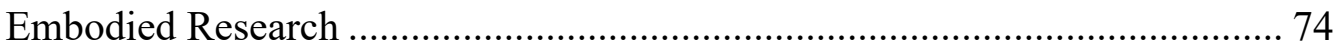

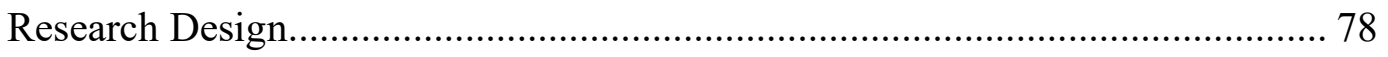

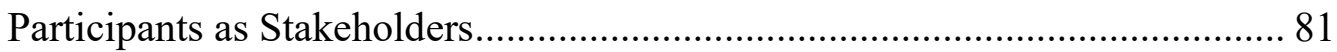

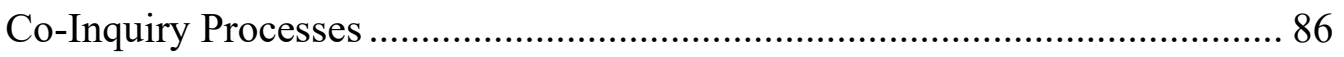

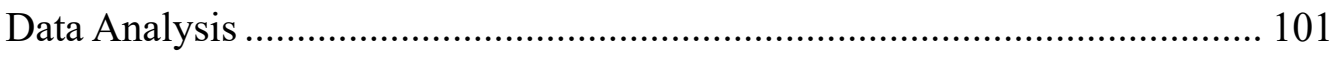

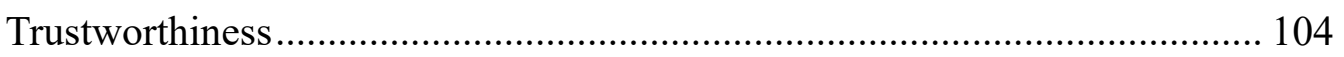

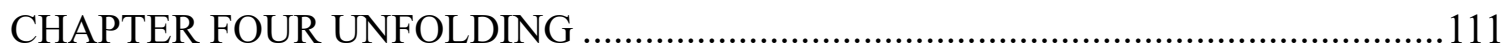

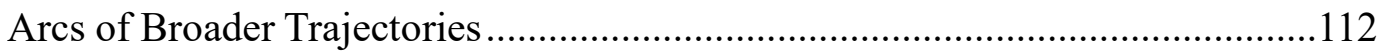

Igniting Intentionality, Glimpsing Growth Edges...........................................112

Connecting With Different Aspects of Ourselves, Bonding With Others........118

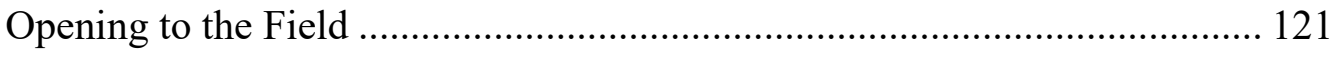

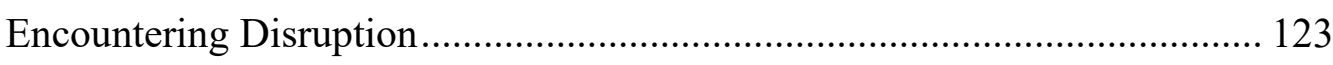

Connecting, Disconnecting, Re-connecting — Blurring our Developmental

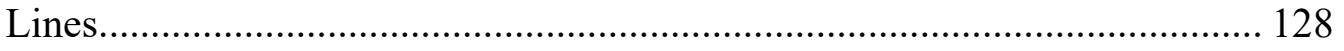

Developing Capacity and Skills to Navigate Systemic Disruptions................ 132

Sketching Developmental Movements ............................................................. 143

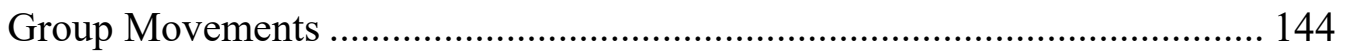

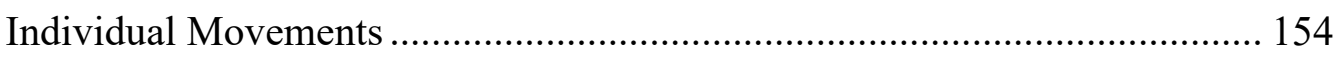

Renewed Awareness Across Developmental Stages: The Expansion of Consciousness is Relational, Eco-Logical, and Ever-Unfolding ..................... 189

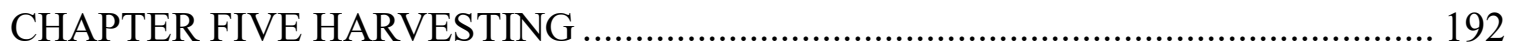

Growing as Instruments Supporting Growth .................................................... 193

Growing as Whole Self............................................................................. 194

Growing as Self in Relationship With Others and as an "Invitation" to

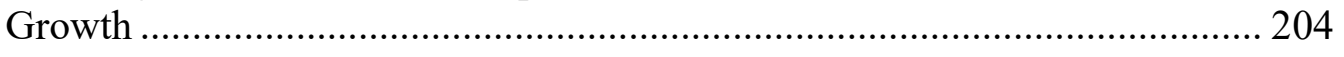

Growing as Part of The Whole .................................................................. 210

Growing in Presence, Integration, and Regeneration ..................................... 216

Growing as A System Supporting Growth...................................................... 217

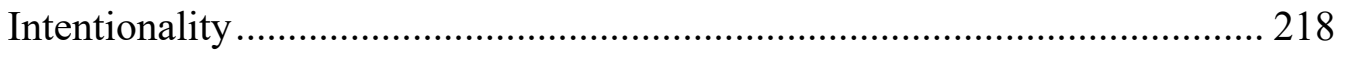

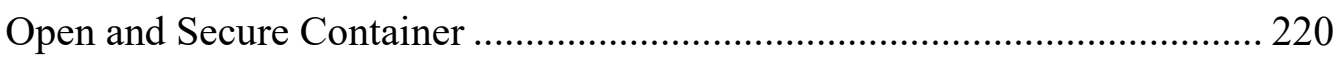

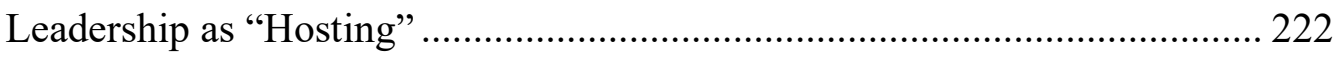




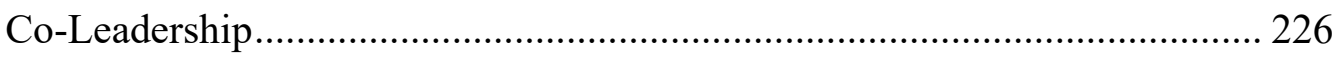

The Space Between and Beyond ............................................................... 228

CHAPTER SIX PLANTING FRESH SEEDS ………………………………....... 230

Three Insights From the Co-Inquiry ………………….................................. 230

Dwelling Within Our Lived Experience ………………………………..... 231

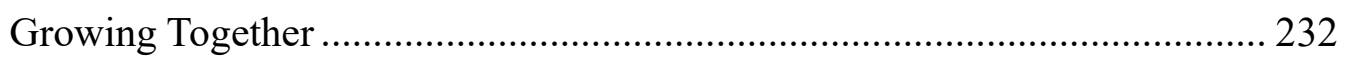

Re-training Unitive Consciousness ............................................................. 235

Pursuing (Action) Research Supporting the Expansion of Consciousness Through Disruption ............................................................................................... 239

Developing Methodologies Supporting Growth Through and From Disruption 242

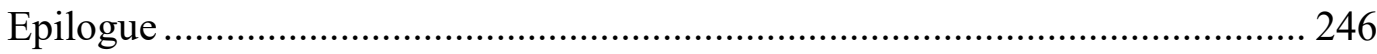

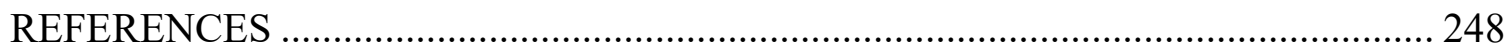

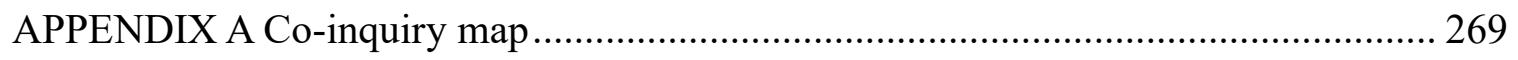

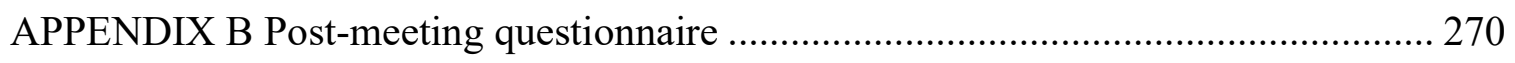

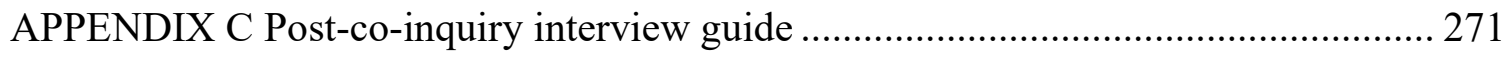

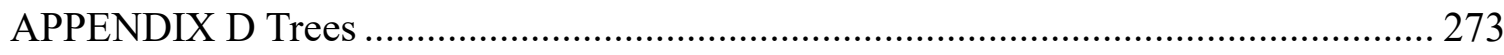




\section{LIST OF TABLES}

Table 1. A summary of Kegan's Subject-Object balances. ............................................ 31

Table 2. Cook-Greuter and Torbert's stages/action-logics and their distribution among US

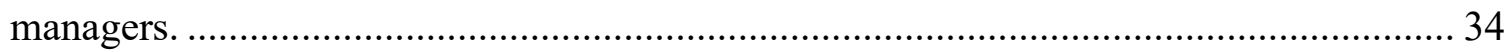

Table 3. Kegan's orders of development and Cook-Greuter and Torbert's stages/action-

logics within Miller and Cook-Greuter's (1994) tiers classification. ............................ 35

Table 4. Co-inquiry members diversity.................................................................... 84

Table 5. Co-inquiry meetings initial calendar......................................................... 88

Table 6. Group membership at each meeting............................................................... 92

Table 7. The potential of the co-inquiry in terms of the co-inquirers' growth as

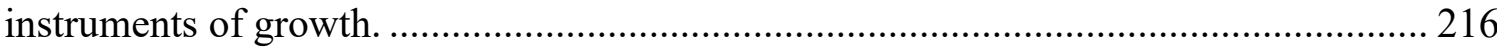




\section{LIST OF FIGURES}

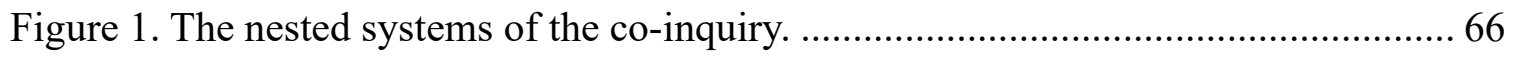

Figure 2. A simplified version of the co-inquiry "map" illustrating its spiraling, emergent

movement, and the key factors substantiating the process. ........................................ 79

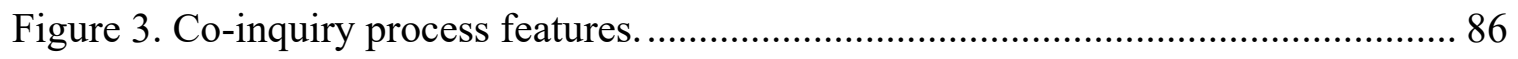

Figure 4. Meetings' topics against the disruptive space/time of the co-inquiry............... 94

Figure 5. Emerging elements of the co-inquirers' growth edges. ...............................117

Figure 6. Impressions of racial brutality processing, at our sixth meeting, on June 8, 2020.

Figure 7. Words emerging from our work around systemic racism and our personal

calling in life at our sixth meeting, on June 8, 2020.

Figure 8. Excerpt from my presentation of my MAP assessment debrief built through

synchronicities. 


\section{CHAPTER ONE}

\section{BACKGROUND}

The planetary, societal, and personal challenges of our times call for the expansion of leaders' consciousness. The development of comprehensive, differentiated, integrated ways of making sense of self and systems is critical to artfully and adaptively deal with our world's increasing complexity (Heifetz, 1994; Kegan \& Lahey, 2009; Torbert \& Associates, 2004). A growing number of scholars and practitioners claim that skillset or "horizontal" development, based on the acquisition of knowledge, competence and efficiency is not sufficient: leadership development needs to be augmented by incorporating the "vertical" development perspective (Harris \& Kuhnert, 2008; Joiner, 2013; Petrie, 2011; Torbert, 2017). If horizontal development is based on what we know, vertical development is centered on how we know. It can be described as a shifting in the way we make sense of the world, "how we learn to see the world through new eyes, how we change our interpretations of experience and how we transform our views of reality" (Cook-Greuter, 2004, p. 276). A specific nature and quality of leadership emerges at expanded levels of consciousness. Complex and integrated ways of making meaning of experience are conducive to increased effectiveness, and enhanced transformative capacities and skills (McCauley et al., 2006; Torbert, 2017). These include self-awareness and self-inquiry; the capacity for connection with and integration among different perspectives, cultures, and dimensions of experience; the capacity for complex thinking and for embracing and overcoming paradox; an experience of reality that is more direct and variegated, supported by different ways of thinking, feeling, sensing, and intuiting; the exercise of power as embedded in mutuality and imbued with authentic care for 
people, systems, and ecologies (Anderson \& Adams, 2016, 2018; Brown, 2012; Hewlett, 2004; Joiner, 2011; Kelly, 2013; Legault, 2010; Nicolaides, 2008; Presley, 2014; Rooke \& Torbert, 2005; Torbert, 1996; Torbert \& Associates, 2004). Arguably, these capacities and skills are "no luxury" in complex times, as Kegan (2009, as cited in Bachkirova, 2009 , p. 17) puts it, and appear vital in the cycle of chaos the world has inexorably entered (Wheatley, 2017).

To support the expansion and strengthening of adaptive and transformative capacities, developmental leadership coaching is embracing the mission to equip leaders with new mind-sets, in addition to new skill-sets, and with new understandings, in addition to new knowledge. Evolving one's way of understanding the world and making sense of experience allows "increases in what we are aware of, or what we can pay attention to, and, therefore, what we can influence and integrate" (Cook-Greuter \& Soulen, 2007, p. 182).

The emerging theory and practice of developmental coaching (Bachkirova, 2011; Berger \& Fitzgerald, 2002; Laske, 1999; Sharma, 2019) integrates the constructivedevelopmental approach (Cook-Greuter, 1999; Kegan, 1982, 1994; Torbert \& Associates, 2004), focusing on the organizing principles of leaders' ways of making sense of experience. Equated to "developmental midwives" by Inglis and Steele (2005), coaches can assist society in growing its "complexity intelligence" (p. 36), defined as an integration of increasingly complex cognitive, emotional, and social abilities.

\section{Problem Framing}

Developmental coaching literature describes the main intention of this practice as to create the conditions for leaders' growth in consciousness and complexity of mind, 
also referred to as meaning-making. Research in the field of developmental coaching is still incipient, and the constructive-developmental perspective is not adequately contemplated in coaching studies, practice, training and assessment (Astorino, 2002; Bachkirova, 2016; Bachkirova \& Lawton Smith, 2015; Laske, 2006). In particular, there is a dearth of studies around the meaning-making of coaches themselves (Laske, 2006; Kennedy, 2012; Perry, 2014; Potter, 2017; Scott, 2009). Yet, existing developmental coaching research highlights the relevance of coaches' own complexity of mind for the coaching processes and outcomes, ultimately calling the coaches to engage for the expansion of their consciousness in order to support growth in the clients (Bachkirova, 2016; Diehl, 2010; Laske, 1999, 2003; Perry, 2014; Scott, 2009; Wildflower, 2006). Highlighting the importance for coaches to be aware of their own meaning-making, Bachkirova (2011), Berger (2012) and Sharma (2019) attempt, with different theoretical lenses, to sketch the traits, driving forces and approaches distinguishing coaches and coaching approach at various levels of development: growing in complexity of mind, coaches tend to become more agile and creative with the tools and frameworks at their disposal as well as more flexible and impactful in using themselves as instruments (Kennedy, 2012), and meeting their clients where they are developmentally. Consensus is strong, among developmental coaching scholars/practitioners, around the necessity for coaches to be at least at the same level of consciousness as their clients to effectively support them developmentally (Bachkirova, 2016; Diehl, 2010; Laske, 1999, 2003; Perry, 2014; Scott, 2009; Wildflower, 2006).

These are important claims about coaches' meaning-making informing the coaching engagement and the role that coaches can play in supporting leaders' vertical 
development. Furthermore, coaches primarily use their self as instrument (i.e., leveraging their consciousness, their ways of understanding, and their cognitive, emotional, and somatic experience of the interaction with the client). Thus, it is critical to explore and expand the consciousness, in addition to the skillset, of these professionals.

\section{Purpose of the Study}

Animated by a personal, professional, deontological commitment to development, seven developmentally oriented leadership coaches including me engaged in this collective inquiry into their own consciousness. Our grounding intention was to explore the ways we could, individually and collectively, evolve our capacities and skills for developmental coaching. The main question guiding this research is: How can we, as a group of developmentally oriented leadership coaches, grow individually and collectively in our consciousness and in our capacity for developmental coaching through action inquiry?

The study is epistemologically and methodologically rooted in action inquiry, and particularly Collaborative Developmental Action Inquiry (CDAI) (Torbert, 2017). CDAI is simultaneously a theory and research/practice approach to the development of individuals and systems. CDAI aspires to generate increased integrity, mutuality among individuals, and social systems' sustainability (Torbert \& Associates, 2004). The individual, mutual, and systemic dimensions are concurrently significant in this study. To honor and highlight its participatory nature, I will refer to the study as "co-inquiry."

\section{Origins of the Study}

The participatory essence of the project is rooted in my experience of being held by "good company" (Baxter-Magolda, 2009, p. 2) during the life passage that I identify 
with the origin of this study. My positionality as a developmental coach and as a developing human being, that I describe here, was shared at the very beginning of the project with the other co-inquirers.

I have been working in people and organizational development for over 15 years, in different capacities and particularly as a certified leadership coach. What inspires me is the exploration of people and systems' potential for continuous growth. As part of my doctoral program in Leadership Studies, I have been learning about human development and experiencing environments as well as research methods conducive to development. Most importantly, the theories and the language I have been learning (in more ways than one, since I mostly used to work in French and Italian before moving to San Diego in 2016), provided me with a meaningful conceptual space in which to make sense of my concurrent personal experiences. During the program, I have gone through life-changing phases such as becoming a mom and, a few days later, experiencing the passing of one of my twins. These experiences allowed me to live and view development in a new light, colored by the search for the meaning — and the mystery—of life. My spiritual life deepened and broadened, and my renewed awareness of our essential wholeness and oneness (Bateson, 1972, 2002; Blackstone, 2006; Bohm, 2002) started to color all my experiences, roles, and intentions. That strengthened my commitment to cultivating integrity and ongoing self-generation through mind-heart-body-soul practices—and (action) inquiry-to support the expansion of consciousness in myself and others. I view developmental coaching as a critical leaderly practice (Ladkin, 2010) for social change, one that can scaffold the shifting of assumptions, beliefs, and loyalties in self and others (Heifetz, Grashow, \& Linsky, 2009), encourage a more purposeful, re-enchanted 
(Berman, 1981) way of being, foster the expansion of human capacities, and help create timely transformation for a more just and sustainable world (Torbert, 1987). That is why I am actively engaged for the evolution, the professionalization, and the dissemination of a developmental kind of coaching, as well as for my own continuous development in my practice.

What supported me in those recent, crucial phases of my life, and continues to support me in the current phase of integration, is the connection with good company. I am infinitely grateful to my family, friends, teachers, mentors, peers and clients who have been holding the space for my inner processes of growth to unfold. And I am deeply aware of the relational nature of my constant, personal and professional development. This study originated from the intention to co-create a space for the deliberate, and mutual evolution of the consciousness of persons whose work includes helping people and systems grow. The literature exploring adult development shows that a developmental holding environment, such as a CDAI-based community of inquiry, and the company of individuals at advanced levels of meaning-making, are critical on the developmental journey (Ghosh, Haynes \& Kram, 2013; Kegan, 1994; McCauley et al., 2006; Torbert \& Associates, 2004). In 2018 I participated in an action inquiry project hosted by scholar and action researcher Hilary Bradbury with five other coaches wishing to explore how coaching can scaffold vertical development, and I directly experienced the transforming impact of such communities of inquiry. That fueled my motivation to pursue this kind of work with another group of committed coaches. Another important source of inspiration for this research was Shakiyla Smith's (2016) dissertation reporting about the experience of seven women of color, including the author, who engaged in CDAI with 
the intention to evolve their consciousness. It is on the strength of these direct and indirect experiences that I engaged in the developmental action inquiry documented here.

\section{Significance}

There is limited participatory action research exploring consciousness (Smith, 2016), and virtually no documented experience of coaches co-inquiring into their own consciousness. The knowledge generated by this study is a function of the specific, emergent qualities of the co-inquiry group, and as such it contributes to the incipient exploration of developmental coaching (Bachkirova, 2009, 2011; Berger \& Fitzgerald, 2002; Laske, 1999; Sharma, 2019), shedding light on the underexplored development of the coaches themselves (Laske, 2006; Kennedy, 2012; Perry, 2014; Potter, 2017; Scott, 2009). More broadly, our experience, methods and learnings could resonate with other practitioners and (action) researchers committed to exploring the dynamics of the evolution of consciousness and the potential of developmental theories and practices to support them (Torbert, 2017).

Beyond the creation of practical knowledge, the significance of the co-inquiry lies in the individual and collective development of the participants, and potentially, through them, of their systems. The cultivation of coaches' capacities and skills has the potential to translate in more effective developmental coaching with their clients, and the expansion of consciousness of coaches and clients alike may be a benefit to their whole ecology (Anderson \& Adams, 2016, 2018; Brown, 2012; Joiner, 2013; Joiner \& Josephs, 2007; Kelly, 2013; Legault, 2010; Presley, 2014; Torbert, 1987, 1996; Torbert \& Associates, 2004). 
Also, this study could contribute to foster critical developmental work in organizations and communities by inspiring leaders and developmentally oriented practitioners to further experiment with coaching- and action inquiry-based methodologies to support the expansion of consciousness in our systems. The simultaneously investigative and developmental endeavor of this co-inquiry appears particularly timely as the world, in its increasing complexity and chaos, calls for capacities and skills, particularly in leadership, to navigate the ecological, social and spiritual challenges (Scharmer, 2018) of our times.

\section{Delineating Developmental Coaching}

The International Coach Federation (IFC), the largest professional coaching organization in the world, defines coaching as "partnering with clients in a thoughtprovoking and creative process that inspires them to maximize their personal and professional potential" (http://www.coachfederation.org, n.d.). The way “deliberately developmental" (Kegan and Lahey, 2016, p. 3) leadership coaching embraces this intention is by specifically focusing on leaders' meaning-making. The quality of perception and awareness undergirds the possibility for the increase of human capacities and the long-term development of the whole person in her systems. The goal of developmental coaching is actually to help clients sustainably be effective at attending to their needs and aspirations, and respond to, engage with, and influence their environment (Bachkirova, 2011; Cox \& Jackson, 2010; Hawkins \& Smith, 2006).

According to Kegan (1994), development happens when we can step back and observe our previously hidden belief systems, assumptions, and life stances - in other words when these move from subject to object. Drago-Severson (2009) offers a clear 
distinction between what is subject and what is object: "we cannot take a perspective on what we are subject to because we are embedded in it; it is not separate from our selves. In contrast, that which is taken as object can be organized and reflected upon" (p. 37). Thus, when our assumptions about ourselves, others, and the world—which govern our making meaning of our experience—-become object, they are "distinct enough from us that we can do something with [them]" (Kegan, 1994, p. 32).

Development is an incremental process that unfolds in the interaction with our environment (Kegan, 1982). It is simultaneously an individual, mutual and systemic dynamic. Kegan (1982) argues that the process can be nurtured and supported, yet it cannot be forced. This is in line with the practice of coaching, which aims to offer a soundboard for the clients to find their own awareness, choices and directions for action, (differently from consulting or counseling, where solutions are mainly offered by the professionals based on their expertise), and has particular significance in the perspective of developmental coaching. Developmental coaches can support their clients' growth in consciousness by holding an environment conducive to it, yet without any claim to know what's best for their clients, where they should be developmentally, and how to reach that point. As Kegan (1982) puts it, “amongst the many things from which a practitioner's client needs protection is the practitioner's hopes for the client's future, however benign and sympathetic these hopes may be" (p. 295).

Developmental coaches evaluate their clients' developmental readiness-i.e., their being ready for the expansion of their complexity of mind-based on internal, environmental and sociocultural factors (Palus \& Drath, 1995). They particularly examine their clients' developmental "heat" (Petrie, 2015, p. 1), i.e., their need to evolve 
their meaning-making in order to meet new or more complex demands of their environment that would otherwise leave them in over their heads (Kegan, 1994). Developmental coaching can particularly serve people who find themselves at a growth edge (Berger, 2012), whose meaning-making proves inadequate in their current situations. However, vertical development may not be perceived as relevant or needed for other clients: depending on the issues and priorities they are facing in their life and work, focusing on horizontal development, or on the strengthening of their capacities and skills within their current meaning-making, may be more beneficial (Cook-Greuter, 2011). Deeper integration of one's current complexity of mind can lead to increased effectiveness and fulfillment (Flaherty, 2010).

If the opportunity and the need for developmental coaching exist, developmentally oriented coaches create the conditions for the examination of hidden assumptions and shifts in awareness. This is generally supported by an assessment of the clients' meaning-making based on a specific theoretical framework (such as Kegan, Cook-Greuter and Torbert's models, explored in the following chapter), and, at times, by the use of an assessment tool. Offering a cross-framework option, and as a way to avoid the issues related to the complexity of developmental measurement, also addressed later, Bachkirova (2011) advises coaches to assess their clients' meaning-making by focusing on the themes they bring to coaching (i.e., the challenges and demands they encounter in their environment). The patterns that a coach can recognize in those themes can usually be associated with specific developmental stages.

Developmental coaches work in different ways with people at different stages of development. They tailor their interventions to help their clients make subject-object 
shifts and evolve along the developmental trajectory (generally according to one specific espoused framework). They can do this by, for example, supporting the beginning of the transition to another stage, a more consolidated inhabiting of one specific stage, or a better integration of elements from previous stages (Sharma, 2019). This requires a skillful attending to the self-models (or understanding of themselves) developed by the clients, and to the unconscious dynamics as well as the emotional and somatic expressions of their experience (Bachkirova, 2011). Also, a good balance of challenge and support is necessary from the coaches' part as the clients experiment with new perspectives and alternative ways of meaning-making of themselves, others, and systems (Berger \& Fitzgerald, 2002, 2019).

Developmental movement is challenging: Kegan warns us that "the first impulse of those who make discoveries about the limited nature of their beliefs, assumptions, or worldviews is not to welcome that discovery" (as cited in Berger \& Fitzgerald, 2002, p. 31), but rather to confirm their previous understandings. Also, what is seen afresh and becomes object during the coaching may easily slip back into subject shortly afterwards, if the clients do not build the psychological strength that allows them to continue to hold that as object. When the increase in complexity of mind is accomplished, it brings about a new set of ways of seeing and dealing with oneself, others, the world. Small shifts in what seems possible, acceptable, and feasible, "can literally change the world" (Berger \& Fitzgerald, 2002, p. 32) of a coach's client. The three main functions of developmental coaching as a developmental holding environment can therefore be described in this way:

1. Recognizing the clients' experience and confirming the meaning-making that supports that, 
2. Challenging the clients' meaning-making in its limitations, and supporting the clients' disidentification from their assumptions (subject-object shifts),

3. Supporting the clients in their re-integration of their objectified assumptions and in their crafting of more complex and adaptive subject-object balances (Baron \& Cayer, 2011; Kegan, 1982).

\section{Coaches' Making Meaning of Developmental Coaching.}

Based on this brief overview of the principles and process of developmental coaching, it appears evident that this practice requires specific knowledge, capacities and skills, and that the coaches' developmental consciousness and meaning-making complexity are particularly significant in the process. Developmental coaching authors converge around the importance for coaches to be aware of their own developmental journey and engage in the ongoing "self-generation" (Silsbee, 2008, p. 50) they invite their clients to cultivate (Bachkirova, 2016; Berger \& Fitzgerald, 2019; Laske, 1999; Sharma, 2019). Research on coach-related factors of success in coaching, and particularly on coaches' meaning-making and vertical development, is still limited (Kennedy, 2012; Laske, 2006; Perry, 2014; Potter, 2017; Scott, 2009).

I conducted a qualitative, interview-based pilot study prior to the beginning of this dissertation (Distefano, 2019). The purpose was to explore the ways five leadership coaches who identify as developmental coaches understood their work and the impact of their own development on their coaching. How does a developmental coach make meaning of his/her work? How does a coach's development impact his/her work? These were the questions guiding the study, which gave the floor to coaches from different personal and professional backgrounds, and diverse in terms of gender, age, race, and 
years of experience in coaching. The illustration of developmental coaching provided by the five coaches converged around the purpose and the key aspects of their work. Within this shared understanding, each coach's enactment of his/her work emerged as colored by his/her own development. In the next sections, I report the main findings of my pilot study in order to complete my illustration of developmental coaching. Complementing the descriptions offered by the literature, often associated to specific frameworks, the coaches' views I documented are based on the multiple theoretical models informing their practice, and on their coaching and life experience. Sharing the coaches' understanding also provides an introduction into the worldview of developmental coaches. Three of the five participants in the pilot study were part of the co-inquiry group for this dissertation.

\section{Developmental purposes.}

The purpose of developmental coaching as reported by the coaches I interviewed echoed the explanations of the coaches' own purpose in life, and for being a coach. All of them indicated that what brought them to coaching was the intention to help others develop and, at the same time, evolve themselves. Finding meaning and fulfillment in life, and the unleashing of potential for clients and coaches alike, appeared at the heart of the coaches' career choice. Three out of five participants referred to their profession as an emanation of their own spiritual purpose, as a way to enact living by their spiritual beliefs and principles. Two coaches described their care for their clients as a form of love and devotion. One of the coaches who did not explicitly evoke spirituality spoke about the intention of spreading compassion, while another one referred to finding meaning in life as the key piece in her work. Seeking deeper purpose and growth seemed central for the coaches—-for themselves and in their intentions for their clients. 
Self- and others' development was also central in the participants' description of their purpose in life. Four coaches alluded at the intention of fostering, and growing in, connection with others, the environment, the universe. The three youngest coaches in the group also evoked their yearning to live their life and work more freely, "choosing [their] own adventure" (Distefano, 2019, p. 14).

\section{The coach as an instrument in developmental coaching.}

The five coaches participating in the pilot study (Distefano, 2019) reported working with a variety of clients' issues. The main themes each coach identified among those issues gravitated around leadership development, communication, collaboration, conflict management, transitions, self-confidence, and work/life balance. Regardless of the issues they worked with, from the coaches' description of their work emerged a few key ingredients of developmental coaching. All the coaches spoke to those aspects in similar words, that are captured in the following list:

1. The quality of presence they were able to offer to their clients - that most of the coaches associated with their capacity for listening, and some of them with undivided attention — sitting with them and holding them as they thought and did their inner work.

2. The alliance they built with their clients, based on mutual respect—which two out of three of the coaches who evoked their spirituality connoted with care and sacredness, and another coach associated with the capacity to accurately reflect what was said by the clients. One coach also reported that sharing her own story and vulnerability in the coaching informed the alliance with her clients. 
3. Understanding the clients' in their ways of thinking and communicating, their personality, their preferences and desired outcomes, their complexity of mind and capacity to engage with the coach—as one coach pointed out, "therein lies the developmental piece [...] so where I will place attention for me is determined by the level of development, personal development I assess the client to be" (Distefano, 2019, p. 15).

4. On the basis of their assessment of the clients' meaning-making, the coaches met their clients "where they were" (Distefano, 2019, p. 15). The capacity to adapt to the clients through the way the coaches communicated and engaged with them emerged as key to support growth.

From this description of the main aspects of developmental coaching emerges the centrality of the coach as instrument: the essential ingredients of developmental coaching rely on the coach's own awareness and meaning-making, and on the way s/he can be in relationship with her/his clients.

\section{Learned frameworks inform the coaches' meaning-making.}

Within the coaches' meaning-making, their capacity to effectively understand/assess their clients and meet them where they are (developmentally and in life), relied specifically on the frameworks that these professionals had been trained with. All the participants evoked specific theories, concepts, and tools used to make meaning and assess their clients. Most of the coaches cited the main constructive-developmental authors among their references. Yet, they described their assessments of their clients as loose and mostly subconscious. It is to be noted that the coaches explicitly said that the theoretical/practical frameworks "are 'there' for them, and at the same time they are 'in 
the background"' (Distefano, 2019, p. 15-16). Two coaches, one of whom had been assessed with a developmental tool as part of her coaching training, declared using the developmental frameworks as a way to provide the clients with specific language supporting their (self-)understanding.

Constructive-developmental theories appeared as one stream in the vast reservoir of the coaches' theoretical/practical knowledge and meaning-making.

\section{Coaches'development informs their coaching.}

My interviews with the five coaches participating in the pilot study showed that the current development of each coach informed the way s/he was and related with others (Distefano, 2019). In the perspective of the coaches' work, their development thus far was an important aspect of their using themselves as instrument of growth. All the participants recognized that their own development impacted their coaching, some of them using reinforcing expressions such as “' $100 \%$,' or 'they are inextricable”" (Distefano, 2019, p. 16).

Interestingly, each coach described the impact of his/her development on his/her practice evoking different aspects associated with the word "development." Many of them referred to their experiences in life; one of them also mentioned her culture and background; two of them, among the youngest coaches, talked about their learning/working style or preferences; another one, with a background as a psychologist, mentioned the depth of her own inner work stating that in coaching " "the depth of your work $[\ldots]$ is only limited by the depth to which you have been willing to go and examine for yourself"' (Distefano, 2019, p. 16). 
The coaches spoke about their work in a way that was congruent with the roles they currently/formerly occupied. For example, the language of the coaches who were also teachers was finer and more precise than the other coaches', and one of them declared being mindful of her natural tendency to consult or train when coaching. Moreover, as previously mentioned, the coaches' studies and training visibly informed the way they spoke about who they were professionally and how they worked: the way they expressed their understanding of their approaches, for example, was colored by the frameworks, theories and concepts they had integrated. Arguably, different aspects of what made each coach who s/he was were transferred in their work.

Of note for the scope of the study, not one of the participants explicitly associated their development with their meaning-making, or their consciousness. Yet, when asked about their current growth edge, i.e., one or more challenges that they were presently facing and that they would like to overcome, the coaches described personal and professional learning curves that were ascribable to their making meaning. In particular, the coaches reported working on the cultivation of a better quality of presence to what was happening in every moment, outside and inside themselves. One of the White coaches mentioned the expansion of her awareness of issues of cultural and race diversity, in order to better serve her clients. Also, the capacity of being with the clients in silence, emphasizing the "being with," rather than the doing or telling, was evoked by many of the participants. For one of them, who reported being engaged in a spiritual retreat and about to enroll in a spiritual direction course, the growth edge was related to living by his spiritual purpose. For the three younger coaches, the growth edge was associated with living and working freer from self- and others' pressure in terms of 
judgements, expectations, specific frameworks or approaches to use. The desire to be free to express themselves through their choices, follow their own path and "show more of themselves to the world" (Distefano, 2019, p. 18) was common to these three participants.

The coaches seemed to implicitly associate development with the expansion of consciousness also when asked about how they cultivated their own development. All of the participants mentioned awareness-based practices such as meditation, time in silence, prayer, inner work, reflection, meaningful exchanges with others, and learning. Each coach's practices, whether geared towards spirituality, inner growth or individual, mutual or collective learning, appeared as congruent with and serving his/her purpose for being a coach and purpose in life, which were intimately linked. The coaches' developmental practices were described as ways to cultivate both personal and professional development. These findings are congruent with those presented by Scott (2009), based on her study of a group of eleven coaches assessed at high levels of complexity of mind: those coaches were engaged for their own development through continuous learning and ongoing practices like critical introspection, contemplative activities, and yoga. The eleven coaches indicated that these activities contributed to the increase of their developmental consciousness and their reflexivity on their own ways of knowing, particularly through the contact with peer coaches with greater complexity of mind. The coaches' perception was that their engagement in developmentally oriented, individual and group practices supported and improved the developmental quality of their work.

Finally, the development and growth edges of the five coaches participating in my pilot study (Distefano, 2019) emerged more or less clearly, and more or less consciously, 
in what they described of the parallel process unfolding between themselves and their clients. The parallel process is activated by the coaches and clients simultaneously with what each of them brings of themselves, their experiences and their meaning-making of those. It is certainly an important channel through which the coaches' own development infiltrates the coaching relationship and processes. Many of the coaches alluded to the resonances and mutual learning that happen in the coaching relationships. Some of them evoked the learning from their clients, one pointed to the fact that both her clients and she had "lots of things to process"” (Distefano, 2019, p. 18) after the sessions. In some cases, what the coaches reported as the issues explored by their clients resonated with what they indicated as their current experiences or growth edges, for example in terms of overcoming insecurity, being able to relate with people with different worldviews, finding a sense of balance, or cultivating expanded awareness.

To conclude, these coaches' views on developmental coaching offered another perspective on the complex, multidimensional, and relational nature of human development, and on the relevance of the coaches' meaning-making for the coaching processes and outcomes. They confirmed the call for research in this specific area as well as for the development of practices in support of the expansion of coaches' consciousness (Astorino, 2002; Bachkirova, 2016; Diehl, 2010; Laske, 1999, 2003; Perry, 2014; Scott, 2009; Sharma, 2019). This dissertation represents my contribution to the continued exploration and enhancement of developmental coaches' capacities and skills as instruments supporting growth, particularly in the complexity and the chaos of our times. In the following chapter, I review the main theoretical foundations of developmental work as conducted in the organizational leadership development field. I 
then focus particularly on the illustration of leadership models and practices at expanded levels of consciousness. 


\section{CHAPTER TWO \\ LITERATURE REVIEW}

In this chapter, I explore the theoretical frameworks and the knowledge informing the logic and processes of the co-inquiry. I start with a review of constructivedevelopmental theory and its critiques, continue with a focus on the two main neoPiagetian adult development models, and complete the chapter zooming in on what we know about the level of consciousness maturation that is broadly considered necessary to tackle the challenges of our times - i.e., the post-conventional level-, particularly in the perspective of leadership and coaching.

\section{Constructive-Developmental Theory}

Kegan (1980) introduced the terms "constructive-developmental" to define the psychological theory describing the development of the meaning-making processes (i.e., the expansion of consciousness) across the life span. He built on Piaget's observations of how children grow through qualitatively different stages, beyond the accumulation of new knowledge, transforming such knowledge within progressively new ways of making sense of the world. The theory is constructive in that it assumes that we construct our reality through our way of knowing and the meaning we make of experience. And it is developmental in that it addresses the process through which our epistemology and interpretations develop, reorganize and grow in complexity.

Constructive-developmental theory focuses on the organizing principles of the different ways of meaning-making, and on the processes through which these principles are constructed and re-constructed through developmental movement (McCauley et al., 2006). The main tenets of constructive-developmental theory are the following: 
- Development occurs all through the life span in a logical sequence of orderslabeled orders of development, orders of consciousness, action-logics, or stages — characterized by consistent, identifiable patterns of meaning-making.

- Orders of development unfold in a specific, invariable sequence, overall evolving from simple to complex.

- Each later order of development transcends and includes the previous oneswhich remain part of the individual's repertoire-supporting more differentiated, integrated, flexible and complex meaning-making.

- Development occurs in the interplay between the person and her environment. (Cook-Greuter, 2013; Kegan, 1982; McCauley et al., 2006; Torbert, 1987). According to the theory, a combination of internal and external factors (e.g., personality, life experiences, and demands and opportunities from the environment exceeding one's current complexity of mind) participate in the unfolding of meaningmaking development through an invariable sequence of stages. Each of these orders of development is characterized by different psychological motivations, tending to evolve from ego-centrism to others- or world-centered aspirations, and progressively allows for more complex and integrated ways of making sense of experience.

A broadly accepted classification of the orders of development categorizes them in four tiers (Miller \& Cook-Greuter, 1994):

- the pre-conventional tier includes the Piagetian pre-rational and preoperational stages of development of infancy and childhood,

- the conventional tier includes the stages of concrete, abstract and formal operations, representing the usual adult cognitive and emotional capacities and 
based on a linear, rational view of reality as well as of society's norms and beliefs,

- the post-conventional tier corresponds to an advanced maturation of the ego, and to affect, intuition, and cognitive dimensions supporting the use of both rational and non-rational ways of knowing, systemic thinking, and the capacity to deal with ambiguity and paradox,

- the transcendent tier includes the orders of development at which reasoning and conceptual thought can be transcended: reality, as well as self, are experienced directly, without filters (e.g., in a non-discursive way), in their being part of an unbounded, universal awareness (Miller \& Cook-Greuter, 1994; Travis \& Brown, 2011). This way of making meaning of experience corresponds to the awareness of being one with all that is, often described as a spiritual experience. Research suggests that practices such as prayer, meditation, and mindfulness are conducive to this kind of consciousness development (Anderson \& Adams, 2016; Baron \& Cayer, 2010; Chandler, Alexander \& Heaton, 2005; Joiner, 2011; Torbert, 1994).

\section{The Complexity (and Ineffability?) of the Developmental Unfolding: Critiques and}

\section{Caveats}

Vertical development unfolds at different paces for different persons in their unique combinations of individual and environmental factors. Also, it is concurrent to horizontal development, i.e., the expansion of one's repertoire within one stage, and both may stop and reverse according to the circumstances. Torbert \& Associates (2004), McCallum (2008), and Livesay (2013) point to the "fallback" phenomenon referring to 
periods, particularly associated with stressful and ambiguous events, when individuals tend to act from earlier stages instead of the latest available to them.

Orders of development are actually artificial categorizations describing balances that we are constantly reaching, losing, evolving, in an ongoing process within our environment (Kegan, 1982). Also, neuroscience teaches us that development unfolds in a messy variety of micro-developments along multiple domains (e.g., visual-spatial, musical, interpersonal, intrapersonal, bodily-kinesthetic, linguistic, logical-mathematical, and naturalistic) (Fischer \& Rose, 1998), rather than in a few clear-cut and comprehensive stages "smash[ing] together" (Freinacht, 2017, p. 172) different lines of development.

Commons et al. (1998), from a behavioral psychology perspective, sustain the idea of a consistent development across domains, but reject the evidence upon which developmental theories rely, advancing that development in orders of complexity can only be traced through the observation of how tasks associated with different orders are solved. With their Model of Hierarchical Complexity (Commons et al., 1998), the authors provide a mathematical model that can explain the behavioral differences observed through performances on tasks. They focus on a particular aspect of human development, i.e. cognitive complexity, which is certainly primordial in the developmental movement. However, a reductionist approach to human development does not support the exploration of its multidimensionality.

Freinacht (2017) differentiates four dimensions participating in the unfolding of development: cognitive complexity (Commons et al., 1998); the symbolic development of language, culture and structures; one's inner, subjective state; and one's depth, 
described as the intimate, embodied, integrated acquaintance with one's own subjective states and lived experience. Chen (2019) highlights the somatic and spiritual processing of complexity as complementary to cognitive and linguistic sophistication, as well as the cultural component: from an Eastern perspective, the author emphasizes that collectivist cultures impact development "sustaining the equilibrium between a self's individual identity and its collective identity. This means that in these cultures, the actualization of self-agency is ideally developed only to the degree that is of service to the well-being of its social (and natural) environment" (Chen, 2019).

Among the critiques advanced to constructive-developmental theories, another important one concerns the instruments used to assess people's levels of development. The available tools present significant limitations: they are essentially based on particular techniques of interviews, such as the Subject-Object interview (Lahey, Souvaine, Kegan, Goodman, \& Felix, 2011), inexorably subject to the interviewers' perceptions, bias, and familiarity with the culture and contexts impacting the responses, and on sentencecompletion tests, ultimately "trying to capture fine differentiations [...] with a brief paperand-pencil test" (Cook-Greuter, 2000, as cited in Travis and Brown, 2011, p. 37). And how could we rely on a measurement realized at one point in time, knowing that people operate from variegated, constantly shifting developmental configurations at any given time and space, across life circumstances and settings (Eriksen, 2006)? Based on her study of the validity and reliability of sentence-completion tests, Pfaffenberger (2011) concludes that "currently no accurate, well-validated instrument for the assessment of higher development is available, nor does it appear likely that such an instrument can be found any time soon" (p. 22). And yet, King (2011), describing her and others' experience 
as a sentence-completion test coder, points to "a moment of recognition... a sudden sense that 'something' is here, that we're getting at something that we could not otherwise measure" (p. 173). As Pfaffenberger (2011) suggests, it is to be hoped that using the available tests will lead to an accumulation of knowledge about their strengths and limitations.

Arguably, if constructive-developmental theories cannot explain the complexity and the granularity of development, they nonetheless provide a conceptual and operational framework to explore the multidimensional developmental movement, a map to identify the main overarching patterns of meaning-making. I adopt the theory as the theoretical foundation of this study being mindful of these critiques and of the following caveats.

\section{Caveats.}

I believe it is necessary to posit some important caveats to the embrace of constructive-developmental theory. First of all, if the theory sheds light on some hidden and important, psychological, emotional and behavioral aspects related to meaningmaking, it does not deal with key aspects that make us human, such as intelligence, morality or psychological health (Berger, 2003), or with factors that deeply mark our life experience like our identities, our cultures and our intersectionalities (Crenshaw, 1989) of gender, race, social location, etc. Meaning-making development is not all in human development.

Moreover, even if constructive-developmental models are presented as unabashed hierarchies, no order of development is better than another: people can be just and unjust, psychologically healthy or unhealthy, happy or unhappy at any order (Cook-Greuter, 
2013). Chen (2019) reminds us that every stage, including the earliest, bears specific developmental gifts, and that specifically in indigenous and traditional cultures, somatic intelligence of complexity and wisdom are not the prerogative of later stages exclusively.

Constructive-developmental theorists point to the fact that our orders of development can be more or less adapted to the challenges presented by our environment, allowing us to deal with them effectively or leaving us "in over our heads" (Kegan, 1994). The hierarchical or vertical sequence of the orders stands for the level of complexity that can or cannot be integrated.

Nevertheless, examining the hierarchical nature of this Western theory that the feminist critiques see as patriarchal (Eriksen, 2006), I am very aware of the "subtle yet palpable prejudice that favors the later and averts the earlier stages of development" (Chen, 2019), and that the very ideas of hierarchy and vertical development can yield new ideologies of domination, discrimination, exploitation. Along with Freinacht (2017), who points to the distinction between natural differences and dominator differences, I believe that adopting the constructive-developmental perspective implies to consider meaning-making diversity as one of the variations that constitute the richness of life on earth. This element of difference is to be critically and non-judgmentally embraced as the convergence of countless internal and external circumstances and dynamics-including histories of privilege and oppression. At the same time, every peculiarity is to be honored as of equal worth in the unitive perspective of our shared human condition.

I was particularly aware of the complexity and the granularity of development as I engaged in this co-inquiry, therefore I intended to hold constructive-developmental 
theory lightly, as a practical conceptual and linguistic framework to explore the coinquirers' unique, messy and multidimensional lived experiences of development.

\section{Constructive-Developmental Models}

I now turn to the exploration of how vertical development is conceptualized in the two main neo-Piagetian constructive-developmental frameworks, i.e., Kegan's and CookGreuter and Torbert's models, which have theoretically and empirically shed light on the developmental dynamics of organizational leadership, and rely on validated diagnostic tools according to their respective conceptualizations. I organize my review by authors, aiming to honor the differences in the ways they describe and measure human development.

\section{Kegan's perspective: orders of development and mental complexity plateaus.}

Kegan $(1982,1994)$ was one the earliest proponents of constructivedevelopmental theory, based on the observation that some adults undergo the same kind of qualitative advances in their mental complexity that characterizes the evolution through childhood and adolescence. These leaps in mental complexity describe the different processes taking place for each individual in the "most human of 'regions' between an event and a reaction to it - the place where the event is privately composed, made sense of, the place where it actually becomes an event" (Kegan, 1982, p. 2). The processes through which emerges the understanding of the world that shapes humans' experiences essentially evolve from simplistic to more complex epistemologies. According to Kegan (1982), human beings and all other living organisms continually seek greater coherence in their organization as they interact with, and make meaning of, an always increasing volume and variety of experiences (Yeyinmen, 2016). It is in the 
interaction with the world that Kegan (1982) sees the impetus for human development. The "principles of organization" (Lahey, Souvaine, Kegan, Goodman, \& Felix, 2011, p. 8) of meaning-making evolution in Kegan's theory are the subject-object balances (Kegan, 1980, 1982, 1994). Typically, we are subject of our assumptions (about ourselves, others, the world) that we hold as unquestionable truths and that govern our making meaning of our experience. Developing, we come to embrace a progressively more holistic, comprehensive view of ourselves, others, and the environment; in other words, more becomes object. Growth through different subject-object balances happens when we can relate to more of our experience as object; develop more complex ways of organizing our experience (that we become subject to); and more thoroughly integrate the newly objectified experiences with the others that compose the reservoir of what is object to us (Yeyinmen, 2016).

Kegan describes a sequence of six (starting with zero) orders of consciousness, or subject-object balances, that human beings can traverse from childhood through adulthood. Each order reflects a greater level of complexity and integration among three lines of development that Kegan (1994) labels (1) cognitive, referring to the thinking processes, (2) interpersonal, representing one's understanding of the relationship to others, and (3) intrapersonal, related to one's understanding of the self. The measuring tool used to identify the orders of development is the Subject-Object interview (Lahey, Souvaine, Kegan, Goodman, \& Felix, 2011), a semi-structured, 90-minute interview that allows the scorers (usually two per interview to support interrater reliability) to identify the most complex level at which a person can make meaning of her experience. 
The orders of development associated with adulthood and leadership are the later three, i.e. Interpersonal, Institutional, and Interindividual (Kegan, 1982, 1994). These are respectively associated with what Kegan and Lahey $(2009,2016)$, adapting the framework for an organizational application, describe as the complexity plateaus of the "socialized mind" (observed in $58 \%$ of the US population), the "self-authored mind" (35\%), and the "self-transforming mind" (1\%) (Kegan, 1994). The first of these three orders of development corresponds to the conventional tier, the second to the transition between the conventional and the post-conventional tier, the third to the postconventional tier. At the complexity plateau of the socialized mind, adults are shaped by the norms, definitions and expectations of their environments: the self finds coherence through alignment and loyalty to those. At the plateau of the self-authoring mind, adults are able to step back and internalize judgments, evaluations and choices about external expectations. At this level, the self coheres in alignment with its own systems of beliefs, codes, ideologies and boundaries. At the self-transforming mind plateau, adults are able to reflect on the limits of their own ideology and personal authority; to see any system as partial and incomplete; to hold difference, contradiction and opposites; and to appreciate the dialectical nature of reality rather than focusing on single aspects or polarities. The self can hold internal consistency and incompleteness (Kegan \& Lahey, 2009).

Table 1 summarizes Kegan's framework and the balances of what is subject and what is object at each order of development/complexity plateau (Kegan, 1982; Kegan \& Lahey, 2009). 
Table 1. A summary of Kegan's Subject-Object balances.

Sources: Kegan, 1982, p. 86; Kegan and Lahey, 2009, p. 17; McCauley et al., 2006, p. 637.

\begin{tabular}{|c|c|c|c|}
\hline \multicolumn{4}{|c|}{ Kegan's Subject-Object Balances } \\
\hline $\begin{array}{c}\text { Orders of } \\
\text { development }\end{array}$ & $\begin{array}{l}\text { Complexity } \\
\text { plateaus }\end{array}$ & What is subject? & What is object? \\
\hline 5. Interindividual & $\begin{array}{l}\text { Self-transforming } \\
\text { mind }\end{array}$ & $\begin{array}{l}\text { Interindividuality, } \\
\text { interpenetration } \\
\text { of systems, the } \\
\text { transforming self }\end{array}$ & $\begin{array}{l}\text { Authorship, } \\
\text { identity, the } \\
\text { autonomous self }\end{array}$ \\
\hline 4. Institutional & $\begin{array}{l}\text { Self-authoring } \\
\text { mind }\end{array}$ & $\begin{array}{l}\text { Authorship, } \\
\text { identity, the } \\
\text { autonomous self }\end{array}$ & $\begin{array}{l}\text { Interpersonal } \\
\text { relationships, } \\
\text { mutuality, the } \\
\text { socialized self }\end{array}$ \\
\hline 3. Interpersonal & Socialized mind & $\begin{array}{l}\text { Interpersonal } \\
\text { relationships }\end{array}$ & $\begin{array}{c}\text { Enduring } \\
\text { disposition, } \\
\text { needs, interests }\end{array}$ \\
\hline 2. Imperial & & $\begin{array}{c}\text { Enduring } \\
\text { disposition, } \\
\text { needs, interests }\end{array}$ & $\begin{array}{l}\text { Impulses and } \\
\text { perception }\end{array}$ \\
\hline 1. Impulsive & & $\begin{array}{l}\text { Impulses and } \\
\text { perception }\end{array}$ & Reflexes \\
\hline 0 . Incorporative & & Reflexes & \\
\hline
\end{tabular}

In Kegan's perspective, the emphasis is particularly on the developmental movement and balancing between orders as a product of the constant interactions between the individual and the complexity of his/her environment. With the idea of "immunity to change", Kegan and Lahey (2009) point to the fear of losing meaning in the process of seeking new meaning as the main obstacle to development, and indicate that the key to overcome it and evolve developmentally are holding environments that both support and challenge one's current meaning-making system-e.g., bringing awareness to 
and questioning assumptions, and providing opportunities for new, transformative kinds of interactions.

\section{Cook-Greuter and Torbert's perspective: stages of development and action-logics.}

I now turn to the exploration of how vertical development is conceptualized by Cook-Greuter and Torbert. The authors' models are particularly relevant for this study: Torbert's CDAI represents the main epistemological and methodological grounding of the co-inquiry, and I used Cook-Greuter's Leadership Maturity Assessment Profile (MAP) (Cook-Greuter, 1999, 2011), based on the premise that our language reflects our complexity of mind, as a developmental assessment tool during the co-inquiry.

Torbert developed his framework on the basis of Loevinger's (1976), then CookGreuter's $(1999,2002)$ work on ego-development. In their perspective, the ego represents a holistic frame of reference against which people make meaning of intrapersonal and interpersonal experience (McCauley et al., 2006) and address questions related to thinking - conceptions, interpretation, knowledge; being and feeling — awareness and affect; and doing — needs and ends, ways of coping, and ways of interacting with self and others (Cook-Greuter, 2013). Different stages of ego-development can be distinguished through an analysis of the language people use. Loevinger's original validated measurement tool, known as the Washington University Sentence Completion Test and based on the analysis of the ways people completed 36 sentences stems, has been revised in time by Cook-Greuter, resulting in the latest version of the Leadership Maturity Assessment Profile (MAP), and by Torbert, whose current assessment tool is called Global Leadership Profile (GLP) (Torbert, 2014). The MAP, which is the instrument used as developmental assessment in this co-inquiry, allows for a simpler realization than the 
Subject-Object interview, and is broader in scope than Torbert's GLP, which is more focused on the organizational manifestations of development.

In this framework, each stage of development corresponds to a specific actionlogic, or "an overall strategy that so thoroughly informs our experience that we cannot see it" (Torbert \& Associates, 2004, p. 66). Action-logics are described as sets of assumptions that allow people and organizations to make sense of their experience and (inter-)act in the world. The logics become more complex, and their focus of attention broadens at every stage of development (McCauley et al., 2006). Table 2 shows CookGreuter and Torbert's nine stages/action-logics ${ }^{1}$ and their distribution observed in a sample of 497 US managers (Torbert \& Associates, 2004). According to the authors, development occurs as "the initial limiting framework is dethroned and becomes a strategic option, or a variable, within a more inclusive assumptive framework" (Torbert, 1989, as cited in Yeyinmen, 2016, p. 46).

Based on empirical observations locating individuals on at least three developmental stages simultaneously, the central one being considered as one's center of gravity, Cook-Greuter (2002) underscores that nobody can be at one or another stage at $100 \%$.

${ }^{1}$ The designations of Cook-Greuter and Torbert's stages/action-logics having evolved over time, along with the respective frameworks, in this study I report and employ the most recent versions. 
Table 2. Cook-Greuter and Torbert's stages/action-logics and their distribution among US managers.

Sources: Torbert \& Associates, 2004; Torbert, 2017; McCauley et al., 2006; Miller \&

Cook-Greuter, 1994; https://integrallife.com/stages-leadership-maturity/.

\begin{tabular}{|c|c|c|c|}
\hline \multicolumn{4}{|c|}{ Cook-Greuter and Torbert's stages/action-logics and their distribution among US managers } \\
\hline $\begin{array}{c}\text { Stages in } \\
\text { Cook- } \\
\text { Greuter's } \\
\text { terminology }\end{array}$ & $\begin{array}{l}\text { Stages in } \\
\text { Torbert's } \\
\text { terminology }\end{array}$ & Action-logic & $\begin{array}{l}\text { \% of a sample } \\
\text { of } 497 \text { US } \\
\text { managers }\end{array}$ \\
\hline Unitive & Ironist & $\begin{array}{l}\text { All-embracing and witnessing: sustained awareness of the } \\
\text { interplay, the unity and the differences among all beings in } \\
\text { time and space }\end{array}$ & \multirow{4}{*}{$7 \%$} \\
\hline $\begin{array}{l}\text { Construct- } \\
\text { aware }\end{array}$ & Alchemist & $\begin{array}{l}\text { Noticing constructs and ego traps, and intersystemic } \\
\text { evolution process: interplay of principle/action rules self- } \\
\text { amending principle }\end{array}$ & \\
\hline $\begin{array}{c}\text { Self- } \\
\text { actualizing }\end{array}$ & $\begin{array}{c}\text { Strategist/ } \\
\text { Transforming }\end{array}$ & $\begin{array}{l}\text { Integrating and transforming: self-amending principle rules } \\
\text { reflexive awareness }\end{array}$ & \\
\hline $\begin{array}{c}\text { Self- } \\
\text { questioning }\end{array}$ & $\begin{array}{l}\text { Individualist/ } \\
\text { Redefining }\end{array}$ & $\begin{array}{l}\text { Relativizing and contextualizing: reflexive awareness rules } \\
\text { effectiveness }\end{array}$ & \\
\hline $\begin{array}{c}\text { Self- } \\
\text { determining }\end{array}$ & Achiever & $\begin{array}{l}\text { Analyzing and achieving: system effectiveness rules craft } \\
\text { logic }\end{array}$ & $35 \%$ \\
\hline Skill-centric & Expert & Comparing and perfecting: craft logic rules norms & $45 \%$ \\
\hline Group-centric & Diplomat & Conforming and belonging: Norms rule needs & $10 \%$ \\
\hline Self-Centric & Opportunist & Getting and defending: needs rule impulses & \multirow{2}{*}{$3 \%$} \\
\hline Impulsive & Impulsive & Impulses rule behavior & \\
\hline
\end{tabular}

In Table 3, Cook-Greuter and Torbert's stages/action-logics are presented against Kegan's orders of development within Miller and Cook-Greuter's (1994) tiers classification. 
Table 3. Kegan's orders of development and Cook-Greuter and Torbert's stages/actionlogics within Miller and Cook-Greuter's (1994) tiers classification.

\begin{tabular}{|c|c|c|c|}
\hline \multicolumn{4}{|c|}{$\begin{array}{c}\text { Kegan's and Cook-Greuter and Torbert's frameworks } \\
\text { against the four tiers of development }\end{array}$} \\
\hline $\begin{array}{c}\text { Tiers of } \\
\text { development }\end{array}$ & $\begin{array}{c}\text { Kegan's } \\
\text { Orders of } \\
\text { development }\end{array}$ & $\begin{array}{c}\text { Cook-Greuter's } \\
\text { stages }\end{array}$ & $\begin{array}{c}\text { Torbert's } \\
\text { Action-Logics }\end{array}$ \\
\hline $\begin{array}{c}\text { TIER 4 } \\
\text { Transcendent }\end{array}$ & & Unitive & Ironist \\
\hline $\begin{array}{c}\text { TIER 3 } \\
\text { Post- } \\
\text { conventional }\end{array}$ & Interindividual & Construct-aware & Alchemist \\
\cline { 3 - 4 } & & Self-actualizing & Strategist/Transforming \\
\hline $\begin{array}{c}\text { TIER 2 } \\
\text { Conventional }\end{array}$ & Institutional & Self-questioning & Individualist/Redefining \\
\cline { 3 - 4 } & Self-determining & Achiever \\
\cline { 3 - 4 } & Interpersonal & Skill-centric & Group-centric \\
\hline $\begin{array}{c}\text { TIER 1 } \\
\text { Pre- } \\
\text { conventional }\end{array}$ & Imperial & Self-centric & Diplomat \\
\cline { 3 - 4 } & Impulsive & Impulsive & Opportunist \\
\hline
\end{tabular}

According to Cook-Greuter and Torbert, at the pre-conventional level, individuals are subject to their impulses, and their primary needs for survival and safety form the basis of their identity, their experience and understanding of themselves and the world. This level of complexity is insufficient to thrive and lead in our society, and only $3 \%$ of the managers in Torbert and Associates' (2004) sample were assessed at those stages.

The conventional level is marked by the internalization of society's and one's community's norms, structures, and ways of seeing, thinking and acting. As shown in Table 2, the majority of the managers in contemporary US organizations are at that level of development (Torbert \& Associates, 2004). In particular, the Diplomat/Group-centric stage is characterized by the need of affiliation which results in obedience and 
conforming, pleasing behaviors. In this action-logic, receiving negative feedback is feared as equivalent to a loss of status and belonging (Torbert \& Associates, 2004). At the Expert/Skill-centric stage competence, expertise, and efficiency become key, often to the detriment of critical thinking about one's (and experts and authorities') references, and of the capacity of being open to feedback, unless it comes from "acknowledged masters of the craft" (Torbert \& Associates, 2004, p. 80). At the Achiever/Self-determining stage, it is possible to realize a more personal integration of conventions and practices, and contribute to evolve self, things and situations on the basis of personal standards. Effectiveness (beyond efficiency) and achievement of results are central. Behavioral feedback is accepted at this stage as useful for self-improvement (Cook-Greuter, 2013).

At the post-conventional level, it becomes possible to contextualize, question, reframe and transform norms, conventions, and processes. Principles, thoughts, actions and effects become more congruent and can be aligned with awareness (Torbert \& Associates, 2004). Also, it is progressively possible to notice how one participates in the construction of one's reality, and to hone one's awareness of such constructs and their impact. Feedback is deliberately sought and valued as essential for continuous evolution of people and systems. Power is increasingly collaborative and "developmentally transforming" (Torbert, 1994, p. 186). In particular, the focus is

- at the Individualist-Redefining/Self-questioning stage, on questioning, (self-)awareness and (self-)inquiry and increasing understanding of complexity; 
- at the Strategist-Transforming/Self-actualizing stage, on integration of different parts of self, and on awareness and transformation of self and others in reflection and in action;

- from the Alchemist/Construct-aware stage, on constructs, dialectical thinking, moment-to-moment mutual redefinition between self, others, and the larger environment, material as well as spiritual transformation, and progressive embracing of all that is - prerogative of the Ironist/Unitive stage.

When we explore Cook-Greuter's $(2002,2013)$ description of the unitive stage of human development, currently extremely rare in our organizations, we find ourselves in the realm of non-duality evoked by the wisdom traditions of our world. It is the realm of ego-transcendence where we experience separation as an illusion, where we are part of an "ongoing humanity $[\ldots]$ fulfilling the destiny of evolution" (Cook-Greuter, 2002, p. 32). The longing for unity is recognized as a return to our true nature, where reality is understood as embedded in natural cycles of creation, destruction, and recreation. At this stage, total acceptance of what is becomes possible, and humility about the limits of being human and the constructed nature of reality is combined with awe about the mystery of life.

The characteristics of post-conventional consciousness are further explored in the perspective of leadership in the concluding section of this chapter. Less represented in our organizations, these action-logics correspond to the complexity of mind and the transformational power called for by the challenges of our times. 
I now turn to Torbert's elaboration, rooted in the theoretical bases I illustrated in this section, of the developmental method for research and practice that grounds this dissertation: Collaborative Developmental Action Inquiry.

\section{Collaborative Developmental Action Inquiry (CDAI)}

Torbert articulated Collaborative Developmental Action Inquiry (CDAI) as a model and method for research and practice simultaneously (Torbert \& Associates, 2004; Torbert, 2017). Action becomes inquiry by generating new information, and inquiries are actions with an impact on the world, hence the organizing question "how can we simultaneously enhance the validity of the information upon which we act and the effectiveness and timeliness of our actions and inquiries?" (Foster, 2014, p. 124). CDAI allows for timely adjustments in the here and now, as "a way of learning anew, in the vividness of each moment, how to best act now" (Torbert \& Associates, 2004, p. 2). Ultimately, it becomes a transformative, developmental practice.

Through CDAI, vertical development unfolds as people and systems strive to find consistency and alignment in their experience across four specific territories, namely (a) the outside world and the observable outcomes of actions and events; (b) one's own sense of embodiment, actions, skills and performance; (c) action-logics, or one's cognitiveaffective frameworks, strategies and plans; and (d) awareness and intentionality, including one's purpose, vision and intuitions (Fisher, Rooke \& Torbert, 2001; Torbert \& Associates, 2004). Processing experiences at these different levels simultaneously allows for more effective and timely interaction among them (Foster, 2014). Torbert recognizes a motive for development in the inherent tension towards increasing integrity in action, and points to the central role of awareness - enhanced through self-awareness and 
mindfulness practices as well as feedback from the outside - in generating timely and effective actions (Torbert \& Associates, 2004).

One of the main intentions of CDAI as a practice is to help people and systems to develop real-time, simultaneous awareness of the aforementioned four territories of experience and the relationship among them. Grounded in developmental theory, CDAI posits that only at the post-conventional level it becomes possible to coordinate and integrate one's experiences across territories simultaneously as "vivifying reality in the present moment" (Torbert, 1994, p. 39). This kind of consciousness allows learning that transcends what Torbert, inspired by systems theory, calls single-loop feedback-which allows transformation at the level of our behaviors based on feedback about the outcomes - , to include double-loop feedback - yielding the transformation of the strategies on which our behaviors are based (Argyris \& Schön, 1974; Torbert \& Associates, 2004). Similarly, triple-loop feedback, linking our strategies and our deeper missions and assumptions, is a prerogative of post-conventional stages: that becomes possible when we can learn about our present relationship between our effects in the world, our actions, our strategies, and our attention and intentionality, i.e., when we are aware of the integration of the four territories. This learning happens at the level of awareness, allowing us to shift our deeper intentions and assumptions (Torbert \& Associates, 2004). The commitment and growing capacity to seek and offer triple-loop feedback, again and again, "requires a humble, comic, lifelong, spiritual, relational, alchemical commitment to a task never completed. Only this commitment and developing capacity to offer and to receive triple-loop feedback provides traction [for adaptive 
transformation] at historical moments of changing paradigms" (Torbert \& Erfan, 2019, p. $6)$.

Triple-loop feedback is also associated with the effective interweaving of the three types of research grounding CDAI, i.e., research in the first person (within oneself), second person (in the mutuality of dialogue with others) and third person perspective (extended to others). Personal learning and development are possible through selfreflection around one's own intentionality, strategies and plans, patterns of behavior and speech, and how they are related to one's effectiveness and timeliness. Second person inquiry plays out in mutuality with others, through the confrontation and the congruity among different experiences of assumptions, strategies, actions and impact. Torbert specifically proposes four parts of speech, namely Framing, Advocating, Illustrating, and Inquiring to explore and align territories of experience between people. Each of these parts of speech corresponds to a territory of experience:

- Framing alludes to the clarification of our intentions and purposes;

- Advocating is about stating an opinion, a plan, a possible course of action;

- Illustrating allows to clarify the story supporting or contesting what is advocated; and

- Inquiring is about asking for feedback and input from others (Fisher, Rooke \& Torbert, 2000; Torbert \& Associates, 2004).

Attending to the four parts of speech in conversations allows one to set clear intentions and genuinely gather feedback, in addition to the more habitual advocating and illustrating practices (Foster, 2014). 
In the spirit of CDAI, applying frameworks across different levels of analysis and contexts, the four territories of experience find specific applications in the two other kinds of research, as well - the first and third person perspective. At the first person perspective correspond the following forms of attention: Attending/Intending, Thinking/Feeling, Sensing/Behaving, Perceiving/Effecting. Third person inquiry refers to the more classical way of researching on something external, and the collective learning and development that can result from that investigation. Applying the four territories of experience in the third person perspective results in the following organizing principles: Visioning, Strategizing, Operating, Assessing (Torbert \& Associates, 2004). In fact, CDAI posits that organizations and scientific methods can also evolve towards more and more complex action-logics.

The cross-level, cross-system lens provided by CDAI is both a conceptual strength and an operational limitation, in that it can be challenging to master the application of the different constructs and their interrelatedness. As Foster (2014) reminds us, "Torbert himself contends that it is not a theory to be mastered and then applied but rather an approach worthy of an entire lifetime of 'living inquiry"' (p. 128). Yet, the transformational potential of CDAI—largely based on moment-to-moment action inquiry, the exercise of mutual power and the generation of single, double and triple-loop feedback - has shown "more powerful impacts than any other research and practice approach on leaders' and organizations' transformation" (Torbert, 2017). It does not offer solutions, rather, a guide to exercise and intensify action inquiry in practice (Marshall, 2012) and develop more apt and timely use of later action-logics, and especially post- 
conventional consciousness, for personal, mutual and organizational/societal sustainable integrity and regeneration (Torbert, 2017).

The next sections explore post-conventional consciousness in the perspective of leadership and coaching.

\section{Post-Conventional Consciousness and Leadership}

In this section, I focus on the post-conventional level of consciousness maturation, which characterizes "optimal adult development" (Pfaffenberger, 2005, p. 279), and its translations into leadership. Research shows that the majority of organizational leaders in the US currently operate from the conventional tier (CookGreuter, 2013; Kegan \& Lahey, 2016; Torbert \& Associates, 2004), yet, a growing number of leadership scholars and practitioners claim that the current level of complexity in our society can only be effectively tackled by leaders whose meaning-making has developed at the post-conventional order (Anderson \& Adams, 2016, 2018; Joiner \& Josephs, 2007; Kegan, 1994; Kegan \& Lahey, 2009, 2016; Rooke \& Torbert, 1998; Torbert, 2017; Torbert \& Associates, 2004).

Starting at the post-conventional level, adults develop a different quality of differentiation and embeddedness in their environment compared to the socially programmed differentiation of the conventional stages. They evolve towards a better defined self-authorship, an integrated, co-constructed (by self and others) identity, and a deconstruction of the idea of separation in favor of conscious interconnectedness and unity (Cook-Greuter, 2009). Post-conventional consciousness implies pointed attention to the relationship between systems rather than the closedness of the systems themselves, and to change and evolution rather than fixedness of entities (Souvaine, Lahey, \& Kegan, 
1990). It is at the post-conventional level that we can understand ourselves, others and situations more deeply; uncover hidden individual and societal assumptions, beliefs, illusions, and dynamics; and transform self, others and the world. The ability to transcend the internally sourced self-authorship and worldview allows one to reflect on them, and to recognize, better hold together and ultimately seek out opposites, contradictions, and paradox. With increasing maturity, the definitions and boundaries which previously used to make meaning dissolve; alertness to paradox is ever-present; and opposites and polarities are seen as in a constant, ubiquitous dance (Sharma \& Cook-Greuter, 2015). Also possible at the post-conventional level is to observe how various forms of the self exist in relationship with others (Baxter Magolda, 2009), and acknowledge the self in the other (or the different), and the other (or the different) in the self (Kegan, 1994). This path leads to (self-)compassion and a more integrated sense of interdependence, which Stevens-Long (2011) ascribes to the specific experience of care and wholeness typical of later stages of development. Anderson and Adams (2016) write: “At this stage, Servant Leadership fully emerges. The leader becomes the servant of the whole" (p. 82). Those leaders who are capable of leading amidst complexity are defined by the authors as "Integral Minds" (Anderson \& Adams, 2016, p. 82). They are characterized by a visionary-strategic capability expanding to include a systemic vision of the welfare of the whole. According to the authors, only $5 \%$ of the adult population currently evolves to this level (Anderson \& Adams, 2016). Inspired by Cook-Greuter's (2002, 2013) unitive stage of ego-development and, more broadly, by spiritual literature, Anderson and Adams (2016) further distinguish a unitive kind of leadership. The authors describe it as possible when emerging from a solid, long-term spiritual engagement in the awareness of 
interconnectedness, wholeness, and unity, and aiming at enacting "world service for the greater good" (p.85).

Because it is more rarely assessed among leaders, the number of studies investigating leadership at the post-conventional level of development is extremely limited (McCauley et al., 2006; Pfaffenberger, Marko, \& Combs, 2011). However, we observe a recent, promising interest in qualitative descriptions of how vertical development at the post-conventional level informs what, paraphrasing Ladkin (2010), we can define leaderly meaning-making, embodiment and enactment in organizations (Anderson \& Adams, 2016, 2018; Brown, 2012; Hewlett, 2004; Joiner, 2011; Joiner \& Josephs, 2007; Kelly, 2013; Legault, 2010; Nicolaides, 2008; Presley, 2014; Torbert, 1996).

\section{Post-Conventional Leadership Capacities}

With mature consciousness, self-expression becomes more unique and articulated (Cook-Greuter, 2009), and fewer common markers have been isolated by the scorers of developmental assessments. Yet, the qualitative descriptions offered by the existing leadership and organizational research inspired by constructive-developmental theory, particularly in recent years, show a clear convergence around the main post-conventional leaderly capacities and the forms of awareness associated with them. The same convergence is observed in similarly oriented literature from other fields, and mostly from education (Smith, 2016; Yeyinmen, 2016). The studies focusing on the experience of leaders at post-conventional orders of development are mainly based on in-depth interviews, phenomenological and/or narrative approaches, and action inquiry. They share some significant limitations: small samples, particularly for each order of 
development explored within the post-conventional tier, sample homogeneity in terms of culture (mostly US-specific), philosophy of life and leadership, the adoption of one kind of assessment tool exclusively and one primary theoretical lens, and researcher-related biases such as interview skills, meaning-making, possible selective perception based on the assessment of participants at specific stages (Hewlett, 2004; Kelly, 2013; Legault, 2010; Nicolaides, 2008; Presley, 2014).

From the analysis of the descriptions of post-conventional leaderly capacities emerge two main overarching themes, namely the capacities for integration and regeneration. These seem to be rooted in the shifting of motivations that characterizes the passage to tier three: the ego/self tending to cease to exist as a separate entity and, rather, to be integrated in a unified view of reality. Leaders at the post-conventional tier think and have a heartfelt sense of what is good for them as blended with what is good for the world. This results in a single motivation orienting their actions to serve the needs of others and the environment (Anderson \& Adams, 2016, 2018; Brown, 2012; Legault, 2010; Yeyinmen, 2016).

\section{Integration.}

Integrative awareness (Torbert, 1994), pointing to connections and patterns rather than dichotomies and polarities (Berger, 2012), and holistic, trans-cognitive awareness (Cook-Greuter, 1999; Torbert, 1994), accounting for a more direct, unmediated experience of reality, support the capacity for integration. Trans-cognitive awareness completes integrative awareness in that it makes the notion of everything being interconnected become a lived experience (Hewlett, 2004). 


\section{Integrative awareness-based capacities for integration.}

The post-conventional leaderly capacities based on integrative awareness particularly inform leaders' relationship with otherness, at different levels, and their exercise of power. In terms of connecting (with) differences, leaders at post-conventional levels of development show:

- the ability to see oneself and others as a complex assortment of patterns and subpersonalities (Hewlett, 2004),

- the ability to hold and compare different ideas, experiences, and systems, to make meaningful connections between them, and come to a clear and decisive action (Anderson \& Adams, 2016, 2018; Berger, 2012; Brown, 2012; Joiner, 2011; Kelly, 2013),

- the ability to enter different frames while honoring one's own perspective, and to step back and view issues from multiple sides and within a broader perspective (Berger, 2012; Joiner, 2011; Legault, 2010),

- the appreciation of novelty in apparently familiar situations (Joiner, 2011),

- the recognition of the multiplicity and relativity of different frames, truths, and paradigms (Hewlett, 2004; Torbert, 1994),

- dialectical and paradoxical thinking, recognition of the dilemmic, rather than problematic, and paradoxical, rather than clearly defined nature of social life (Basseches, 1984; Kegan, 1982; Torbert, 1994; Torbert \& Associates, 2004),

- the shifting from the mundane to the sublime in describing and making sense of experiences (Hewlett, 2004). 
Mutuality and power are imbued with authentic care, love, and spirituality. Postconventional leaders exercise power:

- $\quad$ practicing mutual, inquiry-supportive, love-based, and mutually transformational forms of power (Joiner, 2011; Kelly, 2013; Torbert \& Associates, 2004), condemning any misuse of power (Hewlett, 2004),

- fostering open dialogue and integrating assertiveness and accommodativeness as required by the situation (Joiner, 2011),

- prioritizing and delegating through inquiry (Merron, Fisher, \& Torbert, 1987), seeking different kinds of formal and informal feedback from a variety of sources (Kelly, 2013; Legault, 2010; Torbert, 2004) and believing in genuine dialogue as contributing to improvement (Joiner, 2011),

- with compassion, capacity to engage with, and co-create mutuality (Anderson \& Adams, 2016, 2018; Kelly, 2013; Legault, 2010; Nicolaides, 2008), and sensitivity to the inner workings of relationships, to interpersonal dynamics, to deep connection (Hewlett, 2004),

- non-judgmentally challenging other people's perspectives while maintaining deep relationships (Hewlett, 2004), fostering heterogeneity and diversity as a way to strengthen the ability of a system to survive (Presley, 2014),

- providing a context in which all the contributors, including the leader, can collectively create a vision, mission, purpose (Kegan, 1994; Brown, 2012),

- with the ability to undertake visionary initiatives and implement solutions that are both personally meaningful and mutually beneficial for a variety of 
stakeholders simultaneously (Anderson \& Adams, 2016, 2018; Brown, 2012;

Joiner, 2011; Kelly, 2013),

- with the ability to manage both clearly bounded groups of people and the broader community, in their environment (Anderson \& Adams, 2016, 2018;

Berger \& Johnston, 2012; Joiner, 2011; Kegan \& Lahey, 2009).

\section{Trans-cognitive awareness-based capacities for integration.}

Post-conventional consciousness allows for a more direct and variegated experience of reality, supported by different ways of thinking, feeling, sensing, and intuiting. Unity and diversity seem to be honored simultaneously. Characteristics of leaders at the post-conventional level are the following experiences of trans-cognitive awareness:

- the use of intuitive, analogical and metaphorical forms of thinking, and of the aesthetic and kinesthetic sense in making meaning (Anderson \& Adams, 2016, 2018; Brown, 2012; Legault, 2010; Nicolaides, 2008; Herdman-Barker \& Torbert, 2011),

- the capacity to feel and share multiple emotions simultaneously, to experience the feeling without the need to analyze it, to witness emotions and let them go (Hewlett, 2004),

- the ability to take language as object, in itself representing and limiting one's reality, like a map never fully capturing the territory (Hewlett, 2004),

- the ability to take the ego as object, and experience and derive identity from a deeper sense of being (Hewlett, 2004), 
- experiences of the merging of knower and known and the disappearance of the sense of self (Hewlett, 2004),

- connection with one's spiritual core (Brown, 2012; Legault, 2010; Nicolaides, 2008), and with the "spirit or creative force [...] felt living and breathing every moment" (Hewlett, 2004, p. 148), as well as transpersonal or peak experiences (Hewlett, 2004),

- the experience of the self as a vehicle for the expression of a deeper creative force, energy, and love (Brown, 2012; Hewlett, 2004; Legault, 2010),

- the use of archetypes connecting one's personal story with the universal story of humanity (Hewlett, 2004; Smith, 2016).

\section{Regeneration.}

Self-awareness, intentional attention, and the awareness of impermanence and non-linearity undergird the capacity for regeneration, intended as constant, adaptive transformation of self, others, and systems (Berger, 2012; Torbert \& Associates, 2004). These allow to appreciate and leverage dynamic complexity and emergence in the here and now. Leaders at the post-conventional level have the capacity to:

- hold a multi-dimensional view of time comprehending past, present and future (Berger, 2012; Kelly, 2013; Torbert \& Associates, 2004),

- think across long time spans and hold the perspective that circumstances can evolve over time in unpredictable ways (Berger, 2012),

- develop visions that can span years to generations (Berger \& Johnston, 2012; Joiner, 2011) while dealing with present realities, seeing oneself shaping the future in the present (Kelly, 2013), 
- recognize the importance of timing and placing in the implementation of every initiative (Torbert, 1994; Yeyinmen, 2016),

- "sit in-wait for the unexpected" (Herdman-Barker \& Torbert, 2011, p. 54), and attune to emergence (Berger \& Johnston, 2012),

- generatively relate and learn with(in) ambiguity (Nicolaides, 2008), and manage tasks involving dynamic complexity and unpredictability (Berger, 2012; Berger \& Johnston, 2012; Brown, 2012).

Post-conventional leaders embrace regeneration as both natural and intentional. On one hand, they tend to live life as "a mystery to be lived and enjoyed in all its complexity rather than something to be figured out" (Hewlett, 2004, p. 146). On the other hand, on the strength of high self-awareness and intentional attention, they have a potential for self-transformation and for catalyzing transformation in others and systems that is unique to post-conventional stages (Basseches, 1984; Kegan, 1982; Rooke \& Torbert, 2005; Torbert \& Associates, 2004).

Regeneration is experienced and initiated first and foremost from the inside-out, starting with a continuous striving for self-development. At the same time, it unfolds within the awareness and the experience of time, space, entities, and phenomena as inherently fluid, interrelated, and constantly changing. Finally, mutuality and interconnection play an important role in driving regeneration: the post-conventional leader is not simply looking to transform self within a system, $\mathrm{s} /$ he seeks communities of collaborative inquiry through which to transform society (Rooke \& Torbert, 2005). S/he can do that by: 
- $\quad$ sustaining present-centered awareness (Hewlett, 2004; Kelly, 2013; Torbert \& Associates, 2004), which provides with direct, mental, emotional, bodily selfknowledge (Joiner, 2011),

- knowing oneself, engaging in self-inquiry, developing awareness and integrity (Brown, 2012; Kelly, 2013; Legault, 2010),

- constantly working to grow, learn, question assumptions, align behavior with values and aspirations (Berger, 2012; Joiner, 2011; Kelly, 2013; Legault, 2010),

- acknowledging the limits of one's inner system, and of actually having an inner system (Berger, 2012),

- inquiring into their own and organizational blind spots (Joiner, 2011; Kelly, 2013; Torbert, 1994), as a political, spiritual, emotional, aesthetic engagement — not just an intellectual exercise (Legault, 2010; Torbert, 1991),

- cultivating vulnerability, which in combination with a state of inquiry allows timely learning and adjustments (Torbert \& Associates, 2004),

- cultivating self-compassion (Anderson \& Adams, 2016, 2018; Hewlett, 2004; Legault, 2010),

- practicing shadow work, and "meet[ing] the enemy and see[ing] that 'they are us"” (Anderson \& Adams, 2016, 2018; Brown, 2012),

- $\quad$ seeking feedback from oneself and others, realizing that self-image is biased and partial (Joiner, 2011; Kelly, 2013), 
- recognizing fallback to modes corresponding to earlier developmental stages and timely correcting for the regression (Livesay, 2013; McCallum, 2008; Torbert, 2011),

- double-loop and triple-loop learning and adjusting to resolve inconsistencies between territories of experience-e.g., between strategies and performance (Rooke \& Torbert, 2005),

- creating and holding safe and challenging environments for deep transformation to unfold in others and in organizations (Anderson \& Adams, 2016, 2018; Brown, 2012; Hewlett, 2004; Joiner, 2011; Rooke \& Torbert, 2005; Torbert \& Associates, 2004).

It is not because a leader has the capacity to be and lead at the post-conventional level that s/he will do so in different inner and outer circumstances. Nevertheless, it appears clearly that the potential for more justice, harmony, and generativity in our world is inherent in leadership at the post-conventional level.

\section{Possible Post-Conventional Mistakes}

To honor the complexity of post-conventional consciousness, I now turn to an exploration of the most common mistakes that leaders at this developmental level can make (in virtue of their very development). Torbert and Erfan (2019) compiled a list of possible mistakes associated with post-conventional levels of development. Those mistakes are to be considered as additional to the ones naturally made when falling back to earlier action-logics.

One of the specific post-conventional mistakes is the tendency to be overconfident about one's ability to accomplish an initial vision on the basis of the 
perceived capacity for (self-)correction based on feedback. Because of their long-term perspective, post-conventional leaders tend to consider a mistake as an action "that misses its initial mark" (Torbert \& Erfan, 2019, p. 2). This can imply scarce attention to the conditions and the processes necessary to learn from mistakes in their organizations, and particularly for individuals at conventional levels of development.

Other post-conventional mistakes are presented by the authors as typical of specific action-logics. For example, at the Redefining/Self-questioning action-logic, a possible mistake is that of overextending the value and efficacy of collaboration in any circumstances, which can result in the sabotaging of one's own and of the system's power in "idiot collaboration" (Torbert \& Erfan, 2019, p. 3). Another typical Redefining mistake could be the absolutizing of their own action-logics and a sense of superiority towards the conventional ones. If disdain of the (more or less recently) transcended action-logics is common, Torbert and Erfan (2019) point to the fact that individuals at their early steps in post-conventional territory still abundantly act in conventional modes and, in their newly embraced relativism, can criticize them ending up in the very absolutism that they are rejecting. The authors claim that another possible Redefining mistake is the exaggerated focus on ideals and spirituality at the expenses of the material reality that also impacts self and others. Sharma and Cook-Greuter (2015) confirm that it is at the SelfActualizing/Strategist-Transforming stage that one can better integrate polarities, even if subtle preferences persist due to the value perceived in the newly discovered perspectives, and the criticism of the previous, more partial views. At the StrategistTransforming action-logic, continue Torbert and Erfan (2019), leaders can find themselves lacking models, strategies, and skills to timely intervene in organizational or 
historical arenas in the same way as they might in one-to-one relationships - as in coaching. Important cultural, systemic change may leave them frustrated in their efforts at timely action. As for the Alchemist action-logic, a possible mistake highlighted by the authors lies in the disruption of early action-logics to a degree that can elicit violent reactions (Torbert \& Erfan, 2019).

Other common mistakes that the authors associate with post-conventional development are:

- those made in the apprenticeship of each of the subsequent action-logics, getting lost in the multitude of the new possibilities, thus in ineffective action;

- incongruencies such as the exercise of unilateral and mutual action/power in different areas (resulting from an uneven or asynchronous development through different developmental lines);

- the tendency to prematurely or inappropriately establish late-action-logics kinds of relationship with people at earlier stages, thus failing to create mutuality (Torbert \& Erfan, 2019).

In conclusion of this section, I explore the main leadership theoretical currents that contemplate post-conventional leadership awareness and capacities.

\section{Leadership Theories Conceptualizing Post-Conventional Awareness and Capacities}

Two main bodies of theory, in addition to the developmental perspective, attempt to conceptualize leadership as based on awareness, and particularly on self-awareness and intentional attention, trans-cognitive awareness, integrative awareness and awareness of impermanence and non-linearity, which I described as at the heart of the post- 
conventional leadership capacities for integration and regeneration. One of these perspectives is Scharmer's $(2009,2018)$ theory U.

\section{Theory $U$.}

With his theory, Scharmer (2009) explicitly calls for a leadership "operating from the whole" (presencing.org), the Source, which is referred to as awareness. The quality of our actions is a function of the quality of our attending to them, and of the holding space that we can create for ourselves and others.

Theory $\mathrm{U}$ is proposed as a theoretic and a methodological framework allowing both to understand and develop leadership as an emergent process. The process consists in accessing the future that wants to emerge, instead of reacting, repeating unproductive (at best) or toxic patterns of the past. Leadership is seen first and foremost as an act of heightening, shaping and shifting awareness, in oneself and for and with others (Scharmer, 2009).

Presencing is the word that Scharmer, with Senge, Jaworski and Flowers (2005) coined to describe the capacity to sense and be present to a deeper and higher awareness, or Source. This connection with Source allows the future to emerge from a non-linear perspective of wholeness, through a process of observation, (listening, sensing, and seeing, described on the left side of the $\mathrm{U}$ ) that leads to the letting go of the old and the letting come of the new. The current self and the higher, best future self meet at the bottom of the $\mathrm{U}$, representing the here and now of awareness. The manifestation of the new into the world occurs through the upward process described on the right side of the $\mathrm{U}$, via the crystallization of the emergence, the prototyping of (and learning from) practical applications, and co-creation from the whole. All through the process, leaders 
are potentially confronted with voices of judgement, cynicism and fear, in constant tension with the movement toward the future that wants to emerge. The tension is resolved by progressing in the process - i.e., journeying the $\mathrm{U}$ - with an open mind, an open heart and an open will.

Scaling the process from the ego-system to the eco-system perspective, Scharmer and Kaeufer (2013) invite leaders to accomplish the shift from ego-awareness to ecoawareness, from caring for the well-being of the ego to caring for the well-being of all, including oneself. According to the authors, practices of co-creation from the whole, based on the merging of the personal, collective and systemic dimensions of awareness, would give us the confidence to connect with, and manifest together, our deepest aspirations.

Theory $\mathrm{U}$ is currently the most sophisticated and practical framework conceptualizing leadership from a perspective of wholeness and interconnection. It also serves as a reference methodology for leadership development in the same perspective, and as a meta-framework for different awareness- or presence-based models and practices (Coughlin, 2015; Hayashi, 2018; Silsbee, 2008, 2018; Strozzi-Heckler, 2007). These models consider the emotional, bodily, and other trans-cognitive aspects of experience at the same level of the intellectual, rational aspects. They support the legitimization of leaders' emotions, sensations, intuitions and spirituality in the contemplation of leadership effectiveness and decision making.

Another perspective shedding light on post-conventional leadership awareness and capacities is offered by transpersonal leadership theories, which I turn to now. 


\section{Transpersonal leadership.}

Transpersonal leadership is currently conceptualized by different authors as "radical, ethical and authentic while emotionally intelligent and caring," (Knights, Grant, \& Young, 2018, p. 2), operating beyond the ego, for the greater good; as a "potentiating art" (McCaslin, 2008) holding the space for the actualization of one's and others' potential for greater good; and as a soulful emergence, based on the consideration of humans essentially as spiritual beings (Reams, 2015).

These emerging transpersonal approaches to leadership are infused with ethics. They underscore self-care and self-actualization as crucial as the potentiating of others in a perspective of "deep human ecology" (McCaslin, 2008). Also, they build on Greenleaf's (1977) servant leadership, whose commitment to serve originates in what different authors define unconditional love (Focht \& Ponton, 2015), transcendental spirituality, connection with the divine, interconnectedness between self and others, and sense of mission and wholeness (Sendjaya, 2005). The cultivation of multiple intelligences, and particularly spiritual and emotional intelligence, are highlighted in the transpersonal perspective (Jironet \& Stein, 2013; Knights, Grant, \& Young, 2018; Reams, Gunnlaugson \& Reams, 2014; Reams, 2015).

Reams (2015) builds on Scharmer's work referring to Source as the soul, creative unit of pure awareness independent and prior to the mind, the emotions, and the body. "Deep presencing" is described as embodying stillness, as a way to engage the soul in action (Reams, Gunnlaugson, \& Reams, 2014). In this view, deep presencing offers ontological-based renewal. Reams, Gunnlaugson and Reams (2014) cite Palmer's (2004) description of the hidden character of wholeness, and of our soul wanting "to keep us 
rooted in the ground of our own being, resisting the tendency of other faculties, like the intellect and ego, to uproot us from who we are" (p. 33). Leaders' intention and choice are, in this view, generated and sustained in the higher order of the soul, or in a spiritual intelligence (Reams, 2015).

Reams, Gunnlaugson and Reams (2014) and Jironet and Stein (2013) point to the space between one another as the environment where deep listening and close attunement allow transformational shifts. The authors, and particularly Jironet and Stein's (2013) psycho-spiritual model, highlight the transcendent nature, i.e., the energy field, of this orbit of connection and evolution. Through the concept of soul, authors in the transpersonal arena, and particularly Reams, Gunnlaugson and Reams (2014) focus on the potential for good. Leaders' integrity is seen as alignment with the soul (Reams, 2015).

\section{Coaching and Developmental Levels}

I conclude this chapter with an overview of the current knowledge around coaching and coaches' specificities at different developmental orders.

At every level of development, it is vital for leaders "to feel understood by their coaches and to have the sense that their coach can really make sense of who they are. The more complex the client, the bigger the demands on the coach for mirroring that complexity" (Berger, 2012, p. 88). In particular, at the post-conventional level the "internal authority" (Berger, 2012, p. 88) of the coach needs to be perceived by the client. The kind of coaching that is realized at this level, or in support of the transition to postconventional consciousness, calls for coaches' capacities, skills, and motivations associated with post-conventional maturity (Berger, 2012; Sharma, 2019). This 
corroborates the idea that in order to be developmentally effective, a coach needs to be at least at the same level of development that his/her clients (Bachkirova, 2016; Diehl, 2010; Laske, 1999, 2003; Perry, 2014; Scott, 2009; Wildflower, 2006). Also, this tends to confirm the importance for coaches to have clarity around their own as well as their clients' meaning-making in order to better meet and support them (Bachkirova, 2011; Berger, 2012; Sharma, 2019).

A few authors attempt to delineate the characteristics of coaches at different levels of development based on specific developmental frameworks, and particularly Sharma (2019), based on Cook-Greuter's model, and Bachkirova (2011), distinguishing between coaches with an unformed ego (corresponding to the conventional tier), coaches with a formed ego (corresponding to the early post-conventional tier) and coaches with a reforming ego, and with a soul (corresponding to the later post-conventional tier).

In offering a summary of the authors' descriptions of coaches at different developmental levels, I am mindful that "the capacity to do a thing is not the same as the skill to do it. And both of those are different from the desire to do it" (Berger, 2012, p. 86).

The transition from the conventional tier seems to happen when the coach loosens the grip on:

- techniques, tools and tips as providing structure, guidance and safety for both the clients and the coach;

- $\quad$ supporting and understanding the clients, and acritically conforming to the clients' organization framing and expectation for their work; 
- focusing on the clients' achievement of their goals as a gauge of the quality of their work.

Developing toward the post-conventional tier, coaches tend to fine-tune a specific approach to coaching that corresponds to their own style, to rely more on their spontaneous contributions to the process as it unfolds, thus being more flexible and agile in dancing with the different perspectives at play in the client's situation, and to judge the quality of their work based on their own criteria and philosophy (Bachkirova, 2011; Sharma, 2019). At the post-conventional level, coaches can adapt and make rules for their work depending on the client's context, and focus on inquiry and exploration (more than on specific changes). At this stage, coaches are also more aware of their own biases and interpretations, and of the parallel processes and the shifts that the mutuality of their work with clients triggers in themselves. Later in their development at the post-conventional level, coaches may come to appreciate, and leverage with agility, the contribution of the previous stages of development. Also, they can offer a system view, take multiple perspectives, and "focus on the interrelations and the forces in the [clients'] issues rather than the particular people or events involved" (Berger \& Fitzgerald, 2019, p. 300), helping to weave multiple ecologies and situations together, in virtue of specific principles benefiting the client and his/her systems. The focus is increasingly on (self-) inquiry, feedback, and illuminating and owning blind spots, assumptions and dichotomies (Berger, 2012; Sharma, 2019).

There is very little empirical research exploring the developmental consciousness of coaches and its impact on their coaching. Kennedy's (2012) dissertation based on interviews of 15 coaches (graduates of Integral Coaching Canada's Integral Coaching® 
Certification Program) assessed, with one exception, at the post-conventional level, suggests that developing at the post-conventional level coaches can make use of self as instrument through:

- an empowered experience, based on an expanded sense of consciousness, connection, capacity and contribution;

- embodied, grounded and authentic presence;

- empathic connection at the physical, energetic and spiritual level of consciousness;

- the active use of self in response and co-creation with the clients.

Perry (2014) developmentally assessed 36 certified professional coaches through the Subject-Object interview (Lahey, Souvaine, Kegan, Goodman, \& Felix, 2011) and found that $28 \%$ had not fully achieved Kegan's fourth order of consciousness (corresponding at the edge between conventional and post-conventional level), the majority of the coaches $(66 \%)$ had achieved the fourth order or was in transition to the fifth (corresponding to the post-conventional level), and only six percent of the participants had fully achieved the fifth order of consciousness. Perry (2014) found no relationship between coaching experience and/or the level of professional certification and developmental consciousness. Yet, coaches at different levels of consciousness showed different meaning-making of their engagements with clients, urging the author to conclude that it is important for coaches to be aware of their developmental consciousness and for coaching education programs to support increasing complexity of mind. 
Finally, as previously mentioned, Scott's (2009) dissertation, based on her study of a group of eleven coaches assessed at high levels of complexity of mind, shows how those coaches were engaged for their own development through continuous learning and ad hoc practices.

In the next chapter, I explore the methodology that supported the co-inquiry members, all coaches invested in their ongoing development, in the exploration and expansion of their consciousness. I discuss my methodological choices as informed by specific ontological and epistemological stances, and by the overarching developmental intention of this research. 


\section{CHAPTER THREE}

\section{METHODOLOGY}

This study was conceived as a participatory action research project.

Methodological considerations naturally stem for me from an ontology that Freire (1982) described as follows:

In my view, thinking dialectically, the concrete reality consists not only of concrete facts and (physical) things, but also includes the ways in which the people involved with these facts perceive them. Thus in the last analysis, for me, the concrete reality is the connection between subjectivity and objectivity, never objectivity isolated from subjectivity. (p. 82)

I believe that what holds our attention, in every moment, in practical, emotional, and conceptual terms shapes our experiential subjectivity (Center of Action Research, 2018). And in its constant interweaving with others' subjectivity and with the world unfolds our experience. My ontological model is that all that is is essentially interconnected and interdependent, and our subjective (and intersubjective) consciousness constructs ever-evolving patterns of experience emanating from that essential, universal oneness. Different authors describe oneness from the quantum (Bohm, 2002), ecological and biological (Bateson, 1972, 2002), whole-person (Blackstone, 2006; Mills et al., 2020) and whole systems (Scharmer, 2009; Scharmer \& Kaeufer, 2013), as well as the spiritual perspective, based on millenary Eastern and Western wisdom traditions (Chopra \& Kafatos, 2017; Miller \& Cook-Greuter, 1994; Prendergast, 2019; Wilber, 1979). The trans-cognitive experience of oneness, and of the self as one with it, is broadly defined as unitive consciousness, and corresponds to what 
Maslow (1971) defined as "self-transcendence", alluding to a disidentification with the ego and its roles in favor of an identification with universal awareness (Mills et al., 2020). This inner knowing and experience deepened for me during the time of the coinquiry and certainly grounded my epistemological and methodological stances all through the process. I perceived the co-inquiry as a living eco-system composed of interdependent beings - eco-systems of identities, roles, immanent and transcendent aspects themselves - evolving in and with the larger eco-systems of our time and space, and ultimately part of, and one with, the whole ground of being. To paraphrase Nora Bateson (2016), the nexus of relationships providing meaning to events and patterns in the co-inquiry was ecological. An important corollary of this eco-logical view of the coinquiry was the awareness that any experience at one level impacted the other systems' levels and the whole. This awareness encapsulated the value of the co-inquiry as a developmental, co-creating endeavor expanding the consciousness of multiple systems as fractals of our oneness, and certainly grounded my responsibility as the primary researcher structuring and holding the space for the group.

The ontological premises of the co-inquiry undergirded an understanding of leadership (and co-leadership) from the complexity and relational constructivist perspectives. Those views highlight the shared, fluid, and shifting nature of leadership as emerging from and contributing to the continuous, mutual enactment of reality (Hosking, 2011; Ladkin, 2010; Lichtenstein \& Plowman, 2009; Uhl-Bien \& Marion, 2011; Wheatley, 1992). These perspectives offer a dialogical, or eco-logical view of the self as evolving with each specific co-creation of experience (Hosking, 2011; Ladkin, 2010). In the ongoing emergence of our relational processes, the differentiation between self and 
others becomes "soft" (Hosking, 2011, p.457), inviting us to move in an inclusive direction, towards greater understanding, acceptance, co-creation with the other than oneself. As Uhl-Bien and Marion (2011) put it, leadership lies "in the interconnected actions of individuals [...] engaging with one another through dialogue" (p. 470). In sum, the construction of reality, and of leadership as an emerging phenomenon, becomes manifest through significant connections within and among people and systems (Wheatley, 1992). And together with Ladkin (2010) and her interpretations of MerleauPonty's thought, I argue that these connections as well as our fundamental connectedness are made of immanence and transcendence intertwined. If the concrete aspect of our connections is fundamental to compose the "flesh" (Ladkin, 2010, p. 64) of our experience, so is self-transcendence, the intangible, transpersonal aspect that we can name and picture as the orbit, the space within, between and beyond these connections.

I also found myself espousing the emerging "eco-leadership" discourse (Western, 2013), whose key aspects are the connectivity with the ecologies in which we evolve; eco-ethics engaging for the good of other human beings and the natural world; and leadership spirit, acknowledging the creative, non-rational, spiritual human potential. Figure 1 represents the evolving, interdependent eco-systems composing and nesting the co-inquiry, each to be considered with its immanent and transcendent aspects. 


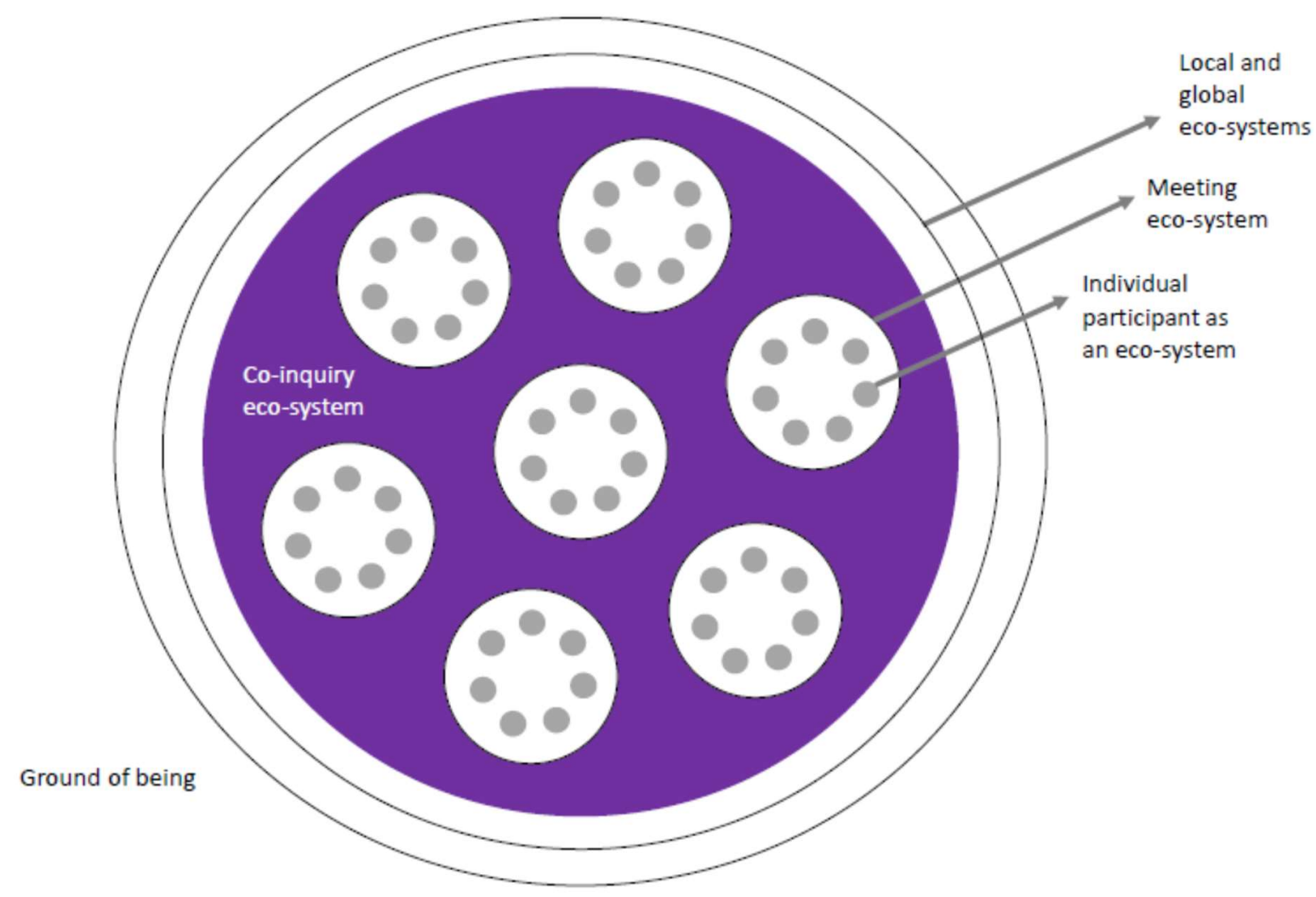

Figure 1. The nested systems of the co-inquiry.

Rooted in the ontological foundations of this study is an epistemology that is based on the generativity of action and reflection within oneself and in collaboration with others (Reason, 1994). Knowing and learning are also a matter of reflective (inter)action. And as Reason (1994) and Bradbury et al. (Center of Action Research, 2018) emphasize, it is the whole person, or the whole system, that participates in the interaction creating knowledge — with mind, heart, soul, bodily sensations and actions. Action research originates from and fulfills these ontological and epistemological orientations seeking "to bring together action and reflection, theory and practice, in participation with others, in the pursuit of practical solutions to issues of pressing concern to people, and more 
generally the flourishing of individual persons and their communities" (Reason \& Bradbury, 2008, p. 4). Across the different research approaches that it designates, action research is:

- collaborative, involving co-researchers investigating with (and not on) others, co-designing and co-implementing the study within their conceptual, relational, experiential space (Center of Action Research, 2018),

- reflexive, based on ongoing, self- and mutual inquiry through conceptual, emotional, practical attention that is conducive to action,

- action-oriented, the theory informing the practice, and reflection informing experiments for the creation of practical knowledge,

- emergent, consisting of and generating knowledge through cyclical processes of reflection and action, and in timely relation to its ever-changing contexts (Ledwith, 2017),

- focused on critical transformations (Bradbury et al., 2019) and on "valuesaware" (Marshall, 2016, p. 5) learning and growth that are meaningful to the coresearchers and their systems, aiming the transfer of knowledge, practices and empowerment as well as the inner and outer development of all.

\section{Research Approaches}

My intention with this exploratory, participatory study was to investigate how a group of developmentally oriented leadership coaches could expand their consciousness, their capacities and skills for developmental coaching through action inquiry. The logic of this research was grounded on understanding the coaches' sense-making of their experience together, and on empirically fostering individual and systemic development. I 
convened a community of inquiry with a pragmatist orientation rooted in Dewey and Addams' philosophy and practice with "experiments in cooperation" (Seigfried, 1996, p. 92) for social progress. This co-inquiry group particularly formed around the intention to give life to new awareness, intentions, strategies and behaviors which would ripple transformative potential in different contexts, and particularly through the practice of developmental leadership coaching. The following three questions informed the coinquiry, distilling and articulating its interpretive and developmental logic:

1. How can we, as a group of leadership coaches, use action inquiry to enhance our capacities and skills for developmental coaching?

2. How can the work that we do together support the evolution of our current meaning-making as assessed through the Leadership Maturity Assessment Profile (MAP)?

3. How can we develop mutual and collective capacity to support development in ourselves and each other?

These questions guided the co-inquirers' generation of knowledge and development throughout the process. Each member of the co-inquiry group engaged specifically in the exploration of a growth edge that s/he had identified for her/himself prior to the start of the co-inquiry. The coaches' growth edges were related to a personal or professional challenge, questioning, or learning curve particularly present to their awareness at the onset of the study.

The creative process of the group unfolded participatorily, essentially through the interactions among co-inquirers during a series of seven meetings, and through ongoing reflexivity, i.e., self- and mutual inquiry among individual co-inquirers and with the 
whole system of participants within its specific ecologies. Informing the methodology of this study are the research approaches that I describe next.

\section{Action Inquiry}

Action inquiry, and particularly CDAI, presented in the previous chapter, offered us co-inquirers a fertile epistemological and methodological space where our experiences could be appreciated as they were lived, reflected upon and made sense of; where knowledge informed practice; and where new insights from our experience informed further experiments. This happened in relation to the ever-changing individual, group and systemic experiences throughout the process - honoring the first person, second person and third person perspectives and their respective forms of inquiry (i.e., "I"'s personal reflections on one's own experience, "we"'s mutual and shared view of our experience, and the stepping out from the experience in order to present it and relate it to a broader "they"). This allowed the emergence of and the learning from our data in a fluid and at the same time messy way, that I describe later in this section.

Embracing CDAI required from each of us co-inquirers individually an ongoing "reflection-in-action" (Schön, 1983), an alertness striving to integrate awareness, assumptions and strategies, actions, and outcomes, i.e., Torbert's four territories of experience (Fisher, Rooke \& Torbert, 2001; Torbert \& Associates, 2004) as they occurred in our work together. This way of being is powerfully captured in the aspirational expression "living life as inquiry" (Marshall, 1999, p. 155). Bringing inquiry at the heart of every situation allows to develop awareness and effectiveness in action (Marshall, 2016). The question "what is alive here?" guided me and helped me keep focused on this intent throughout the co-inquiry. 
For the group as a whole, operating within CDAI set the intention to explicitly share deliberations about the collective vision and mission of the co-inquiry-integrating and enriching my initial vision-, and about the structure and the organization of our work. CDAI is also based on open and authentic communication, sharing, feedback, and disclosure and confrontation of differences; the systematic assessment of collective and individual processes and performances; and the timely and ongoing development of $a d$ hoc transformative strategies and structures for the collective (Reason, 1994; Torbert, 1987). Highlighted since the very first meeting, these were the grounding principles of our group, that we more or less skillfully and thoroughly brought to life through the process.

\section{Co-Operative Inquiry}

Another action research approach informing the methodology of this study is cooperative inquiry. We found inspiration in Heron's description of a self-determining researcher (Reason, 1994) as a "socially sensitive subject involved in mutual gaze with another" (Heron, 1996, p. 11) and participating with all her/his human sensibilities to the generation of data. We engaged in our research "into the human condition" (Heron, 1996) with the quality of participation, mindfulness and mutuality evoked by the author, and within an "extended epistemology" (Heron \& Reason, 2008). We worked with the four kinds of knowing described by Heron and Reason (2008), both in terms of process and outcomes of knowledge creation: (a) experiential knowing, the direct experience of perceiving and resonating with things, people, places; (b) presentational knowing, intuiting "significant form and process" (Heron \& Reason, 2008, p. 367) from the encounter of experiential knowing and expressing them in symbolic, non-discursive ways 
(e.g., images, movements, sounds, art, metaphors, etc.); (c) propositional knowing, the intellectual knowing about something, expressed in statements and theories; and (d) practical knowing of how to do something, translating into competences. Plural ways of knowing (Reason \& Bradbury, 2008) emerged as key in the co-inquiry both from the point of view of the process and the content. In addition to our cognitive intelligence, our heart intelligence, our somatic intelligence, and our trans-cognitive knowing were leveraged in our work, as they are in coaching, allowing us to attune to multiple aspects of our individual and collective wholeness.

The recursive nature of co-operative inquiry (Heron, 1996; Reason, 1994), based on subsequent cycles of reflection and action - mirrored in the cycles of in-session reflection and inter-session fieldwork in the coaching process - supported the spreading of our learning among the different territories of experience, (e.g., new awareness translating into new strategies and behaviors with time), and the depth of our integration. Reason (1994) describes co-operative inquiry as unfolding in four phases:

Phase 1. Co-researchers agree on an area of inquiry and identify some initial research propositions. ...

Phase 2. The group then applies these ideas and procedures in their everyday life and work....

Phase 3. The co-researchers will in all probability become fully immersed in this activity and experience. ...

Phase 4. After an appropriate period engaged in Phases 2 and 3, the co-researchers return to consider their original research propositions and hypotheses in the light of experience (p. 326-327). 
This cyclical work wove an important part of the fabric of the co-inquiry.

At each meeting, we co-inquirers reflected and shared on themes relevant to the expansion of our consciousness and let emerge an intention or a commitment to honor in our own life during the interval between meetings. The intention with this practice was to pursue our reflection after our sessions together, and deepen the inquiry into our work's implications in our life and our growth. The insights we harvested during the intervals were shared in the following sessions and used to formulate hypotheses, integrate learnings, and plan further actions.

\section{Spiritual Research}

Another epistemological and methodological inspiration for the co-inquiry was the spiritual research paradigm (Lin, Oxford \& Culham, 2016). In this perspective, I wanted to honor the inner knowing and the lived experiences of Spirit (that I refer to in this text as Source, the Field, ground of being, nondual and unitive awareness) through meditation, prayer and other contemplative practices, as source by which we can know and be known. Spiritual inquiry highlights the transcendent aspects of our experience, and connects us to the whole, to oneness, and to our shared search for meaning in response to the questions, challenges and complexity that life presents us with (Frankl, 2000). Equally significant for our co-inquiry, as mentioned earlier, developmental literature associates spiritual and contemplative practices with meaning-making evolution and stabilization, particularly at the post-conventional and transcendent level (Anderson \& Adams, 2016; Baron \& Cayer, 2010; Chandler, Alexander \& Heaton, 2005; Joiner, 2011; Torbert, 1994). Embracing the proposition of our human potential for experiencing the unitive realm of awareness as the essential ground of subjective and intersubjective 
experiences, I argue along with Blackstone (2006) that "opening to this dimension can be understood as the direction of human maturity" (p. 25).

Action inquiry allows for a very practical enactment and exploration of the spiritual, unitive dimension. Some scholars go as far as to draw a parallel between action research and spiritual science (Coghlan, 2005; Heron, 1998, 2008; Reason, 2000; Reason \& Bradbury, 2008): they adopt a view of spirituality as an everyday, practical, and participative experience of "coming back to now" (Reason, 2000, p. 3) as a transformative occasion of enhanced human flourishing. Emerging from an understanding of human existence as interconnected, part of an integral whole, this constructive-relational view of spirituality is rooted in Thomas Aquinas' definition of Spirit as "the capacity to relate to the totality of things" (as cited in Reason, 2000, p. 3), and implies attunement to "the space between" (Buber, 1970, as cited in Bradbury \& Lichtenstein, 2000, p. 551).

My personal spiritual explorations, concurrent to and interweaving with the coinquiry, informed my intentionality and the methods and practices I adopted throughout this research. During the co-inquiry meetings, we attended to and built on our experiences of Spirit in different ways and through different practices such as meditation, attending to the present moment, receiving and processing intelligence from embodied, non-mediated sources of knowing (Miller \& Cook-Greuter, 1994) available to us, and “abiding in liminal spaces” (Bruce and Davis, 2005, p. 1329) where separateness and dualities such as self-other, physical presence-absence, work life and spiritual life dissolve. 


\section{Embodied Research}

Creating knowledge through "a living, evolving process of coming to know rooted in everyday experience" (Reason \& Bradbury, 2008, p. 5) with others, action inquiry calls for an embodied understanding and enacting of research. I was personally drawn to an embodied research paradigm, animated by the desire to explore the lived aspects of consciousness. I had come to understand the body as a whole experiential being, physical and non-physical, sensing and sentient, representing and unfolding, constantly created as well as co-creating in interaction with the environment and the Field (Blackstone, 2006; Ellingson, 2017; Jones \& Woglom, 2015; Perry \& Medina, 2015; Prendergast, 2019). This led me to opt for in-person co-inquiry meetings and for the video-recording of our group meetings, to better capture the bodily, kinesthetic, and proxemic aspects of our experience as important sources of knowing about ourselves, our relationships, and the collective. Finding ourselves in the planetary and very personal COVID-19 crisis, we soon had to shift our meetings to a virtual, on-line format (via Zoom) yet my attention to the embodied aspects of our co-inquiry did not fade.

Through the different phases of the study, I was inspired by Ellingson's (2017) model conceptualizing "doing embodiment as an active engagement with reflexivity, sensuousness, and methods" (p. 11). I would add to these elements the active engagement with our emotions, felt-senses - Gendlin's (1982) word for pre-verbal, suffused knowing arising prior to our sensations, emotions and thoughts — and the energetic, subtle dimensions arising within and around us from the transcendent, unitive realm of awareness. These were important aspects of our embodied co-creation throughout the coinquiry. Ellingson's (2017) model lays the foundation for the experience and the inquiry 
into embodiment understanding the body as doing, enacted in everyday life, and becoming, constantly engaged in perception and proprioception through the ensemble of our somatic senses and the fluctuant enmeshment with the environment. From the intersubjective encounter of the world with our bodies we derive our preconceptual, feltsensed, heart and gut capacity for learning and making meaning, which seem to be essential, yet mostly unacknowledged aspects of research, and particularly relevant in this study exploring meaning-making. Also, Ellingson (2017) understands culture "as part of the senses, with cultural norms and ideas, language, discourses, and practices all existing in a 'sticky web' that cannot be separated from our embodied sense making processes" ( $p$. 19). That was evident in our experience throughout the co-inquiry process, marked by the porosity to the national, local, professional and academic culture as well as to other contextual aspects.

Attunement to what was embodied evoked for me a complementary attention to that which was not, and yet was exerting powerful influence (together with that which was) - to the absent, the undisclosed, the untold, and the unexpected. That was particularly alive for me when approaching the absence of one or more participants at the meetings, and offered a way to accept and at the same time attempt to inquire into "the unknowable that is wholeness" (Flood, 1999, as cited in Marshall, 2016, p. 13) of our group, and, through it, of our ecologies.

Another aspect of my embodiment as a researcher, the awareness of my whole “sensorium" (Ellingson, 2017, p. 11), brought me to attune with the different, shifting tones emanating from each of the participants as vibrational signatures (Prendergast, 2019), whether we were meeting in person or remotely, and to experiment with the 
blending and contrasting of the senses, trying to listen into the lights and colors surrounding the participants, or seeing subtle energy. At our first two meetings, which were in person, I was also particularly attentive to the tone I was setting in our locations — classrooms on campus — as potentially shaping "the kind of possible futures that [could] emerge [...] albeit in an open and nondeterministic way" (Ash \& Gallacher, 2015, as cited in Ellingson, 2017, pp. 28-29). Since the very first meeting, I intentionally released warm, colorful, peaceful vibrations in a space that I perceived as relatively cold and dry, where the camera on its tripod was such a central and powerful actant, possibly evoking the intrusiveness and the vulnerability of being video-recorded. I pushed all the tables and boards toward the walls and place our seven chairs in a semicircle with the camera at its open end, in the center of the room. I brought flowers, colorful tissues, treats, a chanting bowl, and always sprayed a fragrance called Agua de Florida, traditionally used by shamans in South America in ceremonies and rituals, and which evokes for me fertility and subtle awareness.

\section{Embodied ethics.}

The participatory nature of the co-inquiry also led me to consider questions of "embodied ethics" (Ellingson, 2017, p. 46) in research, and particularly of reciprocity, which was always on my mind and informed my expressions of gratitude for our partnership, and the question of how our being together was enacted in the ongoing negotiation with our differences and commonalities in terms of aspect, clothing, modes of greeting, sitting and speaking, language, etc. I was aware of how our bodies, especially through the color of our skin and other racial, intersectional, and cultural markers-both physical, e.g., signs of age, gender, wellness, tiredness, wealth, etc.; vocal, e.g., accents; 
and enacted, e.g. "stylized acts" (Ellingson, 2017, p. 75)—were expressions of the potential relationships between identity and power, and committed to naming my/others' standpoints when emerging. This was actually done very naturally by every participant whenever questions of diversity and privilege were addressed. Also, I was mindful of the physical factors of safety. When meeting in person, for instance, I was aware that my spontaneous tendency to hug people as a way to greet them could generate closeness or distance and resistance based on others' conditions for (psychological) safety. I was mindful of that, as well as of the placement of the chairs at a distance that could potentially evoke equality, intimacy and safety at the same time.

I realized, especially through the observation of the video-recording, how these became ways through which I was honoring another aspect of embodied ethics as a coresearcher, namely the care for others. My tone of voice, welcoming, touching, and my facial expressions manifested my deep care for my co-inquires, regardless of the story of our relationship. During our work together, that evolved towards compassion, deep connection and a sense of being one. Caring certainly became a shared experience within the group, embodied by each person in his/her peculiar and evolving ways through presence, listening, and positive regard.

I was also very alert to my self-care as a way to fully be with my co-inquirers and honor our presence and commitment. That became central during the COVID-19 shelterin-place months. If at the beginning of the study I felt in a moment of my life where I was taking good care of my personal well-being and my social boundaries, that was shaken by the COVID-19 experience, especially with my 3-year-old son at home. I became particularly aware of my need to take care of my body and of its dynamism, the flow of 
its circuitries, and of my presence to myself and others, as key components of my commitment to the expansion of consciousness.

\section{Research Design}

Based on these epistemological and methodological foundations, I designed this research as an emergent process of co-creation. The image of a spiral of development represents how I envisioned the synchronous process of reflecting upon the guiding questions and inquiring into our consciousness with the goal to evolve our individual and collective capacities and skills for developmental work. Inspired by Wilber's (2000) AQAL model, I created a co-inquiry "map" to visualize and share with my potential coinquirers, in our first exchanges about the co-inquiry, the "material" I imagined we would work with, i.e., the multitude of individual, collective, internal and external factors that could emerge for inquiry. Figure 2 represents a simplified version of the original coinquiry map (see Appendix A). 
Individual internal factors

Thoughts and mental processes

Emotions and emotional intelligence

Physical sensations

Awareness and intentionality

Identities, cultures and intersectionalities

Developmental story

Meaning-making and growth edge

Intuitions and other unconscious material

Group's shared meaning, values, rules

Group developmental trajectory

Intersubjective dynamics

Unconscious collective dynamics

\section{Collective internal factors}

Individual external factors

Presence

Voice (and silence)

Verbal expression

Non-verbal communication

Skills

Initiatives, actions and contributions

Personal and professional ecologies

Source,

Spirit,

the Field

Collective external factors

MAP assessments

Group characteristics

Group's actions, processes, rituals, and outcomes

Interpersonal and power dynamics

Contextual culture

Figure 2. A simplified version of the co-inquiry "map" illustrating its spiraling, emergent movement, and the key factors substantiating the process.

Many aspects of the co-inquiry map became part of our process:

- $\quad$ among the individual, internal factors informing our work were our mental, emotional, and somatic experiences, our awareness and intentionality, our purpose in life, our values and beliefs, our identities and intersectionalities (Crenshaw, 1991), our developmental factors, as well as our intuitions, dreams, and other information potentially coming to our consciousness from our unconscious. 
- Among the individual, external factors of our experience together were the quality of presence (Scharmer, 2009), the voice and the skills of the coinquirers, our actions and contributions, and the personal and professional ecologies we held and were held by.

- The collective, internal aspects of our experience were essentially relative to the shared meaning and rules, and to the intersubjective and collective unconscious dynamics that were activated.

- As for the collective, external factors, impacting the co-inquiry were our interpersonal and power dynamics, our actions, processes and rituals, as well as the political, social, environmental, and technological context. The global and local implications of the COVID-19 pandemic, the Black Lives Matter protests after the brutal murder of George Floyd by a police officer in Minneapolis, and more broadly the leadership crisis heightened by the imminent presidential elections in the United States exploded during the coinquiry months and indelibly marked our experience.

At the center of the map lies Source intended as the spiritual essence, the unbounded awareness within and beyond each of us—as source of our being, knowing, doing, and becoming.

The spiraling movement of the co-inquiry map alluded to the interweaving and impermanent nature of the individual and collective factors within Source. Each of us coinquirers evolved through our work based on our unique configurations of internal/external factors as dynamically interwoven with the collective internal/external factors and with our experiences of/as Source. Also, the spiral represented the dynamic, 
emergent, action- and transformation-oriented nature of our work. Since the design phase of the study I was very aware that its main component would be emergence, based on the moment-by-moment co-creation of our experience, and that would involve an ongoing revision of my initial intentions and impact the phases of analysis and reporting. I could not imagine that the spiral would become a whirlwind in what evolved as the "tectonic societal shifts" (Scharmer, 2020) of 2020. This substantiated and amplified the complexity of developmental work in many ways.

Sharing the co-inquiry map with the soon-to-become participants of the study (along with methodological and logistical information) was a way to open the conversation around my initial conceptualization of our endeavor, and to invite participation.

\section{Participants as Stakeholders}

The participatory nature of action inquiry brings forth a view of research participants as stakeholders, engaged with their whole being and different ways of knowing for the inner and outer development of themselves, each other, and their systems. As I recruited the co-inquiry members, I had in mind (and in my heart), this notion of stakeholders inquiring together within a shared conceptual, relational, experiential space (Center of Action Research, 2018). Given the in-depth, introspective nature of our investigation, I had decided to limit the number of co-inquirers to six coaches, including me, and because the inquiry was meant to be based on in-person meetings, the participants needed to be locally based. I personally invited potential coinquirers via email or during one-to-one conversations. I "purposefully" (Patton, 2015, p. 53) identified them among the developmentally oriented coaches I knew, to start, and 
asked them as well as the members of my dissertation committee to help me find coaches who could engage as stakeholders in the co-inquiry. Also, the aforementioned interviewbased research of coaches' understanding of developmental coaching (Distefano, 2019) allowed me to identify potential co-inquirers.

My criteria for the selection of the co-inquirers were the following: (a) familiarity with developmental theory and embracing of a developmental mission in their work; (b) they were actively practicing coaching with clients at the time of the co-inquiry; and (c) diverse in terms of gender, race, age, years of coaching experience, and training background. Also, if I could not assess their developmental level or readiness precisely, I had a sense of their (and my) gravitating somewhere in the post-conventional tier or transitioning towards it, which suggested good developmental company. I assumed that the decision to participate in the co-inquiry, that would represent an important engagement in terms of time and personal work, would depend, beyond the availability of each coach, on their being stakeholders in the developmental endeavor, i.e., on their interest in developmental coaching and their commitment to ongoing self- and others' development. My trust that the "perfect" group for this project would form was contaminated by the fear that it could represent an excessive engagement for many coaches. Then the group took shape in less than a month, and, to my surprise, an additional coach asked to join us intrigued by the opportunity of participating in the project. That was the first time that my initial intentions were shifting as to prove their ephemeral character in such a living, emergent project. I had no hesitations in welcoming the seventh coach onboard, also because she had been on my mind since the conception 
of the project as a potential participant, together with my concerns about her availability for such a significant commitment.

As I received the IRB approval for the study (in December 2019), I shared with every potential co-inquirer (all of whom became actual co-inquirers) an invitation letter to the co-inquiry as well as the positionality and the methodology sections of my dissertation proposal including the co-inquiry map (Appendix A), in order to convey my conceptualization of the project and its processes, and offer a basis for the co-creation to dawn. I also had the opportunity to have conversation with the soon-to-be co-inquirers about my intentions with the co-inquiry and the expectations in terms of mutual engagement, and to invite them to identify the personal and/or professional growth edge that they might envisage to explore through the study. Mindful of ethical considerations and as a way to clarify my intentions with the process, I prepared an extended informed consent form (including the video-recording consent) for the participants. The form equally served as a Memorandum of Understanding on the purpose and conditions of our work together.

The group formed around the shared intention to grow together with other developmentally engaged coaches. I was aware, based on previous experiences with collaborative action inquiry, that the engagement on equal terms evoked by the very notion of participation could be difficult to achieve (Marshall, 2016). The fact I was going to work with coaches problematized this further, on one hand allowing me to hope for certain forms of engagement (e.g., in terms of quality of presence, self-inquiry, feedback, etc.) and on the other hand knowing that we would have to play with the complexity of multiple agendas and busy schedules. Soon, even before the COVID-19 
pandemic hit the world, the group helped me to realize that I would rather follow Heron's advice not to over-idealize participation and rather "seek to achieve an appropriate blending of authority, participation and autonomy" (Heron, 1999, as cited in Marshall, 2016, p. 9) in any given situation. It became important to clarify my intentions and account for my different choices in that perspective as the co-inquiry unfolded, which I did mostly through journaling and in conversation with my mentors.

\section{Co-inquirers' diversity.}

Table 4 illustrates the group's diversity in terms of gender, race, age, coaching experience, and developmental center of gravity (which was shared at the fifth meeting).

Table 4. Co-inquiry members diversity.

\begin{tabular}{|c|c|c|c|c|c|}
\hline Co-inquirer & Gender & Race & Age & $\begin{array}{c}\text { Experience } \\
\text { in coaching } \\
\text { (number of } \\
\text { years) }\end{array}$ & $\begin{array}{c}\text { Developmental center } \\
\text { of gravity as assessed } \\
\text { by the MAP }\end{array}$ \\
\hline Les & M & White & 67 & 15 & Self-determining \\
\hline Lisbeth & F & White & 54 & 25 & Late Self-questioning \\
\hline Ted & M & White & 37 & 2 & Self-determining \\
\hline Chase & M & Filipino & 31 & 2 & Self-determining \\
\hline Sam & F & Asian & 36 & 3 & Self-determining \\
\hline Logan & Fluid & White & 45 & 12 & Self-questioning \\
\hline Ilaria (me) & F & White & 41 & 13 & Early Construct-aware \\
\hline
\end{tabular}

${ }^{2}$ All the co-inquirers' names, except mine, have been changed to pseudonyms. 
Among the five White co-inquirers, three national cultures, from America, Africa and Europe, were represented. Majority-minority and privilege-underprivilege tensions were woven into our intersectionalities, and particularly among identity aspects such as race, gender, nationality and language. However, overall, we were a privileged group with high levels of education and a certain comfort and quality of life. Particularly when confronted with the impact of the COVID-19 pandemic and the movement for Black lives, our shared identities and privileges became more evident than our differences and intersectionalities.

I had hoped for a diverse group since the design of the study, valuing the potential of the encounter of different perspectives for mutual enrichment, confrontation and integration. I assumed that our shared coaching culture, in addition to the interest/passion for human development, would be a powerful bonding factor. Another aspect that emerged as important in our experience was the belonging, in different ways, to the community of the University of San Diego and particularly to its School of Leadership and Education Sciences (SOLES) where I was pursuing my doctoral degree. That impacted our work through the pre-existing relationships between some of the participants, and the sharing of a common leadership culture and discourse.

\section{My multiple and blurred roles.}

I was an equal partner and co-inquirer within the group. And, as the primary researcher of the co-inquiry, I was deeply invested in the project as a person and a coach engaged for/with development, a doctoral student completing her dissertation, the 
instigator, facilitator and quality insurer of our inquiry processes, a fellow traveler caring for her co-journeyers, a researcher honoring the science and the purpose of action inquiry. As I engaged in this journey, it was clear to me that I would need to be mindful of the inherent tension posed by my concurrent roles. I expected this and the other tensions that I would experience in the process, and my responses to them, to be important intelligence about my current developmental trajectory, my leadership, my capacity to hold a generative space for myself and others. As an action inquirer, I explored these blurred boundaries with the permissions and the protections offered by the practice of documenting the different reflections, emotions, sensations, choices, decisions, actions, and learnings they brought forth.

\section{Co-Inquiry Processes}

Figure 3 depicts the main features of the co-inquiry, namely a series of seven meetings of two hours each over six months, post-meeting questionnaires, and individual post-co-inquiry interviews.

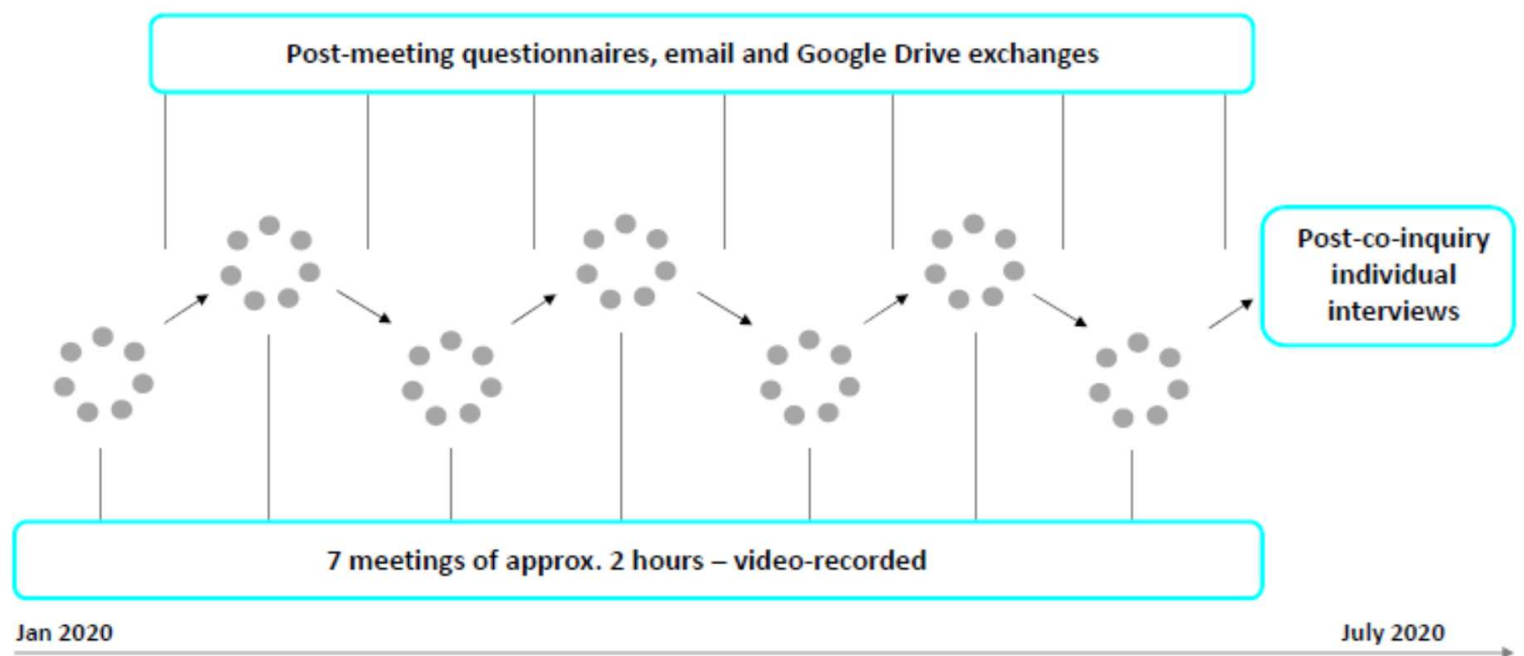

Figure 3. Co-inquiry process features. 
I had carefully designed the methodology of the co-inquiry knowing that the way it would come to life would ultimately emerge from the project itself. As in coaching, we co-inquirers worked together with the contents that were present to our awareness meeting after meeting. Also, the turbulence of our environment rocked our contents and processes alike. In fact, the living character of the co-inquiry and the multidimensional complexity of the different eco-systems involved informed every methodological step that I/we took. I believe that it was largely thanks to the initial intention I set for myself in terms of openness and curiosity to whatever would be co-created by the group that I found myself navigating the various departures from the original plan with relative ease, enjoying most of the unsettlement as part of the living process and as inspiring opportunities to steer the co-inquiry towards what seemed more fertile directions, one after the other. I will describe the methods we used starting from my initial intentions and reporting the shifts that $\mathrm{I} /$ we were led to imprint on the process to honor its emergent character.

\section{Co-inquiry meetings.}

The co-inquiry was structured in seven meetings of two hours each, between January and June 2020. Based on my and others' experiences, I thought that six months represented a sufficient lapse of time for a personal and collective trajectory to unfold, and seven meetings of two hours allowed for meaningful dynamics to develop within a group of six persons, who became seven when another coach expressed the desire to be part of the group. 
I had originally imagined a regular interval of about three weeks between each meeting, and at the same time I was aware the scheduling would be complicated with the group. I unilaterally set the date and time of our first meeting, where we agreed to use a Doodle to schedule all the following sessions. What emerged was the calendar illustrated in Table 5.

Table 5. Co-inquiry meetings initial calendar.

\begin{tabular}{|l|l|}
\hline Co-inquiry meetings dates & Time \\
\hline Monday Jan 13,2020 & $10 \mathrm{am}$ \\
Tuesday Feb 25, 2020 & $10 \mathrm{am}$ \\
Tuesday Mar 10,2020 & $12 \mathrm{pm}$ \\
Tuesday April 14, 2020 & $12 \mathrm{pm}$ \\
Tuesday May 12, 2020 & $10 \mathrm{am}$ \\
Monday June 8, 2020 & $12 \mathrm{pm}$ \\
Monday June 29, 2020 & $10 \mathrm{am}$ \\
\hline
\end{tabular}

My concern about the long intervals between the meetings possibly impacting the bonding within the group, which was later echoed by the questioning of another participant, increased my intentionality and strategies for connection and inclusion. Also, balancing my concern with curiosity were the shared commitment to growth expressed by the co-inquirers at our first group meeting, and my trust in the significance of our process' unfolding as an action researcher and co-creator of our experience. These became important standpoints that supported me throughout the unpredictable shifts we experienced in our process.

\section{Shifting from in-person to virtual meetings.}

My initial intention to hold in-person meetings was overturned by the global and local effects of the COVID-19 pandemic. The two first meetings were held in person, 
while we had to meet remotely, via Zoom, for the rest of the sessions. This was part of a general adjustment to working remotely that all of us co-inquirers had to realize through the shelter-in-place and social distancing ordered by the authorities in our part of the world. We were no longer physically together in the meetings, and only part of our body was visible. That would become an important aspect of the presence/absence and connection/disconnection dynamics that characterized the co-inquiry. Three co-inquirers explicitly referred to the virtual setting as "creating a barrier" to their own full engagement in the moment, and to the connection with others, even if for short periods of time, during the meetings. Experiences with wi-fi connection issues, with messages appearing on our screens, and with the living ecology of our physical locations, with their stimuli and events, became sources of disconnection for all of us. Also, eye-to-eye connection with one another appeared to me as a primary sign of sustained connection in our meetings in person, yet, through Zoom, it was not possible to directly meet the eye of the other. Even when deeply engaged in listening, what we could see, and connect with, were persons looking at their own cameras - offering the illusion they were looking at all the participants indistinctly — or at some particular areas of their screens, based on where the others were located in their gallery view. Moreover, when working remotely we more frequently tended to shift our gaze to other participants, ourselves through the screen, or our notes. And, when we were sharing slides, during our in-person meetings our eyes and our whole body were essentially focused on the presenter, and only quick glances were directed to the content shared through the video-projector. Via Zoom, our gaze tended to linger on the slides, which were taking the full screen and reducing the view of the presenters (and the other participants) to a smaller rectangle. 
The question of "how much space do I take in a virtual group?" also colored the experience of some of the participants who recognized that in an in-person setting they could more easily count on the felt-sensed intelligence of when to take and give the floor.

The comparison with the first two in-person meetings, where we were all (at least at the physical level) present to and met by one another, suggests that a different kind of connection (and co-creation) could have been generated within the group had we continued in person. Also, I observed that after our in-person meetings the group tended to take some time before disbanding, and most of us enjoyed a few more minutes of informal chat in the company of one another, while the separation was immediate and sharp as we clicked on the "Leave/End the meeting" button on our computers. I noted how I needed to take a few minutes to remain there, in front of my screen, and let the group, its energetic entity and our connection dissolve in my own consciousness, before engaging in other occupations.

Other observations about the shift to meeting remotely include the fact that the audio- and video-recording of the sessions was considerably easier, the Zoom platform offering an integrated recording system, and that we were all equalized in terms of occupied space on the screen, if it were not for the distance we kept between us and our screens, modifying how much of ourselves was visible. Also, the clothes and the colors we were wearing, as well as the specificities of our background were brought to the forefront in the two-dimensional view, and participated in the emanation of the vibrational signature of each participant, composing the collective field of each meeting. 


\section{Shifting configuration of the group.}

As it turned out, different group configurations were present at each meeting. This fluid aspect, which came with the uncertainty around who would be present each time, was another challenging experience for the participants and one that deeply impacted our work. Even if I had hoped for the highest possible degree of participation, I was aware that our commitment was in tension with the complexity of our lives, and in particular when we were flooded by the COVID-19 pandemic. I had to schedule our first meeting knowing that one participant would be absent because of a long trip abroad. At the second and third meeting, three out of seven coaches were absent, mostly because of unexpected last-minute changes in their schedule, which created the conditions for a different, more intimate kind of work, and the geometry of the group kept varying for the rest of the meetings. Also, we spontaneously organized an additional meeting after the fifth meeting, devoted to the debriefing of the MAP assessment, with Les and Lisbeth, the two coaches who were absent at that session. Chase met with Sam (whom he knew outside the group) and Ted (whom he did not know) only at the fourth meeting, and never met with Les. Les, who had been among the greatest supporters of our work and helped me prepare our second group meeting, only participated in the first and in the second Meeting \#5 session. His absences resulted in his stepping out of the group, motivated by his choice to prioritize his commitments in a period where he was feeling overwhelmed. Many of us spoke to the "fullness" of our lives, and to an imbalanced being-doing tension (largely in favor of doing) even before the disruption of the pandemic. With the exception of Logan, who wrote to the whole group when she could not participate in the last two meetings, the other participants communicated about their absences exclusively to me, mostly with 
short notice. This contributed to uncertainty surrounding what group one would meet at each session. Table 6 represents the group configuration at the different meetings.

Table 6. Group membership at each meeting.

\begin{tabular}{|l|l|l|}
\hline Meeting \# and date & Total participants & Participants \\
\hline Meeting 1 - Jan 13, 2020 & 6 & Les, Lisbeth, Ted, Sam, Logan, Ilaria \\
Meeting 2 - Feb 25, 2020 & 4 & Lisbeth, Chase, Logan, Ilaria \\
Meeting 3 - Mar 10, 2020 & 4 & Lisbeth, Chase, Logan, Ilaria \\
Meeting 4 - April 14, 2020 & 5 & Lisbeth, Chase, Ted, Sam, Ilaria \\
Meeting 5 - May 12, 2020 & 5 & Chase, Ted, Sam, Logan, Ilaria \\
Meeting 5 bis - May 27, 2020 & 3 & Les, Lisbeth, Ilaria \\
Meeting 6 - June 8, 2020 & 5 & Lisbeth, Chase, Ted, Sam, Ilaria \\
Meeting 7 - June 29, 2020 & $3+2$ for a limited time & Lisbeth, Chase, Ilaria + Sam and Ted \\
& & present to part of the meeting \\
\hline
\end{tabular}

I trusted the wisdom in the emergence of our co-creation throughout the process. When fleeting currents of concern for the group's engagement visited me during the first months, my curiosity for whatever would emerge as worthy of living and inquiring as a human and developmental experience allowed me to reconnect with the fluidity and the aliveness of the process. However, I came to be somewhat concerned for the sense of psychological safety experienced in the group, especially when our general safety was also threatened by the spreading of the COVID-19 virus, and found myself particularly tending to that. The uncertainty and the challenges experienced in the months between our meetings, and the unknown about the group membership, made it necessary "to reconnect all over again," to use Lisbeth's words, every time we met. The intention of nurturing connection and re-connection with(in) the shifting group impacted much of my facilitation choices, especially mid-way through the process, when a larger group 
reconvened after two more intimate session. The theme of presence and connection to oneself and others revealed itself as crucial in the unfolding of our work together.

\section{Meetings'activities.}

The flow and the methods employed in each meeting were diverse. Except for the first meeting, which I organized and facilitated for the group with the intention of getting to know each other and laying the theoretical and methodological foundations of the coinquiry, our following sessions' process and content emerged from the experiences and the intentions shared at each meeting, and from my exchanges with my mentors and with the Field. I was in charge of the facilitation of the whole series of meeting, and Les and Logan helped me to prepare the second and the fifth meeting respectively. I was consistent in inviting the co-inquirers to participate in the strategizing around and organization of the meetings throughout the co-inquiry. Lisbeth noticed "that was very tantalizing, like, oh, yes! And then finding before I knew it, that we were meeting the next day." I indeed ended up defining the trajectory of the co-inquiry content-wise, identifying the topics and questions to be addressed at the different meetings. They are illustrated in Figure 4. Each of them was intended to contribute to the exploration of the guiding questions of the co-inquiry and to respond to the calls of the disruptions in our environment. 


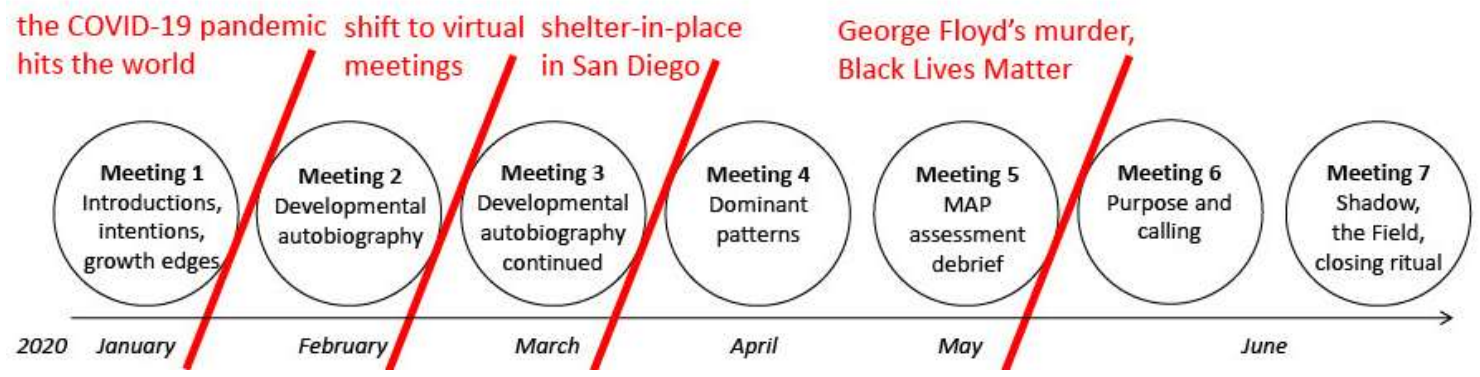

Figure 4. Meetings' topics against the disruptive space/time of the co-inquiry.

Starting from the fourth meeting, I was especially inspired by the confluence of inner, mutual, collective, and systemic experiences that I/we as a society were living, particularly in our part of the United States, in our context. For example, the exploration of our dominant patterns in our fourth meeting served the processing of our challenges and fallback in the chaos of the pandemic. Focusing on our personal purpose and calling at our sixth meeting was a way to inspire and call us to action in response to the unbearable evidence of systemic racism in our society. Exploring our collective and individual shadows (intended in Jungian terms as the aspects hidden to/rejected from our consciousness) seemed necessary, at the following and last meeting, to be able to hold and engage with the shadows of discrimination, exclusion, violence and fear exposed in our systems. Also, in the final meeting, I thought that engaging with Source in creative ways would offer us a generative perspective to identify the path towards our future growth pointed to by our shadows.

During each meeting, we co-inquirers shared, reflected, coached each other and exchanged feedback around our selected topics. We alternated individual reflections, 
presentations, work in dyads or triads and in group, striving to attend to the first, second, and third person perspective of our inquiry.

Plural ways of knowing were leveraged, with a particular attention to symbolic, creative representations of our experiences in addition to narrated, language-based ones. One of my ever-present intentions was to invite knowing from the Field to inform our conscious processes and our embodied action. We attended to the combination of plural ways of knowing by devoting time for meditation and other contemplative practices, and by including the exploration of our emotions, felt senses, and sensations, (Coughlin, 2015; Hayashi, 2018; Palmer, 2008; Silsbee, 2008, 2018; Strozzi-Heckler, 2007), of our dreams (Balogh \& Getz, 2019), shadows, projections and other inter-subjective dynamics, serendipities and synchronicities that we experienced, and archetypes that we enacted (Boyd, 1991; Jung, 1976; Molenkamp, 2012; Smith, 2016).

At the beginning of each meeting, after naming the purpose and specific topic of the gathering, we took two minutes to connect silently with oneself and one another, which became our ritual marking the opening of our inquiry space. After that practice, we took abundant time to check in, to become present to what was going on inside and outside of us, in others and in the group as a whole (there was typically "a lot" to process, especially in the pandemic chaos). That was also a way to reconnect after the interval, resonate with each other's sharing, and find the tone and the depth to flow into the rest of the session.

At the end of our meetings, we debriefed about our individual, mutual, and group experience, and concluded with a checking-out sharing about our respective state of being and/or an intention to contemplate or act upon in the weeks to come. 


\section{Activities supporting our work.}

Complementary and supportive of the active phase of our co-inquiry were the following activities and processes:

- Personal inquiry work. Embracing the recursive nature of co-operative inquiry, based on subsequent cycles of reflection and action, I encouraged the ongoing and in-depth exploration within ourselves in the interval between the group meeting. The final intentions/commitments shared in the meetings were meant to build a bridge of reflections, practices, and inquiry towards the following meetings.

- Email and Google Drive. I sent the group a follow up email after each meeting, recording the essence of our work together and indicating the next steps we agreed upon. A few days before each meeting I sent another email confirming the intention for the session and inviting everyone to prepare for our work. Also, email exchanges among the co-inquirers and a shared Google Drive supported our work's unfolding session after session, and my sharing of resources with the group. Finally, through my emails to the group I shared the gist of my reflections and the gifts from our experience that I believed contributed to hold the space for the group and the quality of our work, inviting personal and mutual continuous inquiry. I was committed to be real and vulnerable in my sharing, as a way to nurture a sense of safety and trust, and to honor the relational nature and the transformative potential of our work.

- Post-meeting Questionnaire (see Appendix B). With the post-meeting questionnaires, I intended to gather the participants' thoughts and insights shortly after our experience together. Also, as I shared with the group, I hoped it could 
become a helpful practice in support of our personal and collective ongoing inquiry. At the first meeting, the group agreed to share the responses to the postmeeting questions through a document on the Google Drive. Yet, in spite of my reminders via email and during the following meetings, only Lisbeth consistently shared her responses on the Drive; Chase used the Drive once and on another occasion shared with me a page from his journal via email; and Ted shared with me his responses only once via email. Les, Sam, and Logan never shared their written reflections with me or the group. When I re-opened the discussion about this at the third meeting, to check if there were any resistances or avoidances related to the single co-inquirers or, perhaps, to the group's developmental trajectory, no challenges emerged other than delays due to busyness and misunderstandings regarding the expectations around the questionnaires. The response rate did not increase after that exchange, which brought me to take time for a verbal sharing at the end of the following meetings, as a way to honor both the agenda of the participants and the importance of the questionnaires to keep track of the individual and collective evolution of our work. On the two occasions when I was not able to open a time for debriefing around the questions during the meeting, I asked for written responses via email or Google Drive, but the response rate remained unchanged. I was aware of the difficulty that writing, and particularly sharing our writing, represents in many projects, yet I was puzzled by the evident inconsistency between the discourse of the co-inquirers and their actual behavior. Despite my explicit asking about that on many occasions, only Ted voiced his experience, privately, after the completion of the co-inquiry: 
I think what threw me off (...) I went in there probably four or five, six times to see if anybody else had posted. There was a part of me that was like, oh, nobody else is putting their thoughts here. So, you know, like there was a little bit of, I feel like we, we have the... the espoused value actually was not happening. [...] And I, there's a couple points where I even started to type in there and I just, I had this like check back and forth. [...] But there's a part of me that was, yeah, that was part of me that just felt super uncomfortable.

The varied engagement of the co-inquirers with the post-meeting reflections, and our inability to overtly discuss about that in the group, were symptoms of deeper dynamics (described in the next chapter) related to safety and connection within the group, self-confidence and vulnerability, co-leadership and co-creation, which were function of our own development and of the environmental instability alike.

- Journaling. The practice of journaling was encouraged during the study as a way to capture and explore what emerged concurrently to our experiences together in terms of reflections, experiences, learnings, intuitions, dreams, etc. At times, we shared from our journals in our meetings to continue and enrich our work on our selected topics and our approach to our respective growth edges, as well as the inquiry into our experience as a group.

- MAP assessment. The purpose for using the MAP assessment in the co-inquiry was to include an objective, validated, external measure of our development in the repertoire of practices, tools and data we engaged with-in our developmental endeavor. Complementary to our subjective self-assessment and self-reflection, 
this objective assessment shed additional light on our respective growth edges, and presented us with some options for development. Offering the assessment to each participant was also a way for me to reciprocate their investment in the coinquiry.

Since the beginning of the project, I had been in contact with Dr. Cook-Greuter, who kindly offered to assess our MAPs herself. Sometime after the first coinquiry meeting, Dr. Cook-Greuter sent me a Word form with 36 sentence stems to be completed. I sent it to each participant asking them, as per her instructions, to complete it and submit it via email to her directly. Our initial plan was to complete the process in one month, but only two of the co-inquires, (interestingly, the same who engaged more assiduously in sharing their post-meeting reflections) submitted their assessment to Dr. Cook-Greuter by the due date she had set. I had reminded the group to submit the assessment multiple times, and it was only when I sent a personal email to the co-inquirers who had not submitted theirs by the due date, that Dr. Cook-Greuter started to receive the rest of the MAPs. A few weeks later, she sent the scores with her commentary back to each co-inquirer. We all received our scores only after our fourth meeting. In the meantime, I had the opportunity to debrief my own MAP, which I completed online, with Dr. CookGreuter. Based on that experience, and on my almost concurrent experience with Torbert's GLP assessment that a friend invited me to take, I organized a collective debriefing with the whole co-inquiry group during our fifth meeting. The reason why I was the only one to benefit from a personalized debrief with Dr. Cook- 
Greuter is the cost of the assessment with debrief, that I could not afford for my six co-inquirers in addition to myself.

The MAP brought us to the heart of constructive-developmental theory and in particular of Cook-Greuter and Torbert's frameworks, enriching our views on our developmental trajectories. Holding the theory lightly, we incorporated the possibilities for development offered by the framework focusing on the directions that seemed important for us in that phase of our life. The experience with the MAP was different for each of us co-inquirers and appeared to be more illuminating for those of us who engaged in further self-study and reflection around our assessments beyond the work within the group.

\section{Post-co-inquiry interview.}

At the end of the eight meetings, I conducted an individual post-inquiry interview (see Appendix C) with each of the co-inquirers to gather their concluding and emerging thoughts at the completion of our journey together. We met for about one hour via Zoom. Four interviews were realized the week following the last group meeting, and two were conducted two and three weeks later respectively. These were for me important times to exchange with more intimacy around the developmental reflexivity of each co-inquirer and receive more direct feedback about their experience of the co-inquiry. The interviews also helped some of the co-inquirers to form or consolidate new awareness that emerged for them through the co-inquiry. Finally, during the interviews I was able to assess a few of my interpretations of our shared experience, which prepared me for the work of analysis and writing that awaited me at the end of the participatory phase of the coinquiry. I now turn to describe how I conducted the analysis of our data. 


\section{Data Analysis}

Throughout the study, we co-inquirers generated different kinds of data including text, audio and video. I audio- and video-recorded all the co-inquiry meetings and the post-co-inquiry interviews, and had them transcribed automatically by Rev.com, an online transcription service provider. In addition to the data from the meetings, I collected all the email and Google Drive exchanges. My lived experience with the group and my personal inquiry continuing in the intervals between the meetings, in dialogue with my mentors and with the literature, were the source of an abundant flow of journaling and analytical memos. I had committed to making use of those during the co-inquiry, and I ended up in what seemed at times like a stream of reflection, analysis, revisiting, reading, and writing constantly evolving in my consciousness, even when I was living parts of my life other than the research. I was amazed by the flow of information —of different natures - that started to come to me in association with the co-inquiry. And by the rapidity with which learnings and shifts in awareness started to happen. I did not want to lose any of their freshness and timeliness in my/our developmental journey. So, I wrote, everything that came up for me that seemed to matter, following those leads inside myself, searching for the roots of the resonance of every specific intelligence, and searching for the accurate words to speak to that experience. I could count on my mentors' sounding board throughout the project, which helped me to get truly intimate with my observations and my responses, to receive resonance, and to test possible future steps. My meetings with my mentors were actually integral part of my inquiry, generating further layers of insight and integration—-further precious data. 
This multidimensional work led to an important accumulation of data, which I initially tackled with a systematic coding approach. I coded all the data relative to each meeting two to five days later, to take advantage of the freshness of my cognitive, emotional and somatic experiences with the group. Because I used an automatic transcription service, I had to consistently review and interpret every transcript for accuracy. That was how my analysis began, as I immersed myself in the data, supported by the audio-recording. Observations, analytical considerations and insights emerged from the examination of the black and white written transcripts against the audiorecording, which revealed the musicality of our expressions and their emotional tones. My analysis was further enriched when the written and audio-data came to life anew, as I watched the corresponding videos to complete my work on each transcript. I must say I experienced a distance between the experience of working with text and audio and working with the videos similar to that evoked by Warr between studying on a map and being in the field (Warr, 2004, as cited in Ellingson, 2017, p.137). The lived, embodied and enacted experience of the meeting I shared with the co-inquirers returned more fully to life in my consciousness as I watched the videos, at times dissolving thoughts that had formed in my mind, at other times confirming my forming analysis.

I adopted the following five-step method, for the coding of the data from the meetings and the individual, post-co-inquiry interviews (systematically after each meeting and each interview):

1. review of the automatic transcription supported by audio- and videorecording,

2. review and integration of my analytical memos from the meetings/interviews, 
3. re-visioning of the video-recording,

4. coding,

5. review of the initial coding based on subsequent exchanges (oral, via email/Google Drive), personal inquiry, and further analytical memos.

I used the qualitative data software MAXQDA, which helped me to code and test multiple coding logics according to the themes that emerged through time. Initially, my coding was based on the factors of the co-inquiry map (Appendix A), which I progressively integrated with other codes that emerged from our interactions. I practiced what Saldaña (2016) would define "concept coding" (Saldaña, 2016, p. 119) to capture the broader ideas and processes emerging from the data. In labeling the concepts, I tried as much as possible to use "the actual language" (Saldaña, 2016, p. 105) used by the coinquirers as a way to preserve and honor their meaning-making.

At the completion of the series of meetings, based on the final codes listing and the segments illustrating them, as well as on the co-inquiry's guiding questions, I started mapping themes and categories, which also allowed me to refine my coding. Testing and organizing my data against the co-inquiry's guiding questions helped me to start delineating findings. The metaphor of a tree emerged in a session with one of my mentors, representing the trunk of my intentions with the co-inquiry—expressed in the guiding questions - and the branches and leaves growing from them in the lived experience of the group with-in its ecologies. The metaphor of the tree became extremely helpful for me to conceptualize, organize and represent what emerged as the findings of the study. I played with different trees (see Appendix D) to articulate the experience of 
the group and my own. Those images served as organic, living structures to evolve and organize my analysis.

This creative process was enriched by further reviewing of the meetings' videos. That allowed me to confirm my analyses and, observing a succession of representations frozen at particular times, to deepen my awareness of the unfolding of our individual and collective evolution through our work. My conclusions are the fruit of the process I illustrated in this section, that I enacted in constant dialogue with the literature. Developmental literature particularly helped me to find and refine the meaning of what my data was telling me about our expansion of consciousness in the larger environment we were evolving with.

\section{Trustworthiness}

The trustworthiness of the co-inquiry was primarily based on the self-aware, “critical subjectivity" (Reason \& Rowan, 1981) practiced by the co-inquirers, in the awareness that knowing came from our particular perspectives, and that implied bias. We engaged in consciously identifying our stances and assumptions, noticing and naming them as they manifested themselves in our work. For me, it was part of a constant inquiry throughout the different research phases, of my embracing the inspiration of "living life as inquiry" (Marshall, 1999, p. 155) and connecting with whatever was being activated and needed expressing, even if at the edge of acceptability (Marshall, 2016), to serve my personal and our mutual and collective development.

Critical subjectivity could be threatened by the unconscious processes through which we could project our anxieties and shadows outside ourselves and onto other elements of the study. I experienced that potential risk when confronted with frustration 
and grief halfway through the process, a few months into the limiting, challenging context of the pandemic. It took all my self-awareness, and the caring help of my mentors, to avoid projection onto the group and rather make it a generative opportunity for development and integration for me and for the group, (described in the following chapter). Throughout the co-inquiry, I was deeply supported by my mentors in my critical subjectivity. My personal clearing brush and shining lights on my experience was an embodied practice in which I engaged not only cognitively but also with my heart and gut, and I often found myself "in over my head," sensing that I was grasping only part of the complexity of my/our experience, and "in over my heart," entangled in my own processes that emerged as a result of the experience with the group. Making space for those experiences in my consciousness, contemplating and processing them in meditation and in dialogue with my mentors were key processes to receiving the gifts they were carrying — for me and for the co-inquiry group alike. Processing my experience with my mentors also helped me track my own trajectory within the group, supporting my personal growth and understanding, and documenting it as a distinct process interwoven with the unfolding of the co-inquiry.

"Consensus collusion" (Reason, 1994) among co-inquirers, to protect oneself and/or the group from challenges to one's/the group's worldview was another potential threat, especially in the fragilizing times we were living. We were open to the exploration of our challenges, dominant patterns and vulnerabilities, and at the same time one of the group's purposes became to offer each of us a sense of relief from the turbulence and uncertainty we were experiencing in the pandemic. That translated into a form of protection from internal challenges that I describe in the following chapter. Mindful of 
the numbing threat of consensus collusion, I intentionally opened the conversation around subjects that seemed relevant and potentially controversial, such as the individual contribution to the co-inquiry through the sharing of one's reflections after the meetings, or our shadow sides emerging through the process. Despite this, I sensed that layers of our experience remained uncharted. In some cases, the individual post-co-inquiry interviews offered the intimacy for some co-inquirers to go deeper in the exploration of more or less conscious dynamics such as avoidance or projections.

Within the limits posed by our individual and collective developmental trajectory, we navigated our critical (inter)subjectivity with the intent of growing through it. At the first meeting, I invited us to be mindful of the ways unconscious processes could impact our lived experience. As an example, and as a request for help with that, I mentioned my general propensity to satisfy others' needs at the cost of forgetting about my own needs. I was also particularly alert to my potential tendency to feel responsible for the group, and to take care of each and all of the co-inquirers by avoiding the emergence of negative emotions or disruption in the group. Aware that these could be critical and fertile moments of learning for both the individuals involved and the group, to be honored as part of the co-created unfolding of our experience, I monitored my responses to their emergence carefully. I believe that my genuine openness to whatever would emerge in the co-inquiry as part of our developmental unfolding helped me to safeguard, as much as possible, any experience as it was and as it evolved throughout the process.

As I operated to preserve the validity and the quality of my research throughout the series of meetings as well as in the analytical and writing phase, I was inspired by Reason and Bradbury's (as cited in Herr \& Anderson, 2014, p. 57) criteria for validity, 
i.e., participatory, emergent, enduring, and significant ${ }^{3}$ development, including the concern for practical outcomes, and the exploration of different forms and ways of knowing. In the spirit of CDAI, I worked with cues from multiple channels - mind, heart, body, soul-attempting to leverage them in the timeliest way possible, noticing and sharing them, and experimenting with adjustments and new explorations based on that intelligence. It was also my intention to keep the inquiry alive with-in the group by pointing to what was particularly vibrant in every here-and-now. In this work of amplification and deepening I was particularly helped by Lisbeth, who could (with natural mastery) leverage her redefining capacities on behalf of herself and the group. In the analytical process, I triangulated my data for "process validity" (Herr \& Anderson, 2014, p. 55), by sharing my interpretations of the themes emerging from the data with my mentors, and most of all, with the members of the group. In fact, the emerging, cyclical, reflexive nature of our work, in addition to features such as the postmeeting questionnaires or the post-co-inquiry interviews, allowed me to test my perceptions and interpretations and gather the co-inquirers' evolving views on what was happening within them and the group. Once a congruent draft of my findings became available, I shared it with the group members asking for their feedback (member

${ }^{3}$ The development generated in the co-inquiry is not significant in terms of developmental distances (stages) travelled by the co-inquirers, but rather in terms of new awareness, breakthroughs along the way, that could potentially translate in further individual, mutual, and systemic development. 
checking), which I included in the final rendition of my reporting. I also attended to the triangulation among data from the first, second, and third person perspectives (Torbert, 2013) as much as possible, for example observing ways of being in relation with others against shared personal reflections and the results from the MAP assessment. In these ways, my analysis was at least partially co-created and validated with the group.

During the whole process, and especially in the writing phase, I was guided by Bradbury et al.'s (2019) quality choice points for action research in the intent to clearly convey our commitment, our efforts, our "falling short" (p. 16), and our impact with the co-inquiry. The authors' (Bradbury et al., 2019) recommendations supported my choices in terms of

- the explication of how the knowledge creation of the co-inquiry could support "collective thriving" (p. 16) in the world, e.g. linking the expansion of consciousness to other- and world-centered psychological motivations;

- my documentation of the choices I made in support of development for the coinquiry group;

- showing how "partnership and participation" (p. 16) were essential values of the co-inquiry and the ways I enacted them with the other co-inquirers throughout the process;

- clarifying how the knowledge creation through the co-inquiry inscribed itself in and contributed to the wider body of knowledge of action research, particularly dialoguing with the literature around its developmental aspects; 
- "show[ing] and not just tell[ing]" (p. 17) the processes and methods of the coinquiry through the voices of all the co-inquirers who created them with me, as whole persons in relation with one another and the group in our specific context;

- illustrating the "actionability" (p. 17) of the co-inquiry beyond its perimeter, i.e., how our experience could serve further actions and action research for leadership and coaching development;

- articulating my "self-location" (p. 17) in the co-inquiry, taking a reflective and critical stance on my roles, choices and trajectories in the co-inquiry, within the ecology where it unfolded, and on my own positionality and reasons for engaging in the research;

- showing how personal, mutual and impersonal knowledge were integrated in the co-inquiry for individual and collective development;

- aiming for significant content and process throughout the co-inquiry, presenting our knowledge creation in its relevance beyond the ecology of the co-inquiry, and showing how the co-inquiry methods helped us co-inquirers "develop a strong and authentic sense of development and evolution in [our] practices, [our] understandings of [our] practices, and the transformation of the situations in which [we] practice[d]" (p. 17).

\section{(De)limitations.}

This study was limited to the exploration and experience of our specific groupseven participants coming together to investigate and possibly instigate development in a particular conceptual, relational, experiential, cultural, societal and temporal context. The knowledge generated with this study depends on its precise, emergent qualities and is 
certainly not generalizable. Also, the duration of the co-inquiry (six months) was limited, especially if we consider that the longevity of this kind of groups is usually part of their developmental “"power' and effectiveness” (Smith, 2016, p. 101).

The essential limitations of this research are related to my skills and experience as an (action) researcher, which led me to the specific methodological choices I described in this chapter, and to my capacity to sustain and infuse rigorous and vulnerable inquiry. Woven with my personal and developmental limits, as well as with those of each other co-inquirer, those limitations informed the emergence, the messiness and the uniqueness of the co-inquiry process and the development it generated.

In the next chapter, I illustrate how the process and content of the co-inquiry came to life. I describe the group's trajectory and our individual movements through the coinquiry's unfolding in its disrupted ecology. 


\section{CHAPTER FOUR}

\section{UNFOLDING}

This chapter shows some of the meaningful passages of the co-inquiry's unfolding. With the intention of honoring what we co-inquirers accomplished together, I draw pictures that I would invite you, the reader, to immerse in, and make sense of for yourself. Nora Bateson (2016) points to the warm aspect of data, their relational nature as co-created by people in relationship and by evolving, interrelated events and circumstances. This chapter is an invitation to understand, be part of, and co-create the meaning of our experience. It is structured in two main parts:

- $\quad$ first, I illustrate the key passages of our journey together through a series of dynamic segments, arcs of broader developmental trajectories, in which you will hear the different voices of the co-inquirers with our inflections, hesitations, and interjections - you will listen to us making meaning in our evolving, disrupted ecologies;

- second, I sketch the trajectories that became apparent, at the completion of our journey together, in our development as a group and as individuals. 


\section{Arcs of Broader Trajectories ${ }^{4}$}

The following sections are an invitation to experience specific, meaningful moments of the co-inquiry through my rendition of the many contributions that brought them to life.

I attempt to honor simultaneously, and as relevant and appropriate, the first, second and third person perspectives of our work, i.e., to offer views of what we coinquirers experienced personally, what we co-created mutually, and how we related to the larger environment. Also, it is my intention to show how the experiences of these arcs are distinct and sequential in timing, and at the same time how they make sense conjunctly in the broader perspective of our individual and collective evolution through the co-inquiry.

My narration follows the chronological order to convey, through the sequence of the different arcs, the broader thread of our trajectory, and to honor its being intimately tied to the evolving time and space of our context. However, what follows is not a stepby-step account of the group's journey. Rather, it is a constellation of passages and themes through which we grew together.

\section{Igniting Intentionality, Glimpsing Growth Edges}

It was our first meeting, January 13, 2020, and the sacredness of that beginning was with me as I prepared and decorated the classroom which was about to host us.

${ }^{4}$ Nora Bateson's (2016) book Small Arcs of Larger Circles inspired the title of this section. 
Certainly it was an important beginning for me as a doctoral student inviting a group of colleagues/coaches in a work of co-inquiry that would inform my dissertation, and on that day I was filled with an immense gratitude for all that had led me to that point, and for all that was opening up from there.

Everything seemed meaningful to me in that beginning: our coming together as an in-the-flesh group, disclosing pieces of our identities, laying the epistemological, methodological, participatory grounds of the co-inquiry, and naming our intentions and glimpses of our growth edges.

As participants arrived, I sensed my trepidation and others' curiosity, colored by what I perceived as a natural, first-day uneasiness. In her post-meeting reflections, Lisbeth wrote:

I noticed a generalised level of hesitation and treading carefully in a new space. I was not surprised by this as it is normal in groups. Interesting that it happened with coaches who are used to entering vulnerable spaces with clients or students. My fellow co-inquirers, accomplished and respected professionals, were then human beings entering an unusual context, meeting new people, colleagues with different backgrounds and experiences, and in a special situation where they were not in charge of leading the work. This compassionate realization was the first sign that even seasoned leadership developers/developmental coaches experience the complexity of enacting leadership, co-leadership, and developmental work.

The sketch of seven chairs in a circle remained in my notebook, and in my mind, as the symbol of the group coming to life after a few weeks of conception and gestation in conversations. As we introduced ourselves, I could sense the uniqueness of each of the 
six of us present imprinting on the fabric of our collective, in a symphony of low and high pitched, calm and energetical tones. Among my post-meeting reflections, I noticed that each member brought a specific quality of energy, ranging from enthusiasm to pensiveness, converging at times towards thoughtfulness and, at the completion of the session, gratefulness.

I had the sense that it was a highly privileged group of educated people with a certain level of comfort and quality of life. I thought that Chase's absence was amplifying that awareness, and I missed his usual bringing of other, critical and peripheral voices with him.

I also noted how our introductions were marked by the personal side of our identities, and by the significant experiences that were happening in our personal/family lives. Three coaches started by introducing aspects of their professional lives (interestingly, three of the participants who were later assessed at the Achiever/Selfdetermining developmental center of gravity, focused on results and effectiveness), and yet, as it turned out, their life was particularly colored by personal events such as Sam's imminent marriage, and Ted's preparing to become a father. Our personal/family dynamics were at the center of our developmental readiness, and at the confluence of our shared intentions for growth (as persons and as coaches) and for participating in the coinquiry.

The intentions grounding our individual commitment to our collective endeavor were shared in the following terms by each co-inquirer:

- Lisbeth evoked the need for self-understanding and self-compassion in the world: I do believe that it's essential that we all continue to grow and develop through 
life. And [...] globally, there's a deep need for, for people to connect with themselves and to understand who they are, for individual self-compassion, so that there's no more projection outwards where the other becomes the enemy. [...] I do think that when we do this work, we're doing more than just working on ourselves.

- Ted shared about his intention to grow personally and professionally: ...learning to be a coach... I feel like my journey there is, is a young one [...] and I mentioned that because I think connected to my intention here is to learn how this format, what I could glean from this format professionally for the work that I'm doing [...] in addition to the wanting to learn and grow myself personally. I'm interested in how that connects to my learning journey in a way that ... you know, that inquiry has not really been a part of my mind before.

- Logan expressed her desire to keep growing with people committed to deep introspection:

... me feeling a little bit isolated from what my people, [...] the way that we work, [...] when I see situations like this, I think, oh, these people are going to dig deep. In the way that we love to dig deep, I want to be a part of that because I miss that experience. [...] And so thinking how do I continue to grow? What's my next route? For me personally, I've been kind of growing others in a space of growing my professional career. But now thinking from a deeper level, what does that look like and how do I make sure I'm continuing to push my edge?

- Sam shared the intention to cultivate presence to one-another: My intention really is to do continuous searching for myself and for this group. 
How do we know more of who we are by just being present with each other? [...] In my current work I do, do, do, and action is paramount. And so, I hope that in this space I can be able to be just present and enjoy doing that with you all.

- Les pointed to the desire to understand "more" about himself and the work of developmental coaching:

I just feel like there's more, there's just something more to help somebody with, and not just help them with, but help them with a bit more of an accelerated fashion. Um, I don't believe in the miracle of, you know, three, four months of coaching, you're a new person! I just don't, I just haven't seen that happen, but I also feel like there's more to understand about myself and more to understand about this work.

- And I reiterated my intention to support development as a way to shift, individually and as a society, towards more others- and world-centered motivations:

Engaging in and for adult development as a social change work starting from within, supporting the development of meaningful and fulfilling lives, and the expansion of our psychological motivations from ego-centered towards more others- and world-centered logics.

These more or less self- and others-centered intentions for learning, digging deeper, and expand our consciousness sealed our mutual commitment at that time. From these emerged the growth edges we specifically wanted to explore with the co-inquiry, or what we could glimpse of them in that initial phase. Being used to working with developmental theories and practices, and to supporting our coachees through their own 
growth edges did not make it easier for us to identify our own. What we shared at that

point was more of an emerging sense, idea, feeling, or image of an evolution awaiting us.

Figure 5 gathers the seven glimpses of growth edges as they emerged from our first

conversations.

just getting out of my head, sort of trusting my heart [...] it also brought up a lot of fear, you know, the fear of loss that if I listen to my heart, it's going to change things. Things are going to change. And I know it's something around that

Les

this idea that my growth edge is that: my growth edge. You know, this idea of the difference between the naming, what are the elements that I need to grow into [...] versus what does the growth edge experience look like and is. [...] It's very complex, but the self in the "self in the self" image

Logan

living more from my heart and, and from my body. I have this sense of [...] I'm almost in search of a different way of being in the world. [...] Today I really feel that I'm finding this connection with my heart and through my heart with Source, I find myself sometimes living in such a fluidity...it's amazing, and it's much more joyous, and at other times I am caught in my mind and I can't find clarity and it's a struggle passion and purpose [...]

I wonder if finding my passion/

growth edge will help me overcome

the negative self-talk and gain a

better sense of self-confidence

Chase

a tree that was initially firmly planted and the roots really are deep down into the earth and soaking up this nourishment [...] Rain, water and fertilizer and like stuff in the soil and then it being shaken a little bit and so it's not as firmly planted as it once was. I just have a feeling of that. There's a lot of complexity [around being present]

Sam

integration, and specifically with regards to spirituality and coaching, it's a personal growth edge, but it's also connected to a very political issue... political spaces. And what implications or what fears that brings up within me as I try to do the work of integration with coaching. Whether it's naming or applying meaning or whatever, whatever that looks like

Ted

Ilaria

stepping fully into my leadership role and not feeling like I need to do it alone

Lisbeth

Figure 5. Emerging elements of the co-inquirers' growth edges. 
Our meaning-making of our growth edges evolved with time, and we were able to put more and more words and experiences around them. However, our developmental edges maintained their essential, ineffable character throughout the co-inquiry.

\section{Connecting With Different Aspects of Ourselves, Bonding With Others}

The co-inquiry's second and third meeting, February 25 and March 10, 2020, both saw the same four co-inquirers present (and the same three absent). This unexpected synchronicity allowed for an intimate experience that unfolded around the sharing of our developmental autobiographies. Les and I had designed the flow of the meetings around the storytelling of our evolving relationship to responsibility. This led us to revisit the most important passages of our life, and our understanding of those as associated with our development. As attested by the following excerpts from the two post-meeting reflections that were posted on the Google Drive after the second meeting, our work was significant in terms of creation of new awareness and integration.

Lisbeth shared her important learning around the participatory nature of leadership with these words:

What I learned regarding my growth edge is that my relationship to responsibility can inform my path of growth. It was an exciting "aha” moment for me. My growth edge has to do with stepping more fully into my power as a leader. Up until this session, my reflection has been around what I need to do internally to achieve my desired outcome. In linking my relationship to responsibility to my growth edge, I've realized that an opening for me into stepping into my power is to accept that I do not have to do it alone. Just like my current relationship to responsibility which ripples out in ever increasing circles of connectedness, I see 
my leadership role more as connection to others and calling on their strengths rather than only relying on myself and my strengths. I have a narrative around needing to do things myself (not trusting others to be there for me) and I see now that this is a barrier to fully inhabiting my power as a leader.

In my own post-meeting reflections, I shared about my renewed awareness of the ever-present nature of the different parts of ourselves that become manifest through time, and of the possibility to work with them intentionally and creatively. Also, I contemplated our willful search for our next developmental step, and how that could be balanced with what I defined "purposeful allowing," i.e., openness to the developmental invitations of life based on the fundamental intention to expand one's consciousness, capacities and skills.

Reflecting on my relationship to responsibility and sharing our stories in the group stirred a lot of learning, new/renewed awareness and questions for me. I am with the inner knowing that every aspect of our journey is still within us, and we can take a more or less conscious, intentional, and generative look at those parts of us, and build on them, in any moment. I am also aware that it is an ongoing journey, and am particularly present to the question of the next [developmental] level evoked by Logan--what is alive and wanting to emerge? As I ask the question, the tension between focus and openness dissolves, and they are harmonized in a sort of purposeful allowing.

Beyond these individual arcs, the two meetings were especially meaningful in terms of heartfelt connection, particularly around grief, injustice, and the other big or small life experiences which emerged as turning points in our developmental trajectories. 
This was an important bonding experience for the group and one in which we encountered the essence of the most important aspects of the participants' identities and personality. This experience was missed by the other participants who re-joined the group only after the two sessions. At our fifth meeting, when we were brainstorming around valuable ingredients for our work together moving forward, Ted expressed "a lack of knowing each other" that might have been lessened if he had joined the group in that experience.

Leaving our second meeting, I was filled with gratitude and with the warmth of deep human connection. Lisbeth shared the words from a "lost" poem with the image and the gesture of "loving with an open hand" to express her "real, sincere gratitude" for what she described in her post-meeting reflections as a "safe space that was co-created through presence and deep, non-judgmental listening."

At the end of the meeting, Logan commented:

I think there's a way that the people that can hold this type of space and work, and conversation, and reflection, you know, they don't exist all over the world. Right? It's sometimes hard to find. [...] This is the work, you know, this is the opportunity we have. [...] So, I'm just thankful for the space and this group of people.

Chase also expressed gratitude for the:

...human experience of connection. I think sometimes we forget that there're so many people that have lives that are so far or so close to us and hearing everyone's stories so far, made it a little bit more alive, you know, that whatever it is that I'm going through is what it is. 
We also agreed that our work was an important reminder of how crucial the "intake" of our clients' story can be in coaching. It is where we listen deeply to our clients' stories to understand their issues from the perspective of the emerging and ever-present aspects of themselves. It is this deeper understanding that allows us to support them in their development.

\section{Opening to the Field}

When we completed the sharing of our developmental stories, I sensed that the emotional connection among us four co-inquirers present at that meeting had created a very special field inviting us to deepen and expand our work together. At that moment, I was inspired to suggest we revisit our intentions for growth/growth edges through a shared meditative inquiry. The group being willing to engage in that "different" kind of exploration, I led a brief meditation to evoke simultaneous focus and openness in the perspective of our growth, as a way to cultivate purposeful allowing. Connecting to the Field of awareness together allowed us at the same time to connect with each other at a different, more subtle level, and to find precious gifts on the path of our individual contemplation.

Lisbeth enjoyed "really feel[ing] into and listen[ing] into that deeper inner knowing that's underneath thought," and felt the desire to continue this kind of inquiry, taking the time to let what she sensed "was wanting to emerge" to manifest in her consciousness.

What Chase "received" from the Field in meditation was a message of integration: an invitation to listen more carefully and iteratively to each of the different parts of 
himself ("my mind, my heart, my body, [...] my gut") and of his life, to make decisions and find clarity around his purpose and passion.

Both for Logan and me the space opened in meditation for a more spontaneous allowing of life to unfold, as a way to balance developmental seeking and non-seeking. I personally felt-sensed softness, lightness, and dynamic aliveness in my body, at the contact with that liberating intention. Logan shared about her insights in this way:

When we started the meditation, the word that popped up for me was trust. And there was sort of this inner deep feeling of trust, in the process, trust yourself. In the past, things... have worked out. If they haven't, you've worked with it, [...] I had an extreme physical sense of fatigue just like I could lay down with this rain and sleep for four hours. [...] Reminding myself that it's sort of like that curse of knowing, right? It's like we know there's a growth edge. We know we can grow. Like, where is it? I want to find it. Am I at it? Versus just chill out, you know, like chill out, stay conscious, trust yourself, trust the people in your life. [...] And so, there was a comfort in that, but then also a fatigue. Like when you realize you've been working really hard and maybe you don't need to...

Probably the most precious gift I received from that experience with the group was the sense of expanded connection I felt with the group and each of its members. In my notes from the meeting I wrote about the "sense that we are one, that we share each other's fears, hopes, trauma, desires..." and since that moment, honoring and nurturing that connection became an important part of my role in the co-inquiry. That shared experience of contemplative inquiry highlighted the value of the knowing that derives 
trans-cognitively from the Field, and the transformative potential of opening spaces to access that in our coaching.

\section{Encountering Disruption}

The COVID-19 pandemic entered the co-inquiry from a relative distance, when the first few isolated cases in our region triggered the shift from in-person to virtual meetings at our third meeting March 10, 2020. Some of us were used to working remotely, while for some others, it was the first experience. After the meeting, Lisbeth wrote

I am left with an awareness of an assumption that I made about connecting virtually as a group. My assumption was that the experience would be diminished somehow and that the screen would be experienced as both a literal and metaphorical barrier to true connection. Although initially uncomfortable, I was able to relax into the experience and by the middle of the meeting was qualitatively more comfortable in my own skin, as well as feeling more connected to everyone on the call.

Still, shifting to virtual meetings was later mentioned by the majority of the coinquirers as a disruptive factor, and certainly it generated opportunities for disconnection as much as it was granting us a precious form of connection through the physical isolation period imposed by the shelter-in-place. At our first remote session, we were somehow becoming aware of our life being on the verge of a turbulent passage, having to cancel our imminent group events or undergoing the adjustments and the personal adaptation required to make them happen remotely. At the beginning of the meeting, we all alluded to our emerging concerns in the situation. When she joined the meeting, we 
could see that Logan was busy on her phone with some organizational details shifting. In my post-meeting reflections, I noted that "being on Zoom with other channels and devices available may have supported at times, instead of calming, Logan's self-declared distraction."

Despite the emotional intensity and depth of connection we co-inquirers generated in that meeting, described in the previous section, the gratitude that was with us at the conclusion of the session was infused with a sense of uncertainty regarding the ecosystem of the co-inquiry, particularly around the in-person or remote mode of the following sessions, and the membership of the group. This dynamic was mirroring the uncertainty and the loss of safety precipitated in the larger environment by the COVID-19 pandemic. In the weeks that followed, we were all directly confronted with its disruptive impact, through the shelter-in-place proclaimed in California, and indirectly through the anxiety, the grief, and the loss that the pandemic was causing, day after day, all over the world.

The fourth co-inquiry meeting, on April 14, 2020, was devoted to being present to and processing our experience within those first weeks of the pandemic. It was the central meeting of our series of seven, and a central meeting in terms of the flow of our exploration, connection in our group, and strengthening of our resilience. The following acknowledgment, expressed with gravity and renewed commitment by Lisbeth at the end of the meeting, captures the impact of our holding and processing of our experience of the pandemic's chaos.

If I can relax into the distress and just be fully present with it, not trying to change it or control it, but truly just be fully present with what is... That, I think that if I 
had been able to do that [in the past weeks when I was feeling so distressed], I think I might have moved through the distress a little differently. Perhaps a little more... a little quickly. But it does remind me about the fact that these times during the pandemic, are certainly in my life a real opportunity to be present with what is, and to keep making the moves needed to stay present, even though I might not want to.

We shared about our symptoms of distress, and about our tendency to preserve a sense of control in the chaos through our dominant patterns, i.e., hyper-organization, focusing on "doing" versus "being," trying to figure things out mentally, or closing ourselves to the emotional and the somatic aspects of our experience. In Ted's words: When you can't go anywhere, you can't go to work, you can't go... you know, like when you're actually forced to stay at home, it's been an interesting experiment to watch the lengths which I'll go to, now that I have actually space more conducive to being present with myself, to avoid being present with myself.

The forced physical isolation of the shelter-in-place had also led us to more deeply realize the importance of community, and we found much comfort and nurturance in our full presence to one another. Ted's sharing at the end of the session exemplifies that:

When I started this particular session, and now as I reflect backwards and it probably was evidenced by my movements, but [...] what I noticed in myself was a lot of, uh, somatically, a lot of just pain and tightness in my neck and in my shoulders. And just bringing a lot of the stress from outside this meeting. And so, I felt the need to continue to try to pop or find relief. But, keeping that line of 
inquiry though I realized near the end I'm not feeling quite near as stressed or there was something that happened over the course of this where I felt even somatically more at ease and not as tight, or as wound tight. [...] The word relax really resonates with me.

The felt-sense of safety and open, empathetic, non-judgmental listening allowed some important noticing around the challenge and, simultaneously, the relief, shared by most of us co-inquirers, of expressing our inner processes in an inarticulate, inelegant, yet authentic way. That awareness was captured by Sam with these words:

I felt really heard. I think there's moments of isolation that I experience, and I think about all the lost connections that I'm experiencing. And sometimes Zoom just doesn't quite cut it for me. And, in this experience, it seemed different. It was different. And I think it's because I felt held in this environment in a different way than perhaps my other meetings in which, you know, the task is really to get things done and a specific timeframe exists.

I think this, even just the practice of being present to you all and then have you all be present to me, has really been impactful. And I think on an individual level it's, it's really created a lot of joy in me and then my desire to also be that to other people $[\ldots]$

I think for our group, language has been critical and important during our time together. And that's one piece of it is what Chase spoke to about letting it just be unpolished, if you will, or be it, have it be even inarticulate, I would say, but have it be real and raw. 
We recognized that being an invitation to others to honor the "being" aspect of life together with the "doing," and to engage in the processing of our experience exactly as we were experiencing it was critical for us in the group, and as coaches. Allowing ourselves and others to be raw, vulnerable and unpolished lifted some familiar selfconscious tensions, and opened the way for embodying an invitation to this kind of hard and essential work in our respective circles.

Our group was helping us support resilience in ourselves and others in an additional way, i.e., through the circulation and the adoption of specific language. We all agreed with how Sam spoke to that aspect at the end of our session:

What I recognize that perhaps we all did to some degree, and I definitely did, was latch onto certain words that we said, and, and I thought that was really wonderful. I mean, even being able to talk about, I don't know, I think like being, "being caught in my mind" was one phrase, [...] and just being able to latch on to some of these phrases with these words, that then become part of my vocabulary in the way that I'm able to articulate what I'm feeling, right? So, I don't have to come up with it myself. I can use the language that we've offered here as in a way to be able to hold things for me [...] and I hope that's something that we all have experienced as a group together, as well.

In our shared coaching and leadership culture, our different ways of making meaning and naming our experiences enriched our individual and collective repertoire, and expanded our capacity to be in support of others. 


\section{Connecting, Disconnecting, Re-connecting-Blurring our Developmental Lines}

As the COVID-19 pandemic was running rampant all over the world, and we were navigating the growing grief and fear that as humanity we were called to hold, it was increasingly arduous for each of us individually and collectively to maintain an open, vulnerable, and generative connection with self and others. This became evident at our fifth meeting, on May 12, 2020, devoted to the debriefing of our MAP assessments and a brainstorming about the following steps of the co-inquiry.

Lisbeth, who had previously shared with me her excitement at the idea of debriefing the MAP together, unintentionally missed the meeting. As she noted a few days later:

In reflecting on my unintentional missing of the session, I was present to an inner feeling of being overwhelmed and saddened by the COVID-19 pandemic in terms of all the losses of life on a national and global scale, the ongoing need to engage in social distancing, and the uncertainty of what life will look like a few months from now. Missing the session (which is very unlike me) was perhaps an outward reflection of this inner confusion. After gaining some insight into this, I took care to take care of myself by slowing my pace of work a little and creating more space for me to pause and be in stillness with myself. This helped me to feel more centered.

As for the group members who were present, at the beginning of the meeting I could observe on my computer's screen that our colors (of our clothes, our backgrounds, and even what I perceived as our emotional/energetic signatures) were particularly different that day. I was intrigued with that diversity, which prompted me to be present to 
the emotional tones that we shared throughout the meeting, as well as to the ambivalences and tensions that they carried.

We all experienced disconnection in different ways. Technology was not on Ted's side that day, causing his intermittent presence and visibility. He had joined the call from his parents' new home, fifty miles away from his own home, where he was helping with the moving since very early that morning. Those were obviously challenging conditions for the "heavy lifting" of self and mutual inquiry, yet he had wanted to honor our group and his commitment by being present. Logan had to step away from her desk once during the meeting, and to leave the session early, to tend to other responsibilities. Chase's rectangle on Zoom was very dark that day, he was wearing a black t-shirt, his background was shadier that usual, and his energy also felt intermittently flowing. As he reflected after the meeting:

On the day of our meeting, on May 12th, my morning was not off to a good start. I woke up feeling overwhelmed and did not know where to begin. A part of me wanted to go back to bed and sleep the day away, but I knew I had prior commitments that I had to live up to.

Sam, Logan, Ted, and I also spoke to the ambivalences we were experiencing, feeling simultaneously overwhelmed by our responsibilities and the adjustments we had to make in our life through the pandemic; deeply grateful for our privileges and joys in the situation; and living our own experiences of grief, loss, anxiety, uncertainty, and separateness.

The tensions and ambivalences we could sense from the beginning of the meeting seemed to find their apex once we got to the debriefing of our MAP assessments. I had 
enjoyed a conversation with Logan who, interested in the MAP as a developmental measurement tool, had offered to help me to prepare the debriefing. Also, I had been deeply nourished by my whole experience with the MAP, and I was looking forward to our collective sharing as a way to continue the inquiry, the learning, the growing from it. During the debriefing with my co-inquirers, I was confronted with my and others' difficulty to engage in the genuine work of self and mutual inquiry with the authenticity and the vulnerability we had found so crucial in our previous meeting.

As Ted put it in his reflections after the meeting.

I [...] noticed that there was a hesitancy to share the actual "scores" of the tests that we took. The assessments we engaged in invited a new level of vulnerability and it seemed that maybe the trust was not present in the group to be able to learn together from our results collectively. I noticed language was vague and guarded. I myself struggled to engage full disclosure... wrestling with a bit of distrust in the instrument but uncertain of how to give voice to this.

Ted had not participated in the bonding experience of the second and third meetings of the co-inquiry. However, participating in the debriefing was not easier for those who had experienced that connection. Chase reflected on the experience in these terms:

I could not find the courage to share my thoughts and engage in the conversation. I could not relate to anything that was being shared by the other members. At one point in the meeting, I noticed myself withdrawing from the conversation. Thankfully, I was able to self-correct and regained my focus. 
I personally experienced a sense of disconnection during the sharing about my MAP, when I found myself caught in a heady monologue around my developmental edges. A few days after the meeting, I shared on the Google Drive my post-meeting reflections:

I am still with the sense of disconnection that I experienced letting myself being caught in my heady space during the sharing around the MAP. I am sorry for that monologue. And full of gratitude for the group's holding that so compassionately and responding in such constructive and action-oriented ways.

On that day, we were not able to move much forward, or inward, with our work around the MAP. The fluctuating nature of development, and our singular experiences with the fallback phenomenon (i.e., operating from earlier available action-logics), which was spreading as another impact of the pandemic, became particularly evident in our group. Most of us were able to recognize that only later, thanks to continued personal inquiry. Among the co-inquirers who directly experienced disconnection, fallback, defensiveness or withdrawal during the meeting, Ted and Chase shared their reflections privately with me a few days later.

Yet, at the meeting, once we acknowledged that the dialogue around the MAPs had dimmed, the Achiever/Self-determining-centered group that we were found reconnection and re-dynamization through an action-oriented final conversation. We were able to reflect together on our work thus far, express our desire to engage in concrete and creative actions for our development moving forward, and to tap more richly into the potential of our mutuality. 
The three gifts from our experience that I shared with the group by email after my own inner processing of the meeting, (an important work described later in this chapter), were the following:

- $\quad$ the reminder, especially after my textbook experience with Construct-awareness being trapped in its heady language space!, that the developmental work that we are engaged in for ourselves and others can't be done (only) with our thinking mind;

- $\quad$ the renewed awareness that this planetary Covid disruption is having a deeper impact that we might think on all of us, and on our capacity for being present to the wholeness of our being in each moment;

- the deepened awareness of how this capacity is key for us, especially as coaches using ourselves as instruments, to be an invitation to more integration and higher consciousness for others.

This session marked a turning point in our work toward increased creativity, expressed through the use of more symbolic forms of inquiry and action, and supported by the setting of clearer goals for our "fieldwork" between the sessions.

\section{Developing Capacity and Skills to Navigate Systemic Disruptions}

The two last co-inquiry meetings, June 8 and 29, 2020, set the stage for important unfoldings within a pandemic context compounded by the heartbreak, the outrage, the guilt, and the groundswell of solidarity after another brutal murder of a Black human being, George Floyd, by a White human being and police officer in the United States, on May 25, 2020. 
The sixth co-inquiry meeting, on June 8 , was largely devoted to making sense of that devastating human experience, and to reconnecting with a sense of our personal calling in life to canalize our upsurge of engagement for social justice, equality, and equity. Figure 6 shows impressions from our checking in at that meeting. In an email sent a few days before the meeting, I shared with the group "Spending time in nature is so important for me these days, in connection with life breathing through it." George Floyd's atrocious murder had taken our breath away, and I invited the group to let an image come to each of us from the natural world, to describe what was particularly present to our awareness as we joined the meeting (Figure 6). We devoted abundant time to our checking in through our images, and to vibrating with the deep resonances those invited in our group. I believe we created the conditions to reach deep within ourselves to find what was alive at that life-sapping time. From that space, answering the question "what is my calling in life?" and reconnecting with our purpose, i.e., the overarching intention guiding our human experience through our whole life, revived our engagement for a better, more just and less divided world. 


\section{peonies}

absolutely gorgeous...

when the leaves start falling off of it, overwhelming sadness...

just the beauty of it dying...

the appreciation might even be stronger

because of its finite time

\section{the floor of a forest \\ dead leaves on the ground... perhaps \\ a tree that's fallen over... the little \\ insects underneath... \\ that part of the forest, the part that's decaying, um, and yet is also the source of nutrients and energy for growth}

\section{a mountain}

a very tall mountain...

at the very top, above the clouds

the bright sky,

the bright granite..

below the clouds green,

woods...

Separation and integration...

\section{succulents}

very resilient...

can go a long time without water or barely any water and some succulents actually, when they don't get enough water, nutrients, sustenance, they actually bloom larger and come out of their bloom, and the flowers are much grander... shining blossoming, blooming, um, when resources are limited

\section{aspen trees}

even though you look at a forest of aspen trees... under the ground, there's actually one organism... just one connected root.

So you're seeing one organism that actually looks, from the outside, as if it's a thousand different ones

\section{soil}

has an abundant amount of stories, from different life experiences...

history does repeat itself...

as our world progressed...

we put more into the soil...gravel or cement, to hide the things that it's supposed to show.

a lot of the ruins... thousands of years later they show up again.

Figure 6. Impressions of racial brutality processing, at our sixth meeting, on June 8, 2020. 
What emerged from that meeting was the generalized awareness of interconnectedness, and of the cyclical nature of history, as well as the intention to honor that awareness in different ways, and by doing something different than usual, through our work. After a portion of the meeting, we split into smaller groups of two and three coinquirers to identify the possibilities for action that had emerged for each of us from our work together. We all committed, each in our very specific ways, to practicing with "funneling through systems," tending to and building on the nestedness of our ecologies. The following exchange between Lisbeth and Sam explored the implications of such commitment in terms of bringing the larger context into our coaching sessions:

Lisbeth: What I'm sitting with here is that from sharing with Ilaria and with Sam I have this, this real sense that there are, that there are so many possibilities right now, in the work that I do, that we do as coaches. That there are so many possible ways in which one could respond to the current situation. And in terms of my question to myself, about what will I do going forward, what I would like to do is to personally set aside time in a week to actively contemplate how I might take the work that I do with individuals and connect it to the larger system within which we're all existing. Now, I think in part that will, that will just happen because people are bringing into the space the impact of what's going on in our society. But assuming that for some people they're not there yet in terms of their own development and they're, they're not focused, um, in that way, I'd like to develop some ways in which I could invite clients to connect with that, also bearing in mind that it would need to be in service of the client. Therein lies the complexity, right? That this feels really important to me. Is it also in service of the clients and 
where they're at? So, I feel like there are a lot of possibilities, but also a lot of questions that I'm, that I'm sitting with. But mostly I'm feeling excited about what could potentially emerge from this, from these two questions that were asked of us today.

Sam: I think for me the intention is around the learning. So oftentimes, what I believe happens between the client and myself, as I'm sure we all do, mirrors what is actually happening in society and the larger world. And typically, I make those connections post coaching session, and, and hardly do I bring it up in our coaching session because a lot of the times it's focused on the client and the things that they're going through. And I wonder, what that would look like to do some of the parallel processing of like, what is actually happening systemically in the world [...] but having maybe those awareness moments brought in real time to those sessions and how that would then broaden and deepen the learning, right? And the curiosity around what that will look like for us in our work together. Lisbeth: I really love what you said there, Sam, because doing it in the moment when, when you are observing that, that parallel... um, certainly I believe would allow, would connect the client to the broader context within which they exist. And for some, it will be a real stretch just thinking in terms of self-sovereign mind, that's a stretch, and for others, they'll be in a different stage of development, and we'll be able to move with it further. But I think even just introducing the notion into, into the space takes away that separateness [...] I think when people hold themselves as separate from what's going on, that's when people don't take 
responsibility, they don't step up, they become silent and allow all the systemic problems to continue.

Awareness and commitments sedimented within the group, which then flowed into a joyful moment of co-creation through the Zoom whiteboard, to design the essential features of our following and last session together. As a bridge towards that final gathering, we concluded the meeting with the evocative words captured in Figure 7, which are evidence of the healing, regenerating character of our shared experience. I sent the composition I created with our words (reproduced in Figure 7) via email to the whole group after the meeting, as a resource and a continued invitation to cultivate ongoing regeneration.

\section{inspired}

\section{wonder}

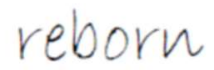

\section{connectedness}

\section{engaged}

Figure 7. Words emerging from our work around systemic racism and our personal calling in life at our sixth meeting, on June 8, 2020.

The generativity of our inquiry was revealed to us when, at the last group meeting, on June 29, 2020, important learning was shared around our using the current 
context as a lens and a source of inspiration through which to engage in coaching and in our other activities.

Chase commented about an experience he had lived with a client:

The whole experience, [...] it's just been a refreshing, and a kind of like another re-ignition of my interest in, you know, really becoming a certified ICF coach. Because I feel like every time something else happens in life, I feel like I'm being always brought back to coaching, to doing this kind of work. So, I'm paying attention more to it now than ever before.

Sam spoke to her experience with her commitment to integrating the larger system in her coaching sessions, in service of the clients:

Last time we talked, there was a lot of work for me around coaching with the individual and, when moments were aligned, to be able to then bring that to the larger societal picture of what's happening. So, mirroring what's going on with that person in relation to what's happening in the world. And I actually did some of that noticing for one of my clients and it was subtle, and I think that she was open to it. [...] I think my next step is to probably ask for feedback on that, as being able to then see how everything is connected.

Lisbeth and I also shared our respective experiences with bringing systemic issues of racism into the heart of our coaching conversations, whether through open, vulnerable sharing or with "a word" of invitation to the joint exploration of the resonance of those societal dynamics within ourselves. We both noticed that those conversations made the systemic issues feel real, tangible, in our personal and mutual experiences, and that everyone could resonate with those in some way. That brought us, no matter where we 
were developmentally and in our experience of life, to connect with others at a deeper level of humanity.

Significant commitments for the broadening and deepening of perspectives to be further developed in our practice beyond the co-inquiry arose from our renewed awareness around systemic racism. Lisbeth captured that in her post-meeting reflections:

I am still seeing systems and interconnections everywhere. Currently the most profound system that is at the forefront of my mind is the systemic racism in the United States which has deep resonance for me as a South African who grew up under Apartheid. I am deep in contemplation about how I can take active steps as a lecturer, as a coach, as a member of my community and family to address this directly and be anti-racist, not just non-racist.

\section{Illuminating shadows.}

The second part of our last meeting was devoted to a creative exploration of our experience of the co-inquiry in its environment. I suggested that each of us participants "draw" our experience with the group, counting on the symbolic power of drawing to capture the fundamental qualities of our shared space, described in the next section. After our respective sharing through the drawings, I invited the group to explore the untold shadows of our luminous, positive pictures. My intention was to "enter" the shadow through its collective, group aspects, to then go deeper in the exploration of our own individual shadow. Shadow showing starkly in our ecology, particularly through systemic racism, I wanted to invite the group to a beginning of personal shadow work as a way to support our capacity to navigate, and grow from, the dark waters of our systems. 
Many of us had spoken to the emotionally draining process we underwent in addressing the question of systemic racism in our life and work. In fact, that challenging societal moment made it increasingly arduous to dive into the shadows it was reflecting back to each of us. At the same time, acknowledging and befriending our personal shadows could support their integration and transcendence - therefore broader meaningmaking and greater responsiveness. It was another form of "listening into the dark" (Torbert, 2013, p. 1) of our consciousness. For these reasons, I invited the co-inquirers to start the process. Yet, as I prepared for that session, I noted: "It feels challenging even to just use the expression 'listening into the dark' with the group at this point." Lisbeth and Chase were the only members present in that part of the meeting, and together, using the evocative power of drawing, we identified the lights and shadows of our experience with the group. I then invited the shift from owning our collective shadows to owning our individual shadows, by suggesting we "play with archetypes card." Both Lisbeth and Chase accepted the invitation, and we let one card "choose us" from a deck of cards (which I was holding, covered, in my hands) representing the universal archetypes with their lights and shadows. The invitation was to let "our" card speak to us about our personal shadow(s) and transform it into a bridge to our future development. The cards catalyzed the emergence of important parts of ourselves and left us with precious gifts. Chase shared with us he was unsure of how to make sense of his card, showing a Native American woman tending to a fire, and at the same time he let the image resonate with him in terms of "igniting" and then "controlling and holding" new ideas. In particular, he noted: 
I think first I saw that I, my card is the only one that had a gender attached to it out of the three of us. [...] And I think the igniting fire that I think of has a lot of masculinity in it, and then kind of keeping the fire intact and holding, it has a lot of the feminine kind of actions to it. [...] That is something that resonates with me a lot.

For Lisbeth, as she shared with me in our final interview, the gift from "her" card was:

The image of those three feathers between the darkness and then the light, that has really, really stayed with me as a reminder that, you know, when the shadow side of my hope and optimism and belief in growth for every human being... when, when the shadow side of that is despair, I can sometimes lose hold of my spirituality as a pathway through the despair. And that card was just such a beautiful and powerful reminder about how connecting to a bigger meaning and a bigger, and wider purpose and doing it intentionally, even when circumstances are not conducive to putting you in touch with that... and that wonder, it was just a really beautiful image that I think I'll carry with me always.

As for the gifts I received from "my" card, they are described in a later section devoted to my personal trajectory through the inquiry. What emerged as meaningful in the perspective of listening into the dark as a way to become aware of, and better navigate, what was present in our shared Field, was that after that session I was drawn into a few days of deep, difficult connection with shadow. A few days later, I shared the following with Lisbeth and Chase via email:

I wonder what is still with you after our meeting Monday. 
I am still processing the shadow work, and I feel called to share a piece of my processing with you, who are integral parts of it and to whom I am immensely grateful.

What has been most difficult, and important, to hold for me these days is the excluding and ostracizing shadow, certainly in resonance with what we are currently experiencing as humanity.

It took me a great deal of self-compassion to revisit times where that shadow was particularly evident in me, in my life. It was utterly ugly, and painful.

Then, gradually, the pain is transforming into an even greater commitment to do my part to allow the richest experience of life for every being. And for every part of our oneness, including the shadows, so precious for us to make conscious and compassionate choices for unity. I am curious about how this renewed awareness and deeper integration (this is how it feels) will translate into action.

Each in our own way, we were processing the challenges posed by the current dynamics unfolding in the world, and particularly in our country, being more or less willing, capable, and called to dive deep into the encounter of our individual part of those shadows. That was how the co-inquiry ended, symbolically inviting us to continue the work of listening into the dark as paramount for growth through the disruptions of our times.

In the next section, I describe the individual and collective developmental trajectories we co-inquirers delineated through the arcs we had drawn together. 


\section{Sketching Developmental Movements}

Between the last group meeting and the individual post-co-inquiry interviews, we co-inquirers were able to acknowledge, celebrate, and express gratitude for the new awareness, strategies, behaviors, and outcomes that had surfaced for each of us from our work together. We had also formed subjective views of the group journey, based on what each of us had been able to experience of it. In this section, I describe our collective and individual developmental trajectories as they emerged from our reflections at the end of the co-inquiry, showing them particularly against Cook-Greuter (2013) and Torbert's (Torbert \& Associates, 2004) developmental model. In doing so, I am aware that the model is a theoretical construct elaborated to shed light on specific aspects of our being human (with the limitations and caveats described in Chapter II), supported by heuristic methods of developmental measurement. Yet, the model provides the framework and the language to at least partially understand our individual and collective movements throughout the co-inquiry. I abundantly share the co-inquirers' own narration and meaning-making as a way to honor the co-created nature of my analysis.

I start by sketching the developmental movements of the group, its progress and challenges throughout the process. I continue with an analysis of the co-inquirers' individual developmental trajectories from their conventional and post-conventional center of gravity, and a section devoted to my own personal trajectory. Finally, I conclude reporting some fundamental new/renewed awareness around development formed across developmental stages. 


\section{Group Movements}

Adopting Smith and Berg's (1987) definition of developmental movement as the "exploration of new ground" (p. 215), we can identify different arcs in our group's development. They were designed by our turbulent context, as well as by the inner and collective factors at play throughout the co-inquiry. If we were to depict the group's trajectory in developmental terms, we would draw a line winding from the Diplomat/Group-centric stage, through the Achiever/Self-determining stage, halting at the Expert/Skill-Centric stage on the way, and approaching the Individualist-Redefining/Selfquestioning stage at times. However, it would not be a clear, straight line; rather, we would perceive the interruptions, the fluctuations and the back-and-forth's that our context imprinted on it. What follows is an illustration of the unfolding of this imaginary line throughout our series of meetings.

The first meeting was devoted to getting to know each other, and people tended to show adhesion to the expectations and the rules of the group (also in ways that proved unrealistic, such as agreeing upon the sharing of our written reflections on the Google Drive - which four members never did). Diplomatically seeking membership and avoiding making negative impressions emerged as the dominant logics for action shared in that first meeting.

Meetings 2 and 3, though characterized by very polite interactions between one another, saw a natural deepening of our sharing, listening and resonating together, (especially around the hardest challenges of our developmental autobiographies, and the learning they allowed), which contributed to the emergence of typical IndividualistRedefining/Self-questioning logics, i.e., the awareness of multiple perspectives and the 
questioning of the subjectivity of our interpretations, the awareness of our impact on others and of others' impact on us, as well as of the difference between reality and appearances. That deepening unfolded similarly in Meeting 4: we examined our dominant patterns as highlighted by the ambient chaos, starting from the perspective of rational knowledge about ourselves, invoking our Expert/Skill-centric action-logic, and progressively opening the inquiry within ourselves and with others, thanks to the profound resonances within the group. We operated again from the IndividualistRedefining/Self-questioning stage at the last meeting, when our creative work (based on symbols, drawings, and archetypes) allowed us to explore more of the hidden areas of our consciousness.

The co-inquirers at the Achiever/Self-determining center of gravity noted that what allowed our group to shift on multiple occasions from what some defined as a “technical" level, to a deeper, inner or "philosophical” level, were specific co-inquirers' interventions. During our final one-to-one interview, Sam expressed that to me in this way:

...there were opportunities for people to be more on the technical side. Right? Like how difficult it is during this time, in terms of our work and not getting things done or getting things done and really being demanding, but not meeting people emotionally. But then I think there were, I mean, I think Lisbeth and you were prime example of maybe how you deepened the conversation, how it became more about the intangibles and more about the philosophical ideas as opposed to the technical. 
Lisbeth, whose center of gravity was at the late Individualist-Redefining/Selfquestioning stage, thought that the sense of being a community engaged for development, and the facilitation prompts and methods we used were key in our inquiry's deepening and flowing. This is what she shared with me in our final interview:

The questions that you asked us to reflect on, that helped a lot. And I really appreciated the movement towards not just using language, but using metaphor and using, you know, the drawing that we did and then in the final session using the cards.

I personally believe that the shift towards creative methods was crucial in exploring deeper aspects that were simply inaccessible to our conscious mind, along with the contribution of the co-inquirers at the Individualist-Redefining/Self-questioning center of gravity, capable of vulnerable inquiry, resonance and amplification of inner dynamics for themselves and the group.

Meeting 5 marked the turn towards a clear Achiever/Self-determining orientation, after an experience that I interpreted as an alert for stuckness. In debriefing our MAP assessments, we were not able to reach and/or share the depth, vulnerability, and flow we were capable of as a group. That happened in May 2020, when we had been suffering from the limitations and the threats of the pandemic for a few months, and when fallback had become most evident in our group. Some of us were struggling with fully receiving Dr. Cook-Greuter's feedback, displaying an Expert/Skill-centric defensiveness; others with sharing and owning that assessment and the subsequent learning with the group. Most of us co-inquirers attributed those reactions, a posteriori, to the regressive impact of the pandemic. Ted shared: 
I think the effects of the pandemic cannot be overplayed. Isolation, stress and anxiety on a global level affects the work we do around ourselves. In some ways, it's hard to do the heavy lifting of self-development work during a season when survival on a number of levels is the goal.

Others pointed to the technological barriers, the lack of attentiveness of some members fragilizing the group's holding environment in that meeting, and to the absence of Lisbeth, who used to help the group reach the heart of issues.

We were able to break that immobilizing spell through the work around the future directions for the group. When I asked questions like "Where do we want to go next with the group, and as a group?' the Achiever/Self-determining energy ignited a constructive brainstorming that helped us to move forward precisely. However, the conversation remained at a rather technical level, with mostly single-loop feedback (Torbert \& Associates, 2004) offered about practices/behaviors to enhance our group's content and process. With my follow-up email to the group, sharing my meaning-making of the experience — once I had been able to process it vulnerably myself—, I extended the invitation to reach deeper, and that resonated with at least two of the co-inquirers who then shared their raw, vulnerable reflections with me privately.

At Meetings 6 and 7 we continued to play mostly on an Achiever/Selfdetermining basis, with an increasingly participatory efficiency in the way we worked together, marked by a more direct, comfortable, and less polite way of contributing and building on each other's sharing. Our firmer orientation to action also supported our goal setting and accountability during the interval. Within this overarching action-logic, as I mentioned earlier, we experienced glimpses of Individualist-Redefining/Self-questioning 
openings into the dark, mostly at the individual level. The profound difficulty of the moment we were living as a society, in the midst of the pandemic and systemic racism, irrupted potently in the group. This resulted in questioning whether we were living by our values, reviving our calling in life and our active engagement, deepening our introspection and, even if only for some of us, engaging in meaningful shadow work.

The collective completed its journey celebrating new behaviors and actions undertaken in alignment with new awareness and strategies, and the supporting, uplifting, nourishing, and re-energizing nature of our work together through such challenging months. Those were the biggest successes of the group as a whole. In the following sections, I explore the strengths we leveraged and the challenges we experienced as a group.

\section{Connection and mutual inspiration.}

In co-creating our shared space, movement was experienced by the group in the direction of a stronger connection to its shared space, increasing comfort within it, and mutual inspiration. In Lisbeth's words, it was a space "where we could simply bring whatever it was that we were able to bring, [...] a very safe space for sharing and for expression and for, in a way, accountability around our growth edge.” Also, we could go back from our shared space to our respective lives "uplifted" and "re-energized." These movements were noted by all the co-inquirers who remained engaged until the end of the process, in spite of the challenges posed by the absences and the "coming and going" of some participants. Together with the shift to remote meetings, and what we perceived as long intervals between the meetings, membership inconsistencies were recognized as the main obstacles in our work of mutual inquiry. Yet, the co-inquirers talked about how, 
once in the session, who/how many were there did not really matter: at the end of the coinquiry, the sense of connection to the group and its members felt strong and with the potential to live on beyond our shared space. The core members of the group - Lisbeth, Chase and myself — were deeply attuned to the essential, energetic, spiritual nature of our connection. At our last meeting, we could sense and witness that our whole bodies were engaged in the work, leaning forward towards our screen and one another, in what felt like animated, enthusiastic teamwork. I suspect that our bonding at the core was sealed by our deep emotional connection around grief and suffering in the first meetings, beyond the experiences that we shared throughout the whole co-inquiry. Also, knowing that we were doing this work simultaneously for ourselves, others and the larger environment cemented our individual engagement and our co-creation.

On a more practical level, we experienced increased connection as a group through the convergence of the themes we wanted to explore in our fieldwork-namely, how to navigate disruptions across different, nested ecologies (from the personal to the systemic) — and were inspired by one another in the process. Also, Sam noted how language was an important feature of our increasing connection. Not only could we count on a common coaching and leadership language, we also largely "latched onto" and built on specific words and expressions offered by each of the co-inquirers throughout the process, (e.g. "being caught in [the] mind," "being an invitation to others," etc.) whose reiteration and significance participated in the bonding of the group.

What deeply contributed to our increasing connection was our compassionate, non-judgmental presence to one another, and our acceptance of "what was there" for every one of us. Having a safe space for being vulnerable, processing and voicing our 
experience in the midst of the ambient chaos was key for our individual and collective evolution through it. Cultivating resources to personally sustain resilience naturally became a primary intention for the group as a whole: our context was shaping the contours and the features of the group from the outside, as much as we were doing it individually and collectively from within.

\section{Navigating challenges.}

As coaches, we were used to providing the right amount of challenge to our clients to help them progress towards their goals and develop as persons. In our profession, this compassionate challenging was based on the safety, the trust and the intimacy of the relationship built between coach and coachee, in itself one of the most generative aspects of coaching.

The ecologies of our group were marked by chaos and uncertainty at the environmental level, through the pandemic and the racial issues; at the group level, through inconsistent membership and engagement; and at the individual level, through disruption in our personal and professional circles. The very nature of our work, and its group dimension, stirred discomfort and complex inner dynamics to navigate in each of us, as I will discuss in the following section. Apparently, being challenged from the outside-in prevented us to be challenging from the inside-out. Starting with ourselves, we experienced how difficult it was to remain connected to what was truly going on within us, to challenge us to maintain the connection, and deepen the inquiry, without ceding to avoidance and other well-oiled defense mechanisms. This difficulty, which was also one of our main sources of learning about ourselves through the co-inquiry, transferred in our mutual and group dynamics. Because it was exceedingly demanding to process what was 
going on around and within us, a lot of our time was devoted to creating a resonant space for checking in with ourselves first. That was essential to be able to be and work together. The vulnerability of being shaken, the woundedness of being in many ways disconnected from others as well as from ourselves and our full capacities were so apparent, so raw, that we looked, above all, for empathetic, non-judgmental holding through those challenges. In the extraordinary six months of the co-inquiry, we hardly offered/received compassionate challenging or constructive feedback to/from one another. We actually had ample space and freedom in the ways to offer support in our work, yet even when in dyads or triads, we never exposed ourselves and others to what could have been additional tension. In this light, we can make sense of the effort required to share one's writing with the other co-inquirers, or even to (fully) participate in the individual and collective work of inquiry, at that time. Also, that provides an additional lens for the observation of the paradoxical tension between desire and immunity to "go deeper," or "raise the heat," expressed by Logan. In our overturned ecologies, we could only tolerate a certain level of entropy.

During our final, individual interview, Chase shared:

I think that when people shared - and I know this for myself, it was the same way-when people shared their perspectives, I just, you know, I took it as that was it, like, there was no question about it. And it was like, "Oh my gosh. Yes! That's fantastic. That's wonderful." But not once did I ask myself and ask, you know, the, why do you think of that? Like, why do you, why did I just accept that the way that it is? And also, why is that something that you want to do? [...] I think I was just always so scared about like, "Oh my gosh, these..." I looked up to every single 
one of you, you know, as, as people. And so, I didn't want to like bring up or ask anything that was different or that was going to open up a different approach or a different image of what was being presented by that person.

This points to the interweaving of individual, collective, and environmental factors resulting in the holding environment we co-created for each other, and to how developmental dynamics — both at the collective and the individual level—were an intrinsic part of it.

Other territories we minimally explored because of our ecological challenges were mutuality and co-creation on a practical level. We certainly experienced mutual inspiration, gained broader, richer perspectives, served as and learned from models embodied by one another in our way of inquiring into our experience. Yet, unfortunately, as a collective, we were not able to leverage our mutuality further, and the exploration of mirroring and projections (Smith, 2016), together with some of the rawest, darkest parts uncovered through personal inquiry, were not shared with the whole group. Some of this precious material was only disclosed in the dyads of my conclusive, one-to-one interviews with each co-inquirer. In this way, we missed the opportunities for mutual growth offered by the illuminating realizations that came with those arduous explorations.

Also, if we experienced beautiful, profound and generative instances of cocreation during the meetings, despite my continuous invitations, I was not joined by my co-inquirers in the preparation and facilitation of our work. Only Les and Logan helped me prepare two sessions respectively, but Les was not present at the meeting he had 
helped to design, and Logan's thought-partnering didn't translate into co-facilitation at the meeting.

At the end of the co-inquiry, Lisbeth spoke to that in these terms:

I recall you raising that, at one point. I do have a recollection of us, and certainly you were very consistent in inviting it. Just so aware of in your between-session emails, really inviting, and my feeling that as an idea, that was very tantalizing like, "Oh, yes!" and then finding before I knew it, that we were meeting the next day. Right? Well, then you had already come up with an idea and a focus for the sessions.

We also missed the opportunity to explore those missed opportunities for cocreation within the group. Even on the occasions when I raised the point with the group, my/our alertness to the dynamics at play underneath the surface, and the vulnerability necessary to face and own those with-in the group, were washed away by the complexity of living at those times, experienced in the group.

Ted put it this way, during our one-on-one interview: You did a great job of putting it back, putting the responsibility in such a nice... I have to say you are a very compassionate facilitator. Nice way of putting the work back on us, giving the work, and I watched it happen a couple times. That's like a, that's an art form right there. [...] Like, "Oh, I have to take my medicine..." I saw it, I realized my place in creating kind of the anchor that we were having. And then, you know, by that time session was closed, we were moving on... 
During our time together, we could never really sustain a constructive, collective dialogue reaching at the heart of our relationship with responsibility for co-creation in our context.

Evidently, challenges were reflected, amplified and blocked through the nested ecologies of our co-inquiry.

\section{Individual Movements}

I now turn to our individual evolutions in the timeframe of the co-inquiry, highlighting the connecting developmental patterns that emerged throughout the process. You will hear the co-inquirers expressing their own developmental reflexivity — and informing my rendition. Letting individual voices be heard is also a way for me to honor the intimate character of our movements around the different territories of experience (Torbert \& Associates, 2004), and to allow each of us to isolate, from the multitude of factors that contributed to our evolution in the six months we worked together, the specific impact of our co-inquiry.

Our movements were developmental in that they manifested new awareness, strategies and behaviors for more qualitative and timely outcomes in our life and work (Torbert \& Associates, 2004). They did not imply moving to a later stage of development, which generally takes years (Smith, 2016). On the contrary, our evolutions throughout the co-inquiry were conjured by constant fluctuations to and from different action-logics, including bad falls, blurring our developmental lines.

My analysis of our evolution is the fruit of my own meaning-making of our experience — my personal construct — which is grounded on developmental theory — as any other theory, another human construct — and anchored to Dr. Cook-Greuter's 
assessment of our developmental center of gravity through the MAP — a heuristic measurement based on the particular construct that is Cook-Greuter's (2013) version of ego-development theory: it is a fortiori partial and limited, and in no way representative of our whole person and its ever-unfolding nature.

I start by describing the movements identified around the Achiever/Selfdetermining center of gravity, which, according to Dr. Cook-Greuter's assessment, was shared by Sam, Chase, Ted, and Les, and continue to explore the movements from the post-conventional meaning-making of Logan, assessed at the IndividualistRedefining/Self-questioning stage, and Lisbeth, assessed as IndividualistRedefining/Self-questioning exploring the transition to Strategist-Transforming/Selfactualizing. ${ }^{5}$ I conclude with a section about my own movements through the co-inquiry, based on my "living life as inquiry" (Marshall, 1999, p. 155) throughout the process as the primary researcher, from what Dr. Cook-Greuter assessed as an early Alchemist/Construct-aware center of gravity.

Movements from the Achiever/Self-determining center of gravity.

At the completion of the co-inquiry, the developmental reflexivity of the coinquirers gravitating around the Achiever/Self-determining stage was colored by the sense of strengthened self-confidence and self-expression; enhanced integration and creative experimentation with multiple, different aspects of oneself (including learned

${ }^{5}$ I deliberately report the designations used in both Torbert and Cook-Greuter's frameworks as a reminder of the main action-logics aspects highlighted by each of them. 
frameworks and models); and greater presence to oneself, others, and the larger environment. These movements allowed Sam, Chase, and Ted to operate with increased confidence, agility, and impact as coaches, especially in virtue of the honing of their selfas-instrument.

\section{Strengthening self-confidence and self-expression.}

Interestingly, only the co-inquirers at the Achiever/Self-determining center of gravity brought up issues of self-confidence and insecurity during the co-inquiry, while those assessed at the post-conventional level did not evoke those issues at all. Three of the co-inquirers at the Achiever/Self-determining stage were the youngest in terms of age and experience in coaching. Les, who was among the oldest and most experienced coaches in the group, and was assessed at that same center of gravity, shared important pieces of his own issues with self-confidence in the few exchanges that we had. Unfortunately, Les stepped out from the group at our second meeting, therefore his developmental reflexivity is not included in this illustration.

In our final one-to-one interview, Ted spoke to his own increased self-confidence as a coach in these terms:

I'm a big qualifier, even now as I'm explaining, I'm more acutely aware of when I'm trying to give myself permission to be wrong [...] I'm learning that, that's not always healthy. And in some ways, I can be protecting myself. And so, I think in the end, where [the co-inquiry] hit my coaching is being more comfortable with just saying what I mean and allowing for interpretation to be engaged, instead of trying to cover all the possible bases of misinterpretation before it comes out of my mouth. And I think that's where it really contributed, I was really grateful for 
Cook-Greuter's assessment, grateful in that kind of, "Oh, I thought I kind of had this down!" But I realized I need to learn more in this, and that is to not be so afraid of making mistakes and just to put it bluntly. [...] I think I'm not as scared to make a mistake or to trigger somebody [...] and then if that were to happen, to just let the, let that surface data. [...] So, yeah, I think there's definitely been growth in that particular area of not being as fearful as maybe I have been in my coaching.

Ted's self-confidence as a coach seemed grounded on his capacity to hold "whatever emerged" in the coaching relationship, including mistakes or misinterpretation, and skillfully leverage that in service of his clients.

Chase experienced an increased sense of confidence in his way of interacting with others with empathy, (self-)compassion, and vulnerability. The group helped Chase in consolidating the shift in that direction that had started for him in the months before the co-inquiry. In the words Chase shared with me at our final interview:

When we went into this inquiry, I noticed that I was able to really, in our group, I was able to really keep that mindset, but also practice it. So now I feel really good about having it. So not that it just comes in and out, now I feel like I practice daily. And so, I feel like that is a big difference in the way that I approach things. [...] I think before, it was also, it was always very kind of self-centered, you know, like if something was wrong, it was because either I did it myself or it was because the situation is difficult, then it was all like other people, like, you know, the blaming of other people. And I think now it's very much like, "Okay, how can I understand the situation at hand, who's involved, what their perspectives are and 
how can I, you know, create an opportunity for dialogue” instead of this grudge or like, you know, kind of pushing it out. So, I feel like that is such a big difference in the way that I've been able to do work. [...] I'm so much more aware of my actions and also [of how] my actions create a different environment for other people. And so now I'm so much more aware of that.

The inner shift Chase had been experiencing throughout the months of the coinquiry, supported by the free, authentic, vulnerable self-expression he had practiced and observed with-in the group, was translating into practical new behaviors that made a difference for Chase and for the people around him. At our final interview, he particularly shared about a recent meeting with a co-worker with whom he had a disagreement, when he was able to shift his attitude and the tone of the whole conversation:

I approached it at first with very much "So, what's going on?” Not necessarily defensive, but also very straightforward. And at first it was like, you know, this is the way that I act and that's how I would normally do things. And then I realized that as our conversation started to progress and that emotions were coming up, I think there was something in me that just clicked and switched to this mindset of: "Okay, the problem is at hand, and I think that there's a lot of emotion that's coming up now that have just not been addressed in a few months or so. And now we're addressing it and how can I support this [...] opportunity to actually have a more meaningful outcome?"

The impact of this shift deepened and rippled out for Chase. He continued: Interestingly, after that conversation was over, I just really took the time to reflect and understood, you know, what have I been doing, and realized that a lot of what 
I was putting to my team was a lot of projections. It was the pressure that I was getting from other people [...] And I actually... this has never happened before. This was the first time I felt confident and I felt like I owned it, too. [...] During our staff meeting I brought it up to everyone and said: "Hey, I have thought about this. And I think I'm really projecting and I just want to be able to be vulnerable with everyone." And I've never been like that. [...] I think at work I'm very straightforward and it, and that was such a big awakening for me because, it was the first time that I was able to show that side of me with the group of people that I manage. [...] And I challenged everyone and said, "You know, if this is something that you see me doing again in the future, please call me out on it or please set me aside because what I hope that we can do as a group is actually provide that feedback with each other of how we're presenting ourselves."

This is a beautiful example of alignment among territories of experience: from awareness emerged intentionality, and the experimentation with new ways of being and interacting, including an increased openness to feedback, which Chase had identified as an important growth edge of his, that led to new, better outcomes in his environment. And this had the potential for Chase to keep transforming himself and the people around him in their way of being, interacting, and working together.

The group helped Chase mature in terms of self-confidence as a coach, as well. In the presence of the other co-inquirers, he was confronted with his own insecurities and with the others' alike:

I felt like every time I came into our meeting or our sessions, I got this feeling of like "less than," like I don't know much. [...] So, I had to talk myself out of all of 
those insecurities. And I had to listen to my own, which I normally don't, but listen to my own insecurities and hearing every single one of them out and then throwing them all away. And so, that was a really hard internal process that I had to overcome, because, you know, I think everyone, it feels to me like everyone in our group, um, I didn't get to meet [Les], but, everyone in our group are really well achieved. Everyone, you know, have done so many great work and stuff. And so, I think coming into that was the first thing that I definitely noticed. But again, the way that I was able to hear everyone now and here like that, every single one of us were dealing with some sort of internal struggle, made me realize how the human experience is sometimes isolating, but hearing other people's stories gives you a little bit of hope about, you know, if a person can overcome situations, then I should be able to, and I should be able to talk myself into it to continue to push through, regardless of what's at hand. [...] And really seeing that, you know, we're all going through that. Right? We're all the same.

Witnessing (esteemed) others' vulnerability and their struggling through challenges allowed Chase to connect at a deep human level and find renewed motivation to overcome his own obstacles and insecurities. Towards the end of the co-inquiry, Chase also noted his increased self-confidence with a client:

I've really just learned how to sit in that quietness and just let my client talk. [...] In the last few sessions I've had with this client, I've just been hearing him out, and waiting for him to ask me what I think of the situation. And I think it's been super helpful and we've been able to identify lots of goals and he's, he's actually been doing them! 
Chase was able to be with his client in a different way, to leverage a different facet of his being and coaching.

As Bachkirova (2011) points out, at the Achiever/Self-determining developmental stage, which she refers to as the "formed ego" stage, insecurities can participate in one's own judgment about one's ambitions. Strengthening his self-confidence as a coach may have participated in Chase's sense of renewed commitment to being a coach and pursuing his coaching certification with the International Coach Federation. As he shared at the end of the co-inquiry, that was for him a way to contribute to "ignite $[\ldots]$ the sense of wholeness, the sense of purpose, the sense of having enough hope to keep going" through systemic and personal challenges.

\section{Integrating and experimenting with different parts of self.}

The integration of different parts of oneself, and aspects of one's life, was particularly pursued by the co-inquirers at the Achiever/Self-determining center of gravity. Sam highlighted that with her sharing at the beginning of the co-inquiry:

I would say that I grapple with my identities [...] growing up with the idea that you should have one full-time job and you should dedicate yourself to that. And, just kind of pushing against that. And I think, yeah, I can do all these things and be fulfilled and feel joy.

At the end of the co-inquiry, most co-inquirers emphasized a sense of freer experimentation with different aspects of oneself. At our last group meeting, sharing about a significant coaching session when she had been able to bring the systemic racial issues into the heart of her exploration with a client, Sam referred to an increased flexibility and creativity with her own repertoire of ways of being as a coach: 
That has helped me become more aware of how is it that I'm not just bringing myself one way, a specific way, to this person. And just assuming that what I've done in the past six or ten sessions is what the client needs now. Right? So, getting used to who they are, getting used to who I am in relation to who they are, but really opening myself up to new experiences and saying, I can bring myself differently to this client and to my coaching style and have that be a reflection of how I also want to grow. Right? And how I want to also develop. And that's been pretty critical for me.

Enhanced integration was also evoked by the co-inquirers at the Achiever/Selfdetermining center of gravity with regard to learned concepts and frameworks, in what appeared to be a self-authored re-organization of personal models and practices as coaches. Chase referred to a more creative relationship with what he had learned in his coaching program:

And so, as I'm developing more of my... I guess coaching characteristics, and what I really stand for as a coach, I think that this is something that I want to continue doing is just, you know, not necessarily throwing away all of the things that I've learned, but [...] I think the little skills that I've really taken away from the [coaching] program, I think that those are, they were great foundation, but now I have to be able to like, do what's best in that moment. And not just follow the steps. And I think that, that has been very successful.

These shifts in awareness, coaching strategies and practices, (and ultimately in the outcomes observed in the clients), based on increased confidence in one's own perceptions and insights, are characteristic of a coach shifting from an Expert/Skill- 
centric approach to an Achiever/Self-determining one. Being able to detach from certain specific, learned steps to follow, or frameworks to use, and integrate them in a more personal and creative way is a mark of maturity in terms of coaching expertise as well as of ego development (Sharma, 2019). In our work, it was highlighted by the co-inquirers at the Achiever/Self-determining center of gravity as an essential aspect of strengthening their use of self as instrument: being able to hold frameworks and models "in the background," while listening into the dark of the present moment with the client. As Ted acknowledged during one of our meetings:

There's a challenge here for me too, to more fully lean into being involved in selfobservation in the moment when it's happening and trying to pay attention to what my, what I'm feeling in my mind and my body in that moment, and how those are data points for inquiring with this kind of [theoretical/practical] framework in the back of my mind.

Ted had an important realization about his capacity to integrate different frameworks more harmoniously, and about this very integration becoming object (Kegan, 1982) for him, at the completion of the co-inquiry:

There's a part of me that's feeling a little bit more comfortable to maybe, mix some of my, uh, my religious, for lack of a better word, kind of education [...] with some of the developmental psychology education that I've just been kind of in a... I feel like I've been drinking from a fire hose [...] And I think I was trying to also reconcile that with so much of my religious upbringing, that leaves room for variety, for lack of a better word, but also feels pretty certain about some things religiously. And I think that's the thing I was trying to wrestle with when I was 
going through like: "Okay, so should my end goal be this post-conventional stage, what would that mean for me...um, spiritually?" [...] So, I think there's a growing comfortability with mystery, which I, which is true for me, both developmentally and spiritually.

Ted's sharing also points to the complexity of evolving or expanding our core beliefs and assumptions - an important aspect of our immunity to change (Kegan \& Lahey, 2009). The work of inquiry and the third person MAP assessment supported this Subject-Object shift, that had unfolded almost unnoticed, for Ted. In our final interview, when I asked him about the evolutions he had experienced in his understanding of his growth edge, he shared:

You know, that's interesting, and really powerful that you're asking that right now. 'Cause I don't think I've seen such a full circle as I'm realizing right now. Initially my growth edge, [...] I really had this burning concern to, to reconcile or at least be able to put the two, what I felt like were not as easily aligned parts of myself in terms of my spiritual formation and then my developmental psychology formation, and trying to figure out how could they be assets to each other in my coaching. But then in our sessions, I felt like I didn't really deal with that growth edge explicitly. But what I'm realizing, it just sat there in the back awareness. I was not as intentional with that in bringing it into the space. But once I got the feedback back for the [MAP assessment], I think it brought that learning edge front and center in a heightened way, and I think gave me more tools by which to engage that inquiry. 
Increased integration of different aspects of oneself was reported by other coinquirers.

Chase used Winnicott's (1965) concepts of false self, referring to the mask he put on at work, and true self, intended as his true nature, which he experienced as aligning more spontaneously at the end of the co-inquiry: "I think everything doesn't have to be so, um, black and white, or there doesn't have to be the separation of professionalism and personal kind of experiences."

The capacity to navigate different identities, assumptions, and roles more

smoothly, from the perspective of a self able to encompass them more fluidly, represented for the co-inquirers at the Achiever/Self-determining center of gravity an important form of integration, yielding more spontaneity, sense of flow (Csikszentmihalyi, 2008), and fulfillment.

\section{Nurturing presence to oneself, others, and the larger environment.}

The quality of our presence to "what is in the present moment" within ourselves, in others and in our larger context, was recognized unanimously by the co-inquirers as an essential capacity to develop the use of self as instrument as coaches, and build on the intelligence gathered through presence in service of the client. All of us co-inquirers, and particularly those at the Achiever/Self-determining center of gravity, observed how difficult it was to cultivate presence and how our busy, achievement-oriented times and culture encouraged a focus on "doing" at the expense of "being." And, as shown earlier in this chapter, simply "being with what is" became especially arduous in the chaos of the pandemic, when our presence to ourselves, others and the world was challenged by stress, uncertainty, and social distancing. 
Sam's growth edge gravitated precisely around her quality of presence, and at the end of the co-inquiry she felt she had progressed in the following ways.

- In terms of being more present to herself, she shared:

That emotional piece of sometimes just being able to say, "I'm upset right now," or, you know, "I just feel like I can't, as a coach, hold my clients the way that I'm used to," [...] and sometimes like crying about it and sometimes venting, sometimes being reflective about it and writing about it has been so critical for me. And I don't know if I would have developed that skillset as much as I have if it were not for the conversations of this group, you know? And so there has been a shift in me in that capacity: how do I hold myself when I actually connect with my clients?

- In terms of being more present to others remotely, Sam used the words "captivating" and "chiseling out" time and space with others:

When it comes to being cognitively and spiritually aware of people's presence [...] I've really had a hard time doing that. Like how I show up through Zoom, [...] I've had to accept that it's much of a harder buy-in for me, [...] And so I think for me having the opportunity to be part of this group allowed me to practice that: how do I really practice presence when I feel like my presence is so absent from where you are, you know? And so, I've really felt like that's been an edge that I've really grown and developed.

We certainly experienced Sam as present in the group with her mind, heart and soul, contributing to the special holding environment we co-created. 
- In terms of being present to the larger environment, at the end of the co-inquiry Sam shared:

Being able to use myself as an instrument, [...] I think my awareness around that has really increased dramatically since we've had some of those conversations and that my behaviors around it have been there as well. Such as the questions that I would ask or the noticing that I would do in my conversations with my clients have really been around that. The entire world experience, how, you know, the things that happen in our society often impact us in ways that we might unconsciously be not aware of until we actually bring them into our consciousness.

Being present to the dynamics at play in the larger environment, particularly in the months of the co-inquiry marked by the plagues of the COVID-19 pandemic and systemic racism, became for Sam an important scaffolding for the development of the capacities and skills necessary to leverage nested complexity in coaching.

To conclude, the Achiever/Self-determining stage is one of integration and embedding in the larger environment on the basis of self-chosen, mostly ideological criteria. It seems that for Sam, Chase and Ted, the co-inquiry supported their growth towards the embodiment of their self-authored, ideal, competent way of being, achieving, and contributing in the world, freer from others'/cultural-related pressures. For them, the most beneficial aspects of the co-inquiry were the authentic and non-judgmental presence of the other members of the group, (in Sam's words "the approval of 'we will take you where you're at in life'"'); the experience of others' ways of making meaning, struggling 
with and responding to challenges; the opportunity to join a space where we could cultivate being-with-doing, and doing-with-being.

\section{Movements from the Individualist-Redefining/Self-questioning center of} gravity.

Being and becoming were at the heart of the movements observed in the coinquirers' different territories of experience, yet they had a different significance at the conventional and the post-conventional tier. For the co-inquirers at the Achiever/Selfdetermining center of gravity, being was seen and cultivated as an antidote to the overdoing of the mind, heart and body; and becoming, as a self-determined quality of alignment with self-selected ideals in a skillful, "seamless" way, "being this type of person that doesn't need to think about it all the time," to quote Sam. At the postconventional level, these self-authored pressures seemed lifted or, more appropriately, easier to be navigated as object (Kegan, 1982). And, in the overarching trend towards "increasing embrace" (Cook-Greuter, 2013, p. 1) of inner and outer complexity that distinguishes the post-conventional tier, being and becoming were cultivated more specifically in the perspective of connection and co-creation with others.

\section{Experimenting with mutuality and co-leadership.}

Logan, whose center of gravity was assessed at the Individualist-Redefining/Selfquestioning stage, missed most of the second half of the co-inquiry, and interestingly, at the moment when it took an Achiever-oriented turn. We could hypothesize that, more or less consciously, she reacted in a way typical of people finding a new independence from the conventional views of life, i.e., rejecting a modus operandi reflecting the previous stage. What was observable was her desire, also typical of a stage having somehow 
disconnected from a previous holding environment, to reconnect with like-minded and like-principled people. She expressed that as her primary motive for being part of the coinquiry, and reiterated it sharing her ongoing questioning about the people and spaces to work with in order to continue to grow. During the months of the co-inquiry, she had been working with different people she thought could help her "become" what was next on her developmental trajectory.

Her harvesting from the co-inquiry was "a renewed commitment to want to explicitly grow." At the end of the co-inquiry, the way she spoke to what she saw as a necessary shift to impress on her work reflected a more integrated awareness, compared to the somewhat vague idea expressed at the beginning of the co-inquiry. The pandemic had actually brought about important structural change in her work. In our final interview, she shared with me:

I feel like I'm at an edge right now with my work, [...] with what I want my work to be. So I feel like there, I'm kind of at that edge and it requires the growing, like, you know, I said that next level, getting to that next place, next sort of stage or step if you will, of growth. But I think I just understand that it's a necessary... it's very present for me. I don't, in the moment, I don't have a clear answer though, of how to get there. It's like, you know, when you see you're at the ground floor and you see that there's a second level and the third level, [...] but you can't find the staircase, the elevator's broken. It's like, I need to get up there, but I don't have a knowing of how to get there.

Paradoxically, Logan's questioning around the "how to get there" seemed to invite the depth of (self-)inquiry of her Self-questioning center of gravity, as much as the 
leveraging of her Achiever/Self-determining mindset. We experienced that as a group, as well: when we worked with our questions around where to go with the second part of the co-inquiry (interestingly, Logan had to leave the meeting at that time), the Achieveroriented energy of the co-inquirers who were present was critical for us to come up with a plan and identify the first steps forward, based on our set intentions. The importance of the re-integration, at the post-conventional level, of the gifts of the conventional stages emerged also in my own trajectory with the co-inquiry, as I will describe later.

Lisbeth, whose center of gravity was assessed as late-IndividualistRedefining/Self-questioning exploring the transition towards StrategistTransforming/Self-actualizing, also joined the co-inquiry attracted by the idea of "growing together." At the end of our journey she expressed gratitude for "the experience of being part of a community engaged in personal self-reflection and growth, and doing it together and with an invitation to co-create." Connecting and co-creating with others were at the heart of her growth edge — and of her developmental movements — with the co-inquiry. As she shared with me in our final interview,

Initially, when I came in and I was thinking, you know, my growth edge is around my leadership and how to step more fully into it... And I didn't even know what I meant by stepping more fully into it. And I think initially there was a sense of there are things that I need to do differently, but what's definitely shifted for me in this time, and it's been really helpful to make the shift, [...] I've come to an understanding and an inner felt-sense that it's much less to do with what action steps I need to take and it's much more to do with the being part.

With "the being part," Lisbeth meant her "form of mind" and her 
movement of awareness from self as a leader to a "what do we create together?" So much more of a connectedness and a leadership through and with others versus as a leader "what's next for my growth?” So, that's been a very big, big shift. And probably the biggest shift has been in my awareness and in terms of my behaviors. Because that awareness has shifted, I think it's affected the way I think about my clients who are leaders and it's just in the sense that I'm listening to them and observing them very differently.

Lisbeth assiduously engaged in co-creation and co-leadership throughout the coinquiry: her ability to relate to the heart of others' sharing, and to build on that mutuality in the moment was extremely helpful to nurture connection and deepen the inquiry in the group; and her frequent clarifying questions about my prompts and her willingness to dive into the exploration first were crucial for the flow of our work. Lisbeth was also the only co-inquirer who systematically shared the fruit of her personal inquiry by posting her post-meeting reflections on the shared Google Drive throughout the process.

Lisbeth's new orientation toward co-creation in leadership also brought her to invite more feedback, and to listen more fully to it, as a way to co-create with others. I have noticed that rather than just wanting to expand everything on my own [...] there really is a sense of seeking out and desiring input from others too, to grow it even more. So that's been, I have noticed that and I'm hoping that that will keep growing.

We know from the developmental literature that genuine openness to feedback becomes real only at the Achiever/Self-determining level (Cook-Greuter, 2013)—which was experienced in our work by Chase, in his inquiry around accepting feedback — and 
that at the post-conventional stages feedback is intentionally sought as an opportunity to unveil blind spots and grow self, others and systems. At the end of the co-inquiry, Logan shared with me that she would have loved to receive challenging feedback within the coinquiry, which, because of individual, collective, and ecological factors and dynamics, did not happen.

During the co-inquiry months, Lisbeth had the opportunity to enroll in a developmental coaching training, which she decided to take. On the basis of that experience, together with the work with the co-inquiry, she acknowledged that in her coaching and in her other relationships she had come to use much more of a developmental lens [...]. I think the developmental lens was always in the background, but [this work has] made it very much in the foreground. And so, I'm definitely alive to where clients are developmentally and then just being mindful of, of leaning with them into where they want to go, as opposed to pushing, you know, out of one developmental phase and into another. That allowed Lisbeth to develop a heightened sensitivity to her clients and to what they were capable of and ready for, developmentally:

I think that what I've learned about myself as a coach is that I am really comfortable holding, you know, paradoxical things and sitting with not knowing, and just the important reminder that not everybody is as comfortable with that.

The purposeful company of the co-inquirers was the most beneficial aspect of the co-inquiry at the conventional as well at the post-conventional level. If the presence of others' doing the work was liberating and instructive for the co-inquirers at the Achiever/Self-determining stage — fostering self-acceptance, self-confidence, and self- 
authorship, and offering models of how to navigate complexity, at the post-conventional level the motivational aspect of engaging in hard work together was enriched by what looked like a deeper awareness of the mirroring occurring between co-inquirers. As an example, Lisbeth built on my sharing around frustration (illustrated in the next section) in this way:

when you were speaking to your frustrations sometimes about how, you know, perhaps a desire for things to be deeper or go differently, you know, that was really helpful for me, too. I found the expression of the frustration helpful. And it was in its own way speaking to some of my own inner frustration, mostly with myself.

Our mutuality fostered new awareness and continued self-inquiry for Lisbeth, and by sharing that with me, she supported our mutual inquiry and, more broadly, our work of expansion of consciousness. Throughout the process, Lisbeth expressed other-centered and world-centered (in addition to self-centered) motivations as decisive in terms of her sustained engagement in the co-inquiry.

\section{Movements on my personal trajectory.}

I conclude this section by offering an illustration of my personal movements throughout the co-inquiry. My intentions, my commitments, as well as my different roles and responsibilities within the project complexified and enriched my experience in many ways. This study led me to explore new territories within myself, as a person in relation with others, and with my environment, and particularly as the facilitator of a developmental community of inquiry in the midst of chaos. I describe my movements 
through the main developmental themes that emerged in my experience of living inquiry, at my personal growth edge.

\section{Living awareness of oneness.}

The co-inquiry helped me to clarify, put words and "live" the growth edge I brought into our work. I started with the hazy intention to "live 'more' from my heart and my body." I was looking for ways to temper my familiar "being caught in my mind," to more generatively relate with the established routines of my ego, and, more broadly, to honor the new integration that I was sensing in the process of reconstruction of myself after the profound deconstruction(s) of motherhood and grief in the previous three years. I was pursuing the alignment and harmonization of my mind, heart, body and soul as a way of life, and I was committed to honoring the felt-sensed knowing of interconnectedness and oneness (with others, with different dimensions of life, with Source), that had emerged for me in recent years. I wanted to embody more fully that "connected" way of being, potentially in every moment, and become an invitation for others into the awareness of our being whole and one. It was a way for me to be responsible for the whole, to contribute to its evolution, participating in the awakening to our true nature and fundamental unity.

That quest for a better integration and alignment among territories of experience brought me to explore beautiful landscapes through different ways of knowing. If at the beginning of the co-inquiry I was not able to clearly articulate with words what I perceived as my growth edge, I had very clear experiences of what that could imply in practice. After the very first meeting of the group, I felt overwhelmed with gratitude for my co-inquirers' presence and dedication to growing together, and at the same time, my 
mind started a familiar process of self-criticism — my English was not fluid enough, my explanations could have been crisper, etc. Until, in meditation, I had the clear sense of acceptance of everything I had said/done as it was, as an integral part of the experience of our group. My mind and my ego, with their familiar self-criticism, had stolen my attention from my commitment, as a person and a researcher, to compassionately and curiously stay with whatever emerged without judging, and without resistance. In meditation, I reconnected with a way of "just being with" my experience. I knew that my mind could not accept unconditionally, but my heart could. When I calmed the mind chattering enough to be able to listen to my heart, I clearly saw that everything was organic, exactly as it was, and I could pursue the exploration with open mind, heart, and will (Scharmer, 2009, 2018). My meditations, where I could open to a trans-cognitive way of knowing and to the infinite possibilities of the Field, became an important part of my personal inquiry throughout the process, and offered precious support in my exploration of my growth edge.

My attunement to my heart, body, and the Field allowed me to live another unexpected experience after our first group meeting. In the spaciousness opened in meditation, I became aware of an overwhelming sadness, and I had the clear sensing that that sadness was not (all) mine, that I was transubjectively (Blackstone, 2006) - i.e., through direct, unmediated attunement to our unitive, shared consciousness - contacting, receiving, holding sadness on behalf of others. I intuitively felt connected with Logan at that moment, and I recalled she evoked the difficulty of a particular separation passage as a mother. Was her situation resonating deeply with my own grief as a mother? Was I experiencing the sadness she was not allowing herself to fully feel? Was I carrying 
sadness and grief for the group as a whole? I chose not to share this experience with the group, not feeling intimate enough with them (or with Logan), and not trusting my capacity for transubjective experience and learning enough to convey that in a generative way. The experience of feeling and sensing with and for others, of accessing a deeper dimension of our intersubjectivity, was not new for me, and yet at that point it shed new light on our fundamental oneness, and how our essential connection can become an emotional and energetic vector of intelligence or knowing, when we are open to receive those signals. Throughout the process, I was often struck by the inner experience of essential connection, of "being one another" with the group members beyond their individual uniqueness, as I wrote multiple times in my journal, and by the waves of emotions I could receive and hold on behalf of the group, whether in its presence or not. Experiencing oneness in these ways led me, halfway through the co-inquiry, to write down the following questions: "What experiences are mine, and what are others'? Is that even a relevant question, in the perspective of oneness?"

Yet, after the second meeting, I contacted within myself some form of resistance to connection. After the experience of deep, human, emotional connection with the three other co-inquirers through the sharing of our developmental autobiographies, I sensed there was an infinitesimal part of me that had remained untouched, cold. I needed to explore that, for myself and for the other members of the group - who contributed to stir and steer my inner work in that direction. One of my mentors invited me to work with the idea of harmonizing mind, heart and body at the level of my lived, embodied experience - to know and understand that through my heart, my body, my connection with the Field. I was used to that kind of exploration, which I had integrated in my 
personal practices and my coaching from my experience as a hypnotherapist, therefore it was relatively easy for me to accept the invitation. It was a transformative experience where I was able to sense and somatically overcome a grey barrier preventing my heart to fully radiate light. Continuing my inquiry after that felt and sensed experience, aspects of my life coming from my childhood emerged into my consciousness as woven into that grey, cold barrier I had sensed. At the same time, the light that I perceived as radiating through my heart from Source itself dissolved the need for distance and protection that the barrier was standing for.

Those lived experiences of connection with my heart and my body's knowing as portals to the Field, supported my commitment to being, as I wrote in my journal on March 9, 2020, "the wave that is not separate from the ocean," and an invitation to that awareness of unity for others. I felt increasingly responsible to hold the co-inquiry's intersubjective space in the awareness of its transubjective dimension. I started by sharing with the group about my somatic experience of overcoming barriers to connection, and throughout the co-inquiry it became more and more comfortable for me to leverage my intuitions and felt-sensed experiences in ways that could contribute to our work. That brought me to more confidently follow my insights from the Field, lead the group in explorations through different ways of knowing (meditations, somatic experiences, creative expression), and voice bits of every single one of my discoveries throughout the process as a way to share the gifts I received from our work-for them to continue to inspire, nourish, and enrich our inquiries. As an example, later in the process, just before our sixth meeting, I felt a current of anxiety coming transubjectively from the group, and my intuition, supported by echoes from conversations and notes shared by the co- 
inquirers, was that it could be related to the study's outcomes and the "performance" of (each member of) the group. I then opened the sixth meeting sharing what I had sensed, and clarifying that each of our contributions to the co-inquiry was valid and worthy precisely as it was and for what it was. I had the impression that helped immensely to oil our co-creation in that session.

Also, the increased felt-sensed, energetic, spiritual connection with others, and trust in the unfolding of our process - as of life-led me to write down realizations about our co-creation such as: "I don't have to 'figure it out' alone," or "I don't have to 'fill in,' to 'carry' everything myself." My ever-growing trust in the group and in the co-created nature of our work allowed me to more steadily hold the space for the co-inquirers in their "coming and going." I felt that my authority in the group was primarily substantiated by my holding that space for whoever was there to join in the work, keeping the inquiry alive, and infusing a sense of psychological safety, energetic/essential belonging and compassion, through the ambient challenges.

As a coach, after my experiences with somatically contacting and overcoming what I had perceived as a barrier to connection, and my sharing that with the group, I felt a renewed commitment to supporting the exploration of my clients' inner knowing through the attunement to their emotions, their physical and energetic sensations as portals to their true self (Winnicott, 1965), and to the Field of infinite possibilities. I realized how, in spite of my training and my personal practice with that kind of awareness-based work, I somehow did not fully leverage it with my clients, with the pretext it was too "far-out" for the organizational world. The co-inquiry contributed to deepen my awareness of oneness in a way that I could not work but in that oneness-based 
way anymore. At that time, with my clients, it felt like a way to let our awareness as Source do the coaching. And I experienced being connected with my clients at a greater degree of depth, of humanity. On March 13, 2020, I wrote in my journal: "I was surprised by a beautiful sense of aliveness in contact with [the people I was coaching at the time] and in our work." I attributed that to my deeper integration of our being one another and one with the whole, at the energetic and spiritual level, which supported my confidence and skillfulness in living by that awareness. It actually felt more natural for me to leverage that dimension of consciousness as appropriate (and in an appropriate language) with others who might or might not share my unitive worldview.

My increasing and intensifying experiences of oneness led me to amplify my (self-)compassion and (self-)love as the connecting agent of our essential nature. I could sense moments when my presence to others, as a coach and in my life, was informed by a renewed, deepened compassion. On March 30, 2020, I noted in my journal that I had experienced my own presence as "coming from love, from wholeness, and not from the effort of being/doing better with my own loving, compassionate responses." That was another beautiful experience of "living from my heart."

\section{Deepening integration.}

I continued to work on heartfelt and embodied attunement (to myself, others, and wholeness) throughout the co-inquiry, with the awareness that my capacity of "living as Source" (i.e., from the awareness of oneness with the whole) was very fragile, especially in our challenging context.

The sense of disconnection I experienced from myself and others at the fifth meeting, during my sharing about the MAP assessment, led me to engage in a deep, 
somber and enlightening inquiry. It was a very brief moment of disconnection in the midst of endless gratitude for my co-inquirers and sincere joy felt in the work. It all originated from a moment of awareness when I perceived a subtle, yet present sense of frustration in me. In that moment, I was alert enough to resist the fleeting temptation to project that frustration onto the group, to own it and swallow it, and to timely invite the group to move forward by focusing on what was of value in our work. However, in that moment I was not equipped enough to recognize the value of my subtle frustration and offer my experience with it in service of our work on the spot. It took me some time to receive the gifts from that experience and be able to share their essence with the group. My frustration was associated with the fact that I was not able to communicate with others in a resonant way about my meaning-making, which was extremely important for me in my commitment to growing together. Inquiring into that experience of frustration about the incongruence among my territories of experience led me to an inner chasm, exposed by the limitations induced in our life by the pandemic, reflecting on the ecosystem of the co-inquiry, and, most profoundly, created by the passing of one of my twins eight days after they were born, almost four years earlier. Through self-inquiry and meditations, and through meaningful conversations with my mentors, I realized that the experience that I had lived with the group, i.e., the difficulty to generatively deal with my own frustration in service of all, invited me to further integrate the frustration of being a mom of two sons and grieving the passing of one of them.

On May 16, 2020, I sent an email to one of my mentors to thank him for his precious help in my process of realization and integration. Among the lines of that email: 
I've been reconnecting with the depth of grief, and the sadness of expectations not being met, and I realized how the co-inquiry group is somehow bringing me to revisit the emotional and somatic experience of my twins being born and one of them passing eight days later. That was an extreme experience of unbounded joy, gratitude, and wholeness, and abysmal grief and absence.

This morning in my meditation I experienced an infinite wave of (self-) compassion, of love.

That was a beautiful moment in my quest for living from oneness [...] and a precious resource in my intention to be present to, and show up in full colors, all the while holding the color of absencelthe absence of colors, for myself and as an invitation to others.

That was a significant moment on my personal path of integration, which expanded my capacity to be present to multiple parts of myself and co-create with them in service of personal, mutual and collective development. It was another step for me towards living more wholly from my heart, honoring its many contrasting colors as part of our shared wholeness - another significant discovery at my growth edge. Full of gratitude, I immediately felt called to circle that back and share the gifts of that experience with the co-inquiry group.

My MAP assessment offered me other precious gifts of integration. The assessment was another illuminating process for me, in which I felt recognized in my meaning-making, heard in my need to communicate it, and supported in my current developmental trajectory. What stood out for me from the MAP description of my Construct-aware action-logic were the attention to constructs and meta-constructs 
towards an all-embracing witnessing of all that is; the seeking of personal and spiritual transformation and to support others in their life quest; the awareness of continuous selfredefinition and change as part of life unfolding; the possibility of embracing the here and now in a way that liberates from constraints and opens possibilities.

My MAP report included an inspiring koan that I found deeply meaningful in that phase of my life, and of the co-inquiry: "How might I both endeavor to be more connected to myself and others all the while I see that I am always, already connected?" The koan invited me to pursue the process of re-integration of different parts of myself, including my previously integrated action-logics, as a way to be more whole, and to wholly connect with others honoring my inner, lived and living knowing of oneness.

The ever-complexifying context of the co-inquiry offered me extraordinary opportunities to realize how I needed to mindfully and heartfully support the integration of aspects of myself, from the earlier developmental stages, that I had left neglected or disowned. The ongoing, deepening integration of grief in my life, described earlier, is an important example. Also, with the other co-inquirers, I was able to detect my falling back and the resurgence of my need for control in the growing instability and uncertainty of our times. Meeting that vulnerably and compassionately helped me to find and sustain more generative ways of living in complexity, including increasing my time for meditation, movement, and in nature. I found the connection with nature so regenerating that I wanted to extend the invitation to the co-inquirers. At our first meeting, we had expressed the intention to meet outdoors sometimes, which could not happen due to the need for social distancing during the pandemic. However, I invited nature into our work 
suggesting that we bring an object from our environment to our meetings, and evoking natural elements/images as symbolic of our inner state.

The group also helped me reconnect with my Achiever/Self-determining, actionoriented side, and that led to a broader reconnection with my creative power, which I had somehow given up after the passing of my son, sacrificed to the sense of the unpredictability and uncontrollability of life. Within my increased capacity of surrendering and attunement to the unfolding of life, halfway through the co-inquiry, I sensed and shared with the group that I could more clearly set intentions "again" and engage in a creative relation with life. That resulted in multiple ideas and projects to continue to "grow together," and for the actionability of this co-inquiry beyond its boundaries, that I started to nurture at that time.

At our final co-inquiry meeting, when we worked with archetypal cards, the card that chose me allowed me to pursue another kind of integration. It was a beautiful card that resonated with me in many ways and particularly evoked for me the sense of, and the commitment to, bringing what is hidden as a gift to the world, as a work of love honoring our wholeness and unity. And, there was a word written on the card (which was part of a tarot system): futility. At first, when I read that, I felt the impulse of rejection, then, staying with it, I progressively came to befriend it, and, as I shared with the group, to own my own way of discarding things sometimes, because I believe they can be futile, or they can be seen as futile. [...] And it's really a reminder that everything has meaning [...] and it's worth exploring and sharing.

This was another gift I received "from the unexpected," to quote one of my mentors, throughout the co-inquiry experience. 


\section{Cultivating simplicity.}

Another invitation I received from the MAP assessment was to welcome simplicity within complexity, noting how I tended to express my most analytical, complex side. The pandemic highlighting and altering very simple, taken for granted aspects of our human experience, and my witnessing that not only in my life but also in the life of the co-inquirers and beyond, brought me to take a more practical, down to earth, and less abstract look at our human affairs. I was moved by the richness of humanity that I could perceive in the simplicity of playing outside with my son, or in connection with my family and friends living their own particular experience of the same global pandemic from all over the world. That also brought my many privileges to the forefront, which resonated within the group, enhancing our gratitude and our sense of commitment to fructify those in service of our communities.

That attention to the more concrete aspects of life became more and more meaningful as I started to approach every circumstance and every situation as specific manifestations of Source unfolding in every here and now. As I was cultivating a fresh approach to every moment, I was gifted with many meaningful synchronicities, and my own life (and the interweaving of all its aspects) appeared to be a fluid dance with Life as the flow of things itself. When I was preparing my sharing around the MAP assessment for the meeting with Lisbeth and Les on May 27, 2020, I was struck by the images I was encountering on my computer's dynamic screensavers. They were perfect illustrations of the thoughts/feelings/sensations and intentions I wanted to convey. I ended up building a presentation for the meeting based on those images. Figure 8 shows an excerpt of that presentation. 


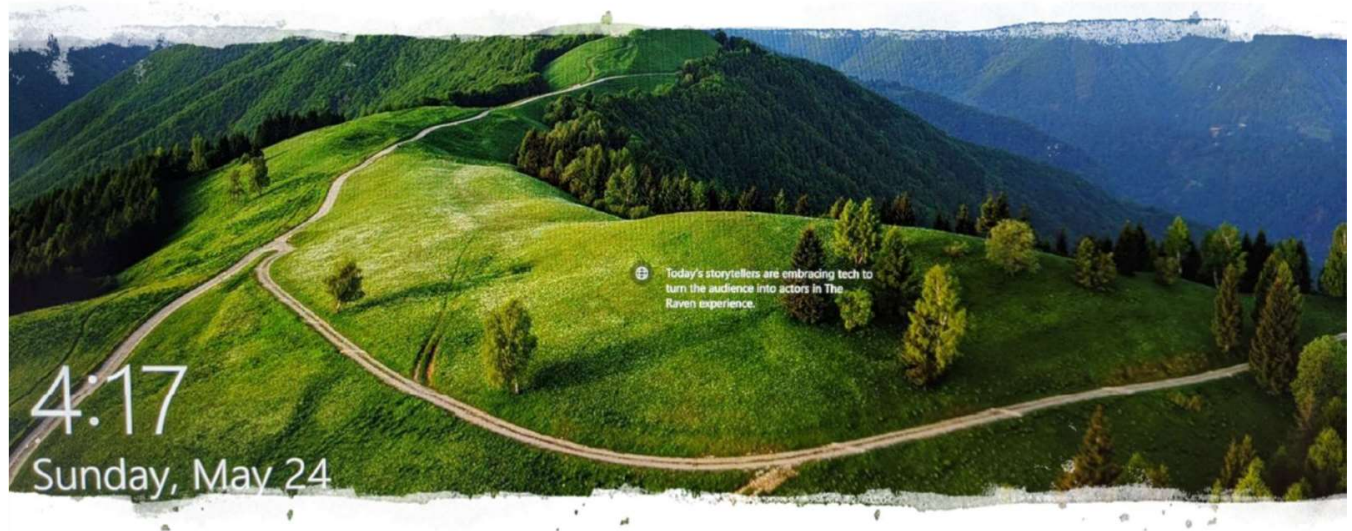

Connecting and evolving through the simplicity (and the richness) of being human

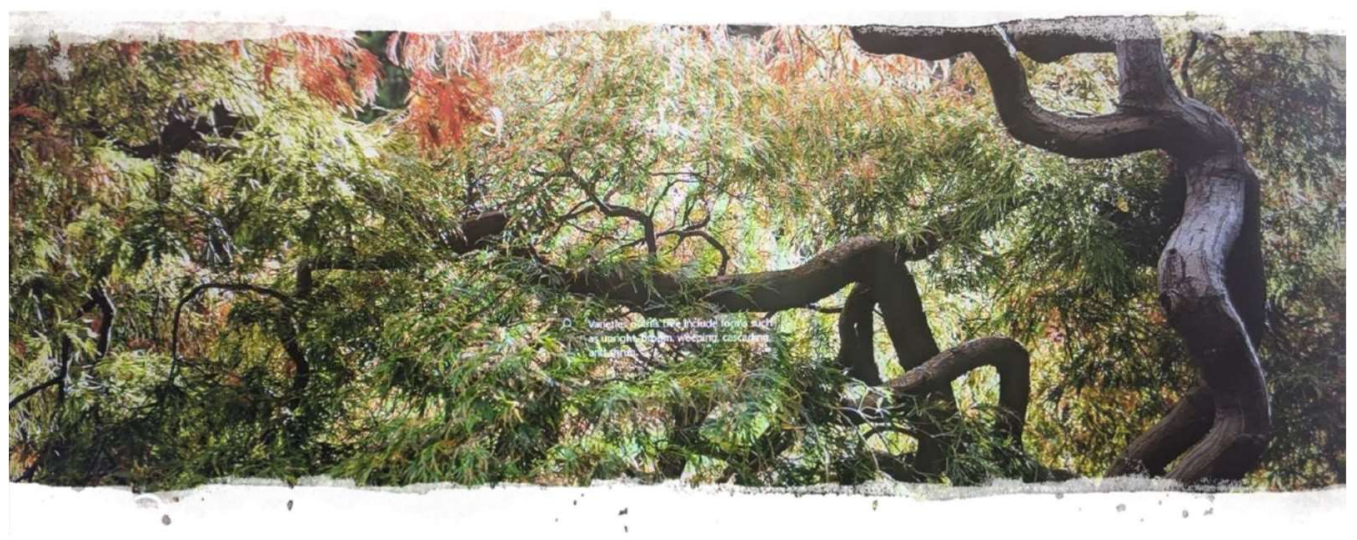

Growing naturally through the freshness in each moment

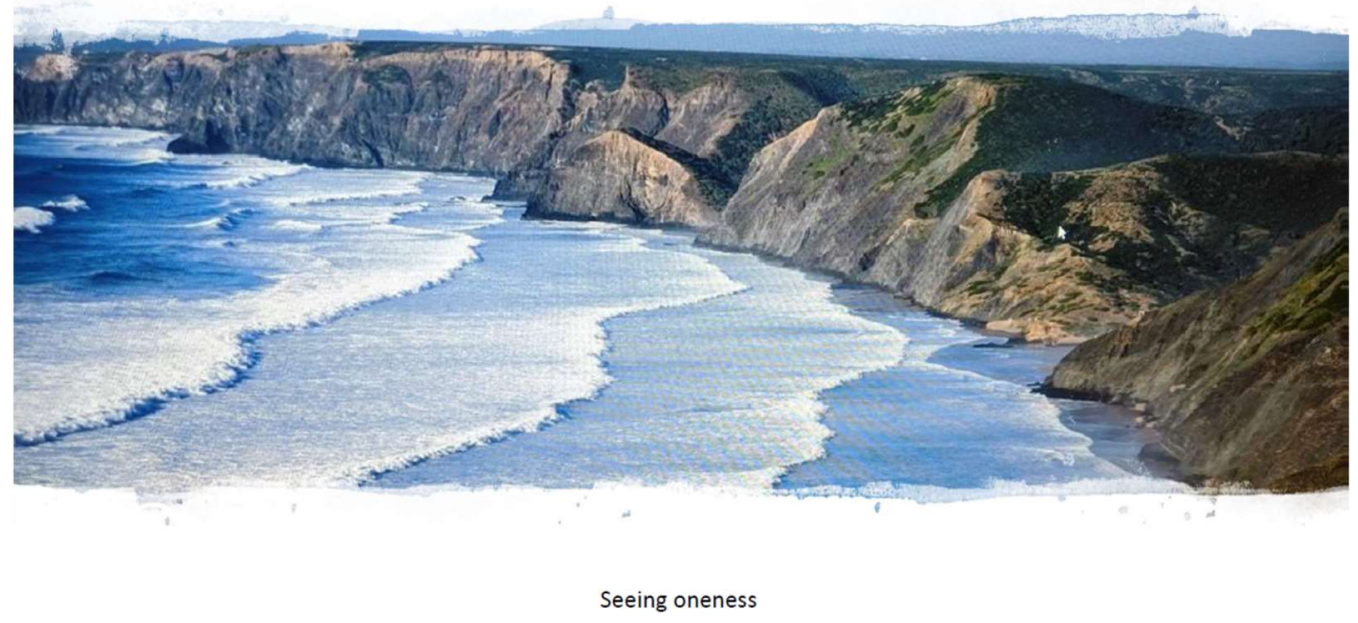

Figure 8. Excerpt from my presentation of my MAP assessment debrief built through synchronicities. 
Using images to convey my meaning-making of my MAP resulted in a very different and more resonant experience than the first debriefing with the rest of the group, when I got stuck in a heady, wordy space.

The creative turn we co-inquirers impressed on our work together actually corresponded to my increased and increasingly spontaneous use of images, colors, and poetry in my communications, in my ongoing personal inquiry, and in my coaching. That allowed for complexity of concepts and experience to be captured with simplicity, and to become communicable to others in meaningful and spacious ways. The question of the language to be found and used to invite others (as many and diverse as possible) to expand consciousness, that we shared among co-inquirers, found a beautiful solution in the symbolic language of creativity — unmediated, open, and inclusive. What I came to realize was that the language question could dis-solve when our presence, the very quality of our being with others, became an invitation to others, beyond any language.

Towards the end of the co-inquiry, I observed I was less and less focused on the detailed preparation of my introductions, prompts and words to use with the group, and more centered on my being attuned to myself, the group and the Field as a way to contribute to hold a generative space for our unfolding, moment-to-moment. That translated into what I could define as an inspired, much simpler way of designing our sessions, where inputs came directly from intuitions and insights, through my own consciousness, from the Field. As I was preparing the last meetings, for example, I felt called to strengthen the connection to my own calling in life, and to the ways it responded to the exasperated needs of the world, then to shadow work, and it felt natural to extend those invitations to the group. Working in that way was an extraordinary experience of 
alignment among territories of experience, from intentions to strategies, practices and outcomes, giving life to meaningful and regenerating work within the group.

\section{Dancing with polarities.}

Another invitation from my MAP assessment was to live from the ground of unified polarities. That made great sense to me in the perspective of wholeness, and of befriending my shadows. The co-inquiry offered me a golden opportunity to experience that vividly in correspondence with our work around systemic racism. My dreams had been marked by profound anger in the days after the murder of George Floyd and the uprising of the movement for Black lives and racial equality. It was an alert sign for me who rarely experienced that feeling. In my waking time, I was aware of my broken heart, but could not perceive anger at my heart horizon. I knew at that point that I/we needed to work with our shadows as part of our effort to mend the systemic brokenness. I proposed that work at our following, seventh and last meeting. The profound shadow work that emerged for me from that work with the group continued for days, as I contacted exclusion, and the ways I had caused that in my life, from deep within. That left me with an infinite (self-)compassion and the sense of being able to navigate a little more fluidly the continuum of inclusion and exclusion, to understand them in their universal dancing nature. I wrote these words in my journal: "when approached from Source, from love, those shadows become gates to inclusion, compassion, oneness." I felt I had had another lived insight into unity: those primitive impulses and reactions were part of the wholeness that I was/we were. It was another step toward the ability to navigate those in myself and others in the world. That freed my commitment to more actively engage for equality, starting with opening and sustaining conversations around the themes of racism, 
exclusion and ostracization, and with supporting the inner work necessary to allow the richest experience of life to every being and every part of our wholeness - including shining light on what we call shadow.

\section{Different roles finding common flow.}

The co-inquiry space provided the opportunity for me to continue the process of integration in my new life and worldview after the disruptive experiences that had prompted them, in a context itself filled with disruptions. My trajectory through the study impacted my whole being and the different roles I had in the co-inquiry and beyond. In the first part of our series of meetings I was very aware of my different roles as a leader, co-leader, primary researcher, co-researcher and coach in the co-inquiry. My dedication to the co-inquiry, its rigor and aliveness, and its rippling developmental potential, together with the authority to lead the process that had been conferred by the group, allowed me to hold my different roles, while juggling their different agendas, for the first half of our series of meeting. Towards the end of the co-inquiry, concurrently with a deepening of my own inquiry and with my growing reliance on my inner knowing, I noted how I was enacting my different roles in a more fluid way, engaging with what was present to my awareness in every moment. I felt freer (from my own constructs around my different roles) to support the co-creation of our inquiry by mobilizing multiple aspects and assets of myself as well as of our wholeness. Similarly to how, in my coaching, I enjoyed my being a conduit for awareness to actually "do" the coaching, in the co-inquiry, my leadership (as my participation) became infused with the sense of being an instrument of our oneness and its unfolding - through my intentions and attention, and my openness to what would come as guidance from Source in any 
situation. I considered that kind of "being an instrument" one of my most important responsibilities, and delights, in our collective developmental endeavor.

To conclude, what I presented here as "my trajectory" is actually a relational, cocreated journey I owe to all my eco-systems, and particularly to the presence and the engagement of my co-inquirers; to the care and the guidance of my mentors who supported me in the many moments when I felt in over my head and heart, inviting me to "listen in"; to our ever-unfolding wholeness.

\section{Renewed Awareness Across Developmental Stages: The Expansion of Consciousness is Relational, Eco-Logical, and Ever-Unfolding}

Reflecting on our experience as expanding our consciousness, Ted shared the following with me:

I guess when I think about expanding consciousness, I think when your consciousness is maybe expanding a great deal, you're becoming more and more aware of the shared experience we have as humanity. And so it feels like that process cannot be done alone. So, I was reminded, you know, and I was pretty committed to that philosophical claim, but just reminded experientially again through this group that we really do need each other to expand consciousness. [...] And we need each other in settings where intention is set on a deep level. The awareness of how our growing was relational was supported in us coinquirers by the increased sense of "how alike we all are," in Ted's words, that "we are all intimately connected," in Lisbeth's language, that "we are all the same," in Chase's, or "we are one," in my own. The global experience of the pandemic heightened our sense of connection and oneness in spite of our different circumstances, which in turn 
strengthened our commitment to contribute to the whole. In my email to the group of March 25, 2020, in the first month of the shelter-in-place in California, I wrote: "I believe that with our inquiry work we are contributing to the expansion of consciousness that is currently called for on a global scale. And I am filled with gratitude."

I knew from the start, when we shared our intentions with the co-inquiry, that Lisbeth was moved by this same commitment reaching beyond ourselves. In our individual interview at the end of our experience she expressed:

I think that in order for the consciousness of humankind and of the planet to be raised or expanded, I really do believe that it takes an honest self-examination, self-awareness and constantly seeking one's edges. But not, not in pursuit of, you know, only self-transformation, but with an intention of being able to contribute to the whole, to the bigger piece, to the bigger parts that are way beyond this dimension. And I know you, you think in similar ways to that, [...] but certainly for me it was, the doing it together had a feeling, like a felt energetic feeling that was a reminder of how we impact one another and the world and all living beings through how we engage and how we focus and train our energy. So, it was a wonderful reminder about how we are all contributing into this consciousness. And so, if we're doing it mindfully, no matter that we think we're very small, we're all contributing to the larger part.

It was clear to us that the same way our environment affects us and our development, which was certainly evident in the months of the co-inquiry, we can impact our eco-system. Also, the awareness of the spiritual dimension of life and of our oneness emerged as a potent motive force for engagement in the co-inquiry as a self-, other- and 
world-centric endeavor. Attunement to this awareness appeared as an organic way to intend and allow the unfolding of our developmental experience.

Most of us expressed the sense that the expansion of consciousness is infinite and somehow ineffable, constantly evolving with-in our environment. We experienced how hard it was to pinpoint a specific growth edge, and even to track its evolution, in its multifaceted, kaleidoscopic, living nature. We confirmed that development implies endless, constant work, breakthroughs and breakdowns, intention and attention. At the same time, as Ted highlighted in our final, individual interview, once an intention is set, "sometimes there's expansion happening outside of our awareness." The awareness of growth unfolding behind the scenes of our subjective consciousness could have been a generative theme to explore together to pursue the co-inquiry. That would have added irons in the fire of our deliberate, developmental "purposeful allowing."

In the following chapter, I distill and discuss the learnings from the developmental trajectories we co-inquirers designed through the co-inquiry. Such harvesting particularly illuminates the co-inquiry's potential in terms of individual and collective growth as instruments supporting growth. 


\section{CHAPTER FIVE}

\section{HARVESTING}

Since the conception of the co-inquiry, I was moved and inspired by the knowing that this was important work for us co-inquirers and for the whole, through the expansion of our consciousness. In this spirit, I share in this chapter the harvest from the co-inquiry. I discuss our findings, co-created through the arcs of our experience, in the perspective of developmental theories and practices. The understanding that I share here is the fruit of a meaning-making process that started during the series of meetings with my co-inquirers, supported by my conversations with my mentors, and ended around harvest moon, after a few months of growing with-in me in dialogue with my peers, my environment, and the giants' shoulders on which I was (and am) standing.

I discuss the knowledge we co-created by reflecting upon the original co-inquiry guiding questions, which contemplate the potential of our work in terms of both individual and collective development:

1. How can we, as a group of leadership coaches, use action inquiry to enhance our capacities and skills for developmental coaching?

2. How can the work that we do together support the evolution of our current meaning-making as assessed through the Leadership Maturity Assessment Profile (MAP)?

3. How can we develop mutual and collective capacity to support development in ourselves and each other?

As shown in the previous chapter, the co-inquiry unfolding and our development through it as co-inquirers were intimately tied to the disruptions of our ecology. The co- 
inquiry started from the awareness that we, as coaches supporting leadership development, needed to become more capable and skillful at thriving individually and collectively through complexity, and our environment provided us with an extraordinarily complex and chaotic terrain to experiment with. Indeed, the findings of the co-inquiry constitute experiential learnings about the potential contributions of action inquiry to the expansion of consciousness across disruptions.

I start by discussing the learnings from the co-inquiry in terms of scaffolding for individual development.

\section{Growing as Instruments Supporting Growth}

The co-inquiry's guiding questions 1 and 2 address the potential of action inquiry for the expansion of our individual capacities and skills:

1 How can we, as a group of leadership coaches, use action inquiry to enhance our capacities and skills for developmental coaching?

2 How can the work that we do together support the evolution of our current meaning-making as assessed through the Leadership Maturity Assessment Profile (MAP)?

These two questions inspired a threefold learning: our work had the potential to support our growth simultaneously as:

- whole, integrated selves,

- $\quad$ selves in relationship with others, and as "invitations" to growth,

- part of the whole.

This is a conceptualization, and as such an artificial categorization, of a broader sense of becoming "a better person," in Sam's words, that encompassed those three facets 
simultaneously, and impacted multiple areas of our life. As we noted during the coinquiry, our growth as coaches corresponded to our growth as persons (who were coaches), in that our self was the main instrument in our work. Indeed, what we coinquirers experienced as instances of progress throughout the process was part of our growth as instruments for resilience and development through complexity—for ourselves, others (including our clients), and our systems.

\section{Growing as Whole Self}

The co-inquiry supported our self-awareness and our capacity to orchestrate different aspects of ourselves as an integrated, whole being. That happened for us essentially through our:

- being with oneself,

- fostering integration,

- embodying and enacting "more of who we are."

\section{Being with oneself.}

Being, first and foremost, and as foundational to knowing and doing, was among the main features of the co-inquiry in our context where the turbulence of our lives was exasperated in different ways. Simply being present to ourselves, checking in with ourselves, processing "what was there" for us in the different phases of our journey was key in our evolving through the complexity of our work as well as of our times. We all acknowledged how the "heavy lifting" of our inner processing was necessary to engage in mindful co-inquiry. As McCallum \& Nicolaides (2015) note, "without attention to that interior sense of 'how I am' it is easy to lose direction, and to miss the opportunity to 
name what is occurring in order to make it discussible, or otherwise intervene in a way that is both timely and open for new learning" (p. 646).

At the same time, being intimate with oneself was difficult in our challenging context. Les felt too "inundated" to continue in the co-inquiry. Others had to miss meetings because feeling "under the weather" or not able to be (fully) present. Distraction intruded in on a few of our meetings. Our "doing" seemed to be getting in the way of our "being" at times, to the point that we set specific intentions to deliberately cultivate "just being," in our meetings and in the intervals, and to explore the difference that made in our life.

A symptom of the complexity of engaging in inner work could be observed in the tension between Logan's expressed desire to go deeper in self-exploration, her awareness that the world was calling us, through the many disruptions we were facing, to "figure [ourselves] out a bit as humans," and the inconsistency of her own engagement in the work. I/we could have noticed an inkling of that ambivalence in Logan's comment when, noticing the limited responses to the post-meeting questions, I opened the inquiry about that with the group. Alluding to one of the questions (addressing our observations about the group), Logan shared

It's not a bad thing, it's just I'm, [...] I'm thinking if, I think what I notice about the group right now, it's like, okay, well, we were commenting on the rain and on the technology. Like it feels like it would be a little flat. Mmm. But maybe not. I mean, maybe I would just need to trust it and get into it and see what may come up.

That could have been interpreted as an unconscious projection of her own challenges with the work onto a feature of our work (namely the post-meeting 
reflections), or, in Torbert's (2013) words, a sign of “the degree to which we can't imagine in any given present moment why we should observe now ('Nothing interesting's going on right now... and aren't I doing enough anyway?')" (p. 271). Unfortunately, nobody's awareness was ready to gather that, and learn from that, at that early time in our process.

Within the limits of our own (mind-heart-body-soul) availability, we co-inquirers were able to engage in honest and vulnerable self-inquiry throughout the process. In some cases, those personal limits were extended by a sense of mutual, collective, and systemic purpose. We were aware that first person work was essential to keep our mutual and collective inquiry alive. Ted used these words to speak to that: "there's a way you can hide in the Zoom physical sessions themselves and participate in that conversation. But if the deep inquiry is not happening on an individual level, there's something being missed." As shown in chapter IV, it took the growth-mindset of the Achiever/Self-determining action-logic — determined to endure the challenges of the work to improve his/her whole person - and the post-conventional psychological motivations for mutual transformation to sustain the commitment to inquiry in our group.

The process of the meetings, with ample space for checking in and resonating with one another, and the prompts for our work were purposefully conducive to deep presence to oneself. Triple-loop inquiry, occurring "at the level of our being-the volitional will to consciously reshape our intentions, purposes, and motives" (Nicolaides \& McCallum, 2013, p. 254) was indeed at the forefront of our project of expanding consciousness. That grounded our double-loop inquiry around our strategies and mental models as well as our single-loop inquiry around our practices and behaviors to enact 
them-i.e., our inquiry into our knowing and doing (Nicolaides \& McCallum, 2013). Scharmer $(2009,2018)$, in theory U, describes a similar trajectory of development starting from a focus on the inner condition as the source for improved processes and results.

We engaged in triple-loop inquiry by asking ourselves questions such as: "what is my purpose?" or "what is my calling in life?" and "how do I/we serve others and the whole in this personal and planetary moment?" Those questions had a "rebirthing" and engaging impact on each of us, and rippled transformation in the different territories of our experience (Torbert \& Associates, 2004) through our strategies and practices as coaches (e.g., leveraging the nestedness of our ecologies in service of our clients), and leaders (e.g., Chase's opening new, more vulnerable conversations with his team). Some other questions that we explored in the group are highlighted by Nicolaides and McCallum (2013) as conducive to inquiry around being:

Is my quality of presence charged with the right energy to communicate my intention, my commitment, and my desire? [...] Do I sense how I fear loss of control, of my habitual way of knowing or even my identity? Am I willing to stand still in this vulnerability? (p. 254).

We were all, in our specific ways, confronted with these questions through the coinquiry, and derived precious learnings about ourselves from them. For example, the question around my quality of presence and my way of communicating my intentions, commitments, and desires was particularly alive in me, and at the basis of the frustration I experienced as I became aware of the incongruence between my intentions, strategies, practices of communication and outcomes during the first debriefing of the MAP. That 
question, resonating at the heart of my experience of disconnection (described in the previous chapter), allowed invaluable learning to emerge, which I was able to experiment with at the following debriefing.

As for our experience of vulnerability and loss of control, that was amplified by the local and global crisis of the COVID-19 pandemic. We were confronted with the difficulty (and the avoidance) of navigating fear, uncertainty, and other forms of vulnerability in particular when exploring our dominant patterns, our defense mechanisms, and our shadows. That work of humble and honest introspection, which we asked of our clients in coaching, was evidently challenging for us - the coaches - in our context. The co-inquiry provided a safe and nurturing space to support us in that endeavor.

Witnessing others struggling and finding ways through complexity and disruption was an important source of inspiration and self-awareness. As Lisbeth put it at the end of the co-inquiry, during our individual interview,

There was something rather lovely about how other people doing the work were showing me to myself, like, "Yes, I'm on this journey, too, and it takes effort and it takes commitment and it's not necessarily easy and it can be very frustrating, too."

\section{Fostering integration.}

Our being with ourselves was particularly fruitful when it allowed us to discover "more of who we [were]," to embrace and better orchestrate different parts of ourselves such as ways of knowing, action-logics, identities, roles, etc. Indeed, the co-inquiry supported integration in many important ways. 
First of all, by embracing the idea and the practice of plural ways of knowing (Reason \& Bradbury, 2008), we engaged in an inquiry that was self-reflective, felt-sensed and intuited. Deliberately making space for our emotions, our sensations, our intuitions and insights to inform our knowing along with our cognitive, intellectual capacities was certainly an important feature of the co-inquiry. We had the opportunity to experiment with leveraging those multiple, coordinated conduits, and harmonizing their different intelligences. One example was the meditative inquiry we shared, which showed us how self-attunement through listening into our heart and body's messages can be complementary and offer more in-depth insights than our thinking. Many of us coinquirers expressed a sense of limitation we often felt with our usual mode of knowing and being, directed "from above the neck." We were aware that there are things that the mind cannot access or accept, but the heart and the body can (Blackstone, 2012; Prendergast, 2019). As noted in chapter IV, attunement to these plural ways of being and knowing became a way to understand more of ourselves and to support integration. Another way inquiring together into our consciousness helped us grow towards more integrated versions of ourselves was through the individual and collective practice of embracing whatever became available to our awareness. The challenges in our ecologies brought us to experience and attune to multiple, different, contrasting emotions such as grief and gratitude, frustration and commitment, joy and uncertainty, privilege and fear for one's safety, etc. Our inquiry space helped us to process those ambivalences and learn from them about ourselves, broadening our self-perspective, and identifying better informed options for (inter)action. Key for us was meeting and holding "whatever was there" with vulnerability, (self-)compassion and acceptance. We used expressions 
and practices of "relaxing into the distress," "taking that by the hand," and found, in that space of communal embrace, new possibilities to respond to our current challenging situation. Sharing our difficulties in our compassionate, non-judgmental group, where others could resonate with them individually and contain them collectively, made it easier for each of us to meet and hold them. In most cases, that "being met" created the space for us to transcend our difficulties, tensions, and negative emotions, and be transformed by that shift. We practiced with what Scharmer $(2009,2018)$ defines "open mind," suspending judgement and old ways of meaning-making, "open heart," empathizing with others, and "open will," letting go of what was no longer needed and letting new, generative perspectives emerge for us. Our mindful, heartful, fertile space was conducive to integration by inviting us to the "rotation of consciousness" (Baron \& Cayer, 2011, p. 354) implied in seeing our experience and hearing our narratives as objectdisidentifying from them as subject (Kegan, 1982) — and reframing and re-integrating them in a more generative way.

An additional way our work supported integration was through the third person, objective MAP assessment of our developmental center of gravity, which enriched our subjective and mutual making sense of ourselves in our complexity. For all of us, whether met with levels of what Lisbeth defined "healthy skepticism" or with enthusiastic openness, the assessment results became a springboard for integration. In the final interviews that I conducted individually with each co-inquirer, most of them evoked an aspect highlighted in their MAP as an area where they had been covering new ground through the co-inquiry. The movement generally went in the direction of becoming more comfortable, and more agile, with multiple parts of ourselves or previously integrated 
action-logics. For most of us, the MAP was also helpful in our consolidation of our current meaning-making. Among the four types of developmental moves supported by the MAP, namely (1) the consolidation of one's current center of gravity, (2) the transition to a further one, (3) the more radical transformation from one stage to another, and (4) the integration of previously acquired action-logics for fuller enactment of one's current meaning-making, most of us seemed to be in the consolidation phase. Lisbeth was exploring transition to the following stage, and I engaged in the (re-)integration of previous action-logics, beyond consolidation.

In addition to the identification and the embracing of alternative, earlier or later action-logics, the co-inquiry helped some of us, and certainly me, to develop a more integrative approach to our shadows, based on acknowledging and gradual befriending, and more skillful navigation of polarities as equally constitutive of one's reality and repertoire. When we listen into the dark, we cannot but meet shadows. As shown in the previous chapter, if the co-inquiry had the potential to support us in this endeavor, its actualization was contingent on our individual, collective, environmental and developmental factors.

\section{Embodying and enacting "more of who we are."}

Experimenting with different parts of ourselves, and different ways of being, knowing, and doing, became central for us co-inquirers as a way to constantly learn from the experiences with-in the group and, more broadly, our turbulent environment.

Creativity was deliberately cultivated by the co-inquirers as a way to sustain resilience and growth through complexity: finding and creating beauty in hardship was highly beneficial for some of us; summoning elements of our immanent and transcendent 
Field alike (e.g., natural elements, art, symbols, etc.) was important for our self-inquiry, understanding, and ongoing regeneration; and committing to (inter-)acting in different ways than usual (particularly, in Sam's language “bringing ourselves differently to our clients") became a way for us to respond to the disruptions we were witnessing by leveraging diverse facets of ourselves.

Our generativity was rooted in our ample space for being and "presencing" (Scharmer, 2009, 2018)-i.e., simultaneously sensing what was there, and being present to what wanted to emerge in our situations - as well as in our triple-loop inquiry bringing us at the heart of who we were in those situation. Reviving our "re-framing spirit" (Torbert, 2003, p. 164) within the group helped us to generate new strategies, behaviors, and outcomes. Referring to presencing as the capacity to let the old ego-related dynamics go on behalf of "the future as it emerges" (Scharmer, 2009, p.13), Scharmer suggests that people can transcend their developmental limits in the experience of a heightened state of consciousness, when facilitated by technologies inducing deep inquiry in an open-mind, open-heart, and open-will holding environment (Nicolaides \& McCallum, 2014).

Arguably, the space we co-created with our presence and deep, non-judgmental, compassionate listening in the co-inquiry had the characteristics of such a generative "social field" (Scharmer, 2018, p. 10). We certainly experienced a form of presencing, for example, when we engaged in in-depth inquiry through contemplative work around systemic racism and our calling in life, and that let strategies and practices emerge for us to embody and enact our engagement for social justice in the world.

Also, fostering the integration of our different action-logics and connecting with others' action-logics, our work expanded the repertoire we could experiment from. That 
certainly supported us in our resilience through the disruptive months of the co-inquiry, helping us to "dance with life, to flex, adapt, and create as life [kept] surprising us" (Wheatley \& Frieze, 2011, p. 126).

Our co-inquiry, and Torbert's (2003; 2017; Torbert \& Associates, 2004) CDAI perspective extended another invitation to grow within our environment: practicing tripleloop learning and adaptation in action, i.e., finding timely, new alignment between incongruencies in our territories of experience (our intentions, strategies, behaviors and outcomes) in the midst of action (Torbert \& Associates, 2004). Yet, we were not able to fully realize this intention. We were able to leverage triple-loop inquiry and learning based on reflection on past actions and situations through most of the co-inquiry, as attested by the reflections we shared in/between the meetings and in the individual interviews, or by the sense of profound regeneration experienced at the end of some of our meetings. However, we could not document many episodes of expansion of our awareness that allowed us to explicitly change the course of our actions, revise our strategies, methods, and even our intentions on the spot. An example of this timely and generative expansion of awareness was offered by Chase in our final interview, when he shared about his own shift in conversation with a colleague, reported in the previous chapter. Nicolaides and McCallum (2014) write:

Triple-loop awareness occurs in any moment when there is an attention distinct from mental thinking, from physical sensing, and from objects of perception, infusing them all with an immediacy that is at once passionate, dispassionate, and compassionate. (p. 53) 
Triple-loop awareness requires a certain complexity of mind, and dedication and practice, even at later stages of development (Torbert \& Associates, 2004; Nicolaides \& McCallum, 2014). The only experience I could personally associate with that awareness during the co-inquiry was when I became aware of my disconnection from the group, of "actions and effects becom[ing] incongruent with mission and strategy" (Torbert \& Associates, 2004, p. 154) as we were debriefing our MAP assessments, and therefore reoriented my intentions and methods in real time guiding the group to a different kind of work. Yet, if that moment of awareness was infused with immediacy, that was not "at once passionate, dispassionate, and compassionate" (Nicolaides \& McCallum, 2014, p. 53) for me. In fact, that experience was ignited by the awareness of a subtle frustration rising in me, and I was not able to be self-compassionate enough to embrace that vulnerably and offer my own inner processing to the group for collective learning in the moment.

Perhaps our capacity for triple-loop awareness in action was hindered by the disruptions we were experiencing in our lives. Yet the co-inquiry work, with its focus on presence, creative and contemplative ways of knowing, and sustained triple-loop inquiry at the level of being, supported its cultivation in each of us.

\section{Growing as Self in Relationship with Others and as an "Invitation" to Growth}

Engaging in the work of inquiry together allowed us co-inquirers to grow in our capacity of being in relationship with others in a generative way, and, to use a word that circulated abundantly throughout our process, become an "invitation" to grow self and others. In particular, the co-inquiry became a terrain for practicing with:

- being with others, 
- relating our different ways of knowing,

- leveraging mutuality.

The co-inquiry significantly allowed us to experiment with our presence to others, our most important asset to our being an instrument for development as coaches.

\section{Cultivating being with others.}

Being truly present to others is probably one of our biggest growth edges as humans: it is tough to be present to others, when we are still learning how to be present to ourselves. Yet, it is the key for harmonious co-habitation, essential for generative, developmental co-creations, and crucial when these unfold through disruptions (Torbert \& Associates, 2004; Scharmer, 2009, 2013, 2018; Schein, 2013; Wheatley \& Frieze, 2011). By nurturing our "being" in the co-inquiry, we made space for ourselves and others in our consciousness, with attention, compassion, and non-judgmental spaciousness. We co-created the conditions for being genuinely present through our multiple channels: we listened into our respective mental processes, experienced heart-toheart connections, active collaboration, energetic and transubjective resonances with one another. Our second person inquiry, focused on our being with and making meaning of our experience in the environmental chaos, was informed by the intensity of our emotions. We had a vast terrain to practice our open mind, heart, and will (Scharmer, 2009,2018 ) with one another, as we faced difficult aspects of our shared human experience. That actually brought us to listen to the voices of resistance-i.e., the voices of judgment, cynicism, and fear (Scharmer, 2009, 2018) — that normally interfere with our approaching situations with "fresh eyes," with the emotional openness of "we are in this together," and with the courage required by the recognition of not knowing. We were 
obviously living, as a society, unprecedented circumstances we had no map to navigate. Being honest, humble, vulnerable with that experience together in our group allowed us to transcend the voices of resistance, and more fully connect with one another. In this way, our shared space, or social field, became a holding environment inviting those voices to quiet within ourselves, in order to cultivate acceptance, (self-)compassion, and resilience.

As Sam pointed out, the co-inquiry particularly invited us to cultivate our presence to and with one another, and our presencing within the group, remotely, via Zoom: "having the opportunity to be part of this group allowed [us] to practice that," which was challenging in many ways. For some of us, not being physically together constituted a barrier to cognitive, emotional and spiritual connection, and our experience helped us to befriend that obstacle and become more skillful at relating remotely. That was recognized as an important aspect in months where the pandemic was redefining work modalities and leading us toward a dramatically more remote way of coaching.

\section{Relating our different ways of knowing.}

Multiple aspects of ourselves were mobilized in our relationship with the other co-inquiry members throughout the study. Relating to others through our different ways of knowing implied for us engaging one another in different, creative ways, e.g., through images, metaphors, symbols, objects, flowers, art, etc. That was based on our intention to inquire at different levels (intellectually, emotionally, experientially, and spiritually), and on the realization that we could not rely exclusively on words in our inquiry work. Creativity served our making "more of who we were" available to others, fueling the abundance of learning and inspiration that emerged from our mutuality. As an example, 
as illustrated in chapter IV, we found that storytelling supported by images-which crystallized and enriched our narratives — was an extremely effective way of connecting at different levels with one another. After experiencing the degree of connection storytelling generated in our group, we acknowledged that was a precious practice to use in coaching. This is especially true at the beginning of the working relationship with our clients, to get to know and connect with them in depth, and invite their self-awareness around the key moments that led them to their present.

An additional way the co-inquiry invited us to relate our different ways of knowing was through the expression of, and the connection through, our emerging sensemaking in the moment. It was a liberating process for us to become increasingly comfortable with the vulnerability associated with our raw, unpolished sharing. Most of us, highly educated people usually in charge of coaching, consulting or teaching others, were not used to expose that side of ourselves. Not "having it all figured out" was difficult, and extremely generative for our group. Being able to be with others as we were, genuinely, in each moment, and with our half-articulated thoughts and perceptions, was an important factor of our mutual development—and certainly in terms of our capacity for vulnerability, (self-)compassion, and truly relating with one another.

\section{Leveraging mutuality.}

The co-inquiry also offered us the opportunity to leverage our mutuality to become invitations for self- and others' growth. It soon became very clear in the group that each of us had her/his own ways of knowing and we could learn from and experiment with those in our meetings as in our continuing personal inquiry. During our one-to-one interview, Sam shared with me about her 
...deeper respect for the voices that were part of the co-inquiry group... I think with each passing meeting that we had, there was this almost mental recognition of how, like you would show up, right? And how, like your voice would be heard in my, in my spirit and in my brain and same thing for [others]. And there was almost like this consciousness of expectation of that to happen: I'm going to go into the space of learning. And there almost became like this Pavlovian... like when I knew that the co-inquiry group was coming up, this excitement around, okay, now I'm going to go into this space together where I don't have to be the one that coaches, or I don't have to be the one that has to teach [...] but I could just be, and be able to hear and receive and gain insight and wisdom.

We honored our lines of diversity by finding mutual inspiration in our respective ways of making meaning, inquiring, "relaxing into the distress," relating and being an invitation to one another, and even in our different energetic signatures. We could enrich our own repertoires of action-logics, language, practices and creative expressions. In particular, the co-inquirers assessed by Dr. Cook-Greuter at the Achiever/Selfdetermining center of gravity benefited from the work with models of being, knowing and doing from later action-logics (between the Redefining/Self-questioning and the early Alchemist/Construct-aware). And, the co-inquirers assessed at a post-conventional developmental center of gravity could benefit from the action- and results-orientation of those at the edge of the conventional tier. For me, co-inquiring with the Achiever/Selfdetermining action-logic supported the work of integration and better, timelier leveraging of previous action-logics. In this way, the co-inquiry showed us how later does not equate with better, as it might be inferred through the hierarchical representation of the stages in 
the theory (Torbert \& Associates, 2004; Cook-Greuter, 2013). Rather, every stage has precious gifts to offer (Chen, 2019), particularly in interaction with specific environments and circumstances (Cook-Greuter, personal communication, March 6, 2020).

Also, as Lisbeth captured in our final interview, the awareness of our developmental differences informed a renewed attention to—and "dwell[ing] within" (Kegan, 2009, as cited in Bachkirova, 2009, p. 16) —the different action-logics and developmental readiness of our clients (as of our students, colleagues, partners, etc.). That in turn fostered our commitment to, and skillfulness at, building appropriate developmental scaffolding in our practices.

Offering resonance to one another's sharing in our meetings also allowed us to practice with mind-heart-body-soul connection and feedback, essential (particularly in coaching) to capture and build on what is at play in the moment for ourselves, others, and in the shared space.

As I have previously underscored, we also missed numerous opportunities for leveraging mutuality in service of our growth by refraining from recirculating some of our personal learning with the whole group - e.g., sharing about our awareness of mirroring and projections within the group — and from offering "challenging" feedback. However, the pragmatic turn that we collectively took towards the end of the co-inquiry, when we started to design and explore together concrete actions to implement individually in our coaching and our life, suggested that we had the potential to develop, with time, mutual and collective capacity for single-, double-, and triple-loop (Torbert \& Associates, 2004) feedback and learning from our experiences. 


\section{Growing as Part of The Whole}

Expanding our space for being and being in relation with others, the co-inquiry also invited us co-inquirers to make space in our consciousness for the "space between" (Buber, 1981, as cited in Bradbury \& Lichtenstein, 2000, p. 551) and beyond us, i.e., to be present to our immanent and transcendent field, and evolve in co-creation within that space. We had the opportunity to:

- be with our environment,

- nurture unitive consciousness,

- cultivate an organic relationship with growth.

\section{Being with our environment.}

The disruptions we were living brought us to be particularly mindful of what was happening around us, in our different ecologies. We certainly must face our external reality, and closely follow the evolution of the COVID-19 pandemic. The human world successively and increasingly becoming source of uncertainty, fear, grief, despair, outrage, we were drawn to the natural world to find relief, solace, and support in our making meaning of the chaos, in reconnection with the constant unfolding of life and death. The connection with nature was highly generative for us in our understanding (and sharing with each other) of what was happening for us in conjunction with our environment. As an example, Figure 6 (p. 134) shows impressions of how we could see ourselves in, and become one with, the resilient succulents, or the decaying forest soil teeming with life, in the crevasse of social and racial crisis. Those images were extremely evocative, and their symbolic character amplified the process of integration of our own 
and others' responses to the present challenges, and its regenerating power. That experience with the group inspired these lines that I wrote shortly after:

\section{Dark matter sifting}

through, heavily, fragile,

reaching the light, met

en-lightened

fertilizing

new possible.

We learned how situating ourselves in interdependence with nature could be precious in terms of regeneration. As described in chapter IV, spending time in nature, and finding inspiration in the natural cycles of life and death, were ways to nurture our capacity for ongoing (self-)regeneration. Nurturing our connection with our environment and with nature's force of life supported our commitment to offer our contribution in our wounded environment. As coaches, that resulted for us in experimentation with leveraging the "nestedness" of our ecologies, and our embeddedness in our systems, in our work with our clients. Some of us became more comfortable with inviting our clients (and ourselves with them) to explore what was outside from within, and what was inside through the lens of our larger system. We experienced that as a way to honor what was happening in the world, its resonance within us, and their mirroring each other. That invited mindfulness to how, in coaching, dynamics at play in the coach-client relationship, in the parallel process, or in a particular area of our clients' life, can mirror similar patterns in other areas or systems. More broadly, that was a meaningful way to support outer, social change starting from within—evolving our capacity to generatively 
"be with-in" our environment. These experiences highlighted the importance of cultivating the capacity and the skills to "funnel" through systems in a constantly complexifying world.

\section{Nurturing unitive consciousness.}

Together with a more skillful and generative connection with our physical environment, we co-inquirers experienced the potential of our connection with our nonphysical field, with Source, or unbounded awareness, regardless of the names and representations each of us used to describe that. We practiced what Scharmer defines "generative listen[ing] from the Field" (Scharmer, 2018, p. 31) in different ways. Some of them, such as meditative inquiry, were deliberately part of our methods, described in chapter III, and some others, described in chapter IV, emerged spontaneously from our inquiry into our intuitions and insights, into our energetic, spiritual or transubjective perceptions. Those allowed us to know and learn from the Field as the space between and beyond us. According to Blackstone (2006) it is our capacity to attune to nondual, unitive awareness that allows us to have a "qualitative, felt sense of the other person," (p. 34) and being seen and met in our essence. I believe that was fundamental for us to experience intense connection with one another and within the group in spite of our working remotely. Connecting at that essential level also allowed us to transcend our unique differences and feel "one with" others. As Mills et al. (2020) put it: "nondual awareness deepens and refines one's contact with one's surroundings. In this way, nondual awareness is the basis or the ground of both individual wholeness and self-other oneness" (p. 3). 
Reconnecting with our own essential nature as unbounded awareness, (Blackstone, 2006; Chopra \& Kafatos, 2017; Miller \& Cook-Greuter, 1994; Mills et al., 2020; Prendergast, 2019) especially through meditation and other creative, transcognitive experiences, allowed me to experience being more wholly present to, and cocreating more fluidly with-in every moment, to expand my (self-)compassion and my capacity to embrace my/our shadow, to co-create more fluidly with the unfolding of life. I progressively got to trust my attunement with unitive awareness and leverage it more naturally for the co-inquiry, as in my coaching and my life. I also experienced how labile my capacity of living from/as that awareness was. Stress of various kinds reactivated more or less subtle defense mechanisms that brought me to disconnect, withdraw, close down from unitive awareness (as from others, and the course of life). My meditation practice was the best antidote to those moments.

In the co-inquiry group, I became aware of how, in spite of our spiritual and/or mindfulness practices, it did not feel natural for us co-inquirers to attune and sustain attunement to the Field as way of knowing. Even though I had been working with that attunement for years prior to the co-inquiry as a meditator and a hypnotherapist, I perceived how I had to somehow authorize myself to invite others to make the time and space for such nurturing in our professional and academic contexts - and to trust its revelations. The co-inquiry allowed me to observe how I needed to better (re)integrate our unitive, essential dimension of awareness in my way of being, knowing and doing, and re-train my capacity to attune to that awareness and live as part of the whole. For each of us in the group, knowing from (and being known as) Source was considered more as an intention to be pursued, rather than a usual way of working and living our life. 
Also, in our group, we needed to deliberately set the intention to practice with creativity (another form of attunement to the Field of awareness), and it was evident that we were not used to leveraging our body's intelligence (i.e., our somatic attunement to the Field) as an habitual way of knowing. Rarely were bodily sensations evoked by the co-inquirers, and I observed that when we engaged in meditative inquiry together, the sharing that followed was polarized towards the conceptual, cognitive plane. Arguably, this had more to do with our cultural conditioning, relegating the body, heart, and intuitions to the background and celebrating our minds as the privileged source of our knowledge and growth, than with our developmental centers of gravity. Similarly, the field of developmental coaching is only at the beginning of the integration of approaches based on the body and the whole person within the main current based on a cognitivelinguistic lens (Coughlin, 2015).

Nurturing the consciousness of our fundamental wholeness and oneness was an important potentiality of the co-inquiry. It was regenerating to observe its impact on my own leadership and coaching, and how that fluidified and imbued with purpose my relationships with others as part of a broader, ever-unfolding co-creation. Similarly, almost all of the active co-inquirers shared about a renewed aspect of their relationship with spirituality, oneness, and their bigger purpose at the end of the co-inquiry. This is particularly important because reconnecting with our wholeness and the transcendent dimension of life (re)ignited our commitment as instruments of growth.

\section{Cultivating an organic relationship with growth.}

Our co-inquiry brought us to gain new awareness about the nature of development (of self, others, and the whole) and the active role we can play in supporting it. 
Intentionality emerged as key in the process, starting with the deliberate intention to grow and engage in the co-inquiry, and as a focus to cultivate in the different areas of our life. Setting personal intentions within the co-inquiry turned out to be very effective, even without bringing conscious attention to them through each phase of the process, as a force of attraction quietly orienting our unfolding. At the same time, simply asking ourselves the question about our growth edge and our next developmental step showed us the ineffability of that unfolding, the impossibility of controlling it, and rather, invited us to balance seeking and non-seeking, shifting from willfulness to willingness (Assagioli, 2010), in what seemed a more effective "purposeful allowing” of our development. Another component of what we can define as a more organic way of supporting growth was an attitude of trust in the unfolding. Many of us were called to rekindle our "trust in the process," in our co-inquiry and in our shaken lives, as a resource to cultivate resilience and developmental agility through disruptions. That was supported in the group by the gradual, systematic "letting go" of what was impeding our engagement in our work, (namely our fears and other negative emotions/thoughts/patterns), to recycle them in a more flexible and inspired openness to whatever was emerging.

The co-inquiry also allowed us to experience movement in our generativity through the re-connection with our calling in life-i.e., our bigger, self-transcendent (Frankl, 2000) purpose - at different times throughout the process and particularly at our sixth meeting, when I invited that explicitly for each of us in the group. My goal was for us to reconnect with our overarching intention in life as a way to respond to the needs of our world. Hearing our calling led us to different ways of embodying and enacting it in 
the world, which, as in the case of our experimenting with "funneling through systems" in our coaching, also supported our skillfulness as instruments of growth.

\section{Growing in Presence, Integration, and Regeneration}

In conclusion of this section, with Table 7 I offer another representation of the territories the co-inquiry allowed us to explore as instruments supporting growth.

Growing as whole selves, as invitations to growth for others, and as part of the everunfolding whole, supported the development of our capacity for presence, integration and regeneration. At the end of the co-inquiry, we noted an expansion in the aspects of our individual, mutual, and systemic complexity we could make available to ourselves and others through our quality of presence. Also, we grew in our capacity to integrate "more of who we were," more of our individual, mutual, and collective wholeness. And we were more open to dance with the flow of life for self- and others' re-generation.

Table 7. The potential of the co-inquiry in terms of the co-inquirers' growth as instruments of growth.

\begin{tabular}{|c|c|c|}
\hline $\begin{array}{l}\text { Growing as a } \\
\text { whole self }\end{array}$ & $\begin{array}{l}\text { Growing as self } \\
\text { in relation with } \\
\text { others }\end{array}$ & $\begin{array}{l}\text { Growing as part of } \\
\text { the whole }\end{array}$ \\
\hline $\begin{array}{l}\text { Being with } \\
\text { oneself }\end{array}$ & $\begin{array}{l}\text { Being with } \\
\text { others }\end{array}$ & $\begin{array}{l}\text { Being with our } \\
\text { environment }\end{array}$ \\
\hline $\begin{array}{l}\text { Fostering } \\
\text { integration }\end{array}$ & $\begin{array}{l}\text { Relating } \\
\text { different ways of } \\
\text { knowing }\end{array}$ & $\begin{array}{l}\text { Nurturing unitive } \\
\text { consciousness }\end{array}$ \\
\hline $\begin{array}{l}\text { Embodying and } \\
\text { enacting "more } \\
\text { of who we are" }\end{array}$ & $\begin{array}{l}\text { Leveraging } \\
\text { mutuality }\end{array}$ & $\begin{array}{l}\text { Cultivating an organic } \\
\text { relationship with } \\
\text { growth }\end{array}$ \\
\hline
\end{tabular}


The expansion of our consciousness through the co-inquiry yielded growth in terms of capacities as well as skills for us co-inquirers as persons and coaches, inviting more of our wholeness into our being, knowing and doing. Allowing us to cultivate presence, integration, and regeneration - which, as discussed in chapter II, are capacities associated with post-conventional leadership — the co-inquiry was developmental across and beyond developmental stages, and supported our ability to scaffold leadership development for our complex and chaotic world.

I now turn to describe the harvesting from the co-inquiry in terms of the features and factors of our growth as a system generating development.

\section{Growing as A System Supporting Growth}

What I present in this section are the learnings catalyzed by the question: how can we develop mutual and collective capacity to support development in ourselves and each other? This was the third guiding question of the co-inquiry. As shown in the previous sections, the co-inquiry group was able to co-create a supportive environment to individually be with, process, and grow through our experiences of the pandemics of COVID-19 and systemic racism. Together, we fostered our resilience, fueled our engagement as coaches and members of our communities, and meaningfully, if only minimally, expand our capacities and skills in support of others' growth. However, personal, collective, and ecological factors interfered with our capacity for developmental mutuality and synergy as a group. A key moment when we engaged in collaborative inquiry for the development of our group and its processes was midway through our series of meetings. On that occasion, we were particularly effective, through single- and double-loop inquiry, at isolating what was of value in our work and what 
practices/outcomes we wanted to pursue for the rest of the process. We engaged in inquiry around what our mission as a group was, and around the gap between our intentions, our strategies and practices (Torbert \& Associates, 2004).

At our last meeting, contemplating our experience with the co-inquiry, we had another opportunity to reflect on our group as a whole, although in a retrospective, evaluative look (and not in a programmatic way), particularly highlighting the benefits of the group in our challenging times. Together with the moments when I intentionally opened the inquiry around our engagement in the process, those were the only occasions where our system could see itself (Scharmer, 2009, 2018). Our experience with the practice of single-, double-, and triple-loop inquiry at the level of our system, allowing itself to timely self-amend and evolve (Torbert \& Associates, 2004), was indeed limited in our (also limited, and turbulent) time together.

The elements that emerged as key in our evolution as a system generating development were:

- intentionality,

- open and secure container,

- leadership as "hosting,"

- co-leadership,

- the space between and beyond.

\section{Intentionality}

As shown in the previous section, intentionality was fundamental for the coinquirers' individual growth through the co-inquiry. Above all, it was at the basis of the very existence of the co-inquiry. Our system was conjured, held, and supported by our 
shared intention to grow (particularly) as developmental coaches. Even if each of us attributed different meanings to the idea of expanding consciousness, capacities and skills for developmental coaching, the power of our intention was crucial for the group to exist and function. In a way, it was the lifeblood of our system.

At the same time, the intention to expand our consciousness and grow as developmental coaches might have been too ineffable to provide a solid and stable focus for the group when the disruptions we experienced put very concrete, survival priorities at the forefront of our personal and professional lives.

Similarly, the self-transcendent aspect of our individual intentions appeared as a potent psychological motivation sustaining engagement in the co-inquiry, and was clearly transferred and alive in the group at our meetings, yet, the other- and world-centered facets of our intention as a group was somehow diluted in the intervals when everyone was caught back in the rough waters of our life at the time. Being involved together in a common, concrete project in/for the outside world might have contributed to sustain the commitment of the group. The immediate cause we were serving was actually my dissertation, and in spite of my intentions to honor the participatory nature of our work, and collectively plant seeds through my rendition of it, there was no evident alignment between our intention, strategies, behaviors and outcomes (Torbert \& Associates, 2004) as a system. Without tangible collective expectations in terms of outcomes for the group, the awareness that we were doing our work for ourselves, each other and for the whole simultaneously was probably not enough, especially in our environment and for the Achiever/Self-determining based group that we were, to fuel intentionality as a group generating development. 
Both Torbert, in the perspective of CDAI (Torbert \& Associates, 2004; Torbert, 2017) and Scharmer, in the perspective of the U process and presencing (Scharmer, 2009, 2018) point to shared intention and attention as a key in systemic developmental work. As I will discuss later in this section, the seemingly diluted intentionality at the group level impacted the quality of our shared leadership and our capacity to engage in transformative work around our own system.

\section{Open and Secure Container}

The disruptions tearing our world apart led us co-inquirers to constantly find (and lose) the balance between openness and safety in our own holding environment. We needed safety to engage in vulnerable inquiry, and at the same time we must make space for the needs and the unexpected in our lives through those extraordinary times. That very balancing act translated in working within lack of clarity around the contours of the group, until it tended to settle at the two last meetings, as well as in abundant time invested to reconnect with each other after the intervals between the meetings (and/or after missed meetings), and more generally, to create and sustain our social field (Scharmer, 2009, 2018). The methodological and logistical structure of the co-inquiry were designed, and ongoingly reviewed, as described in chapter III, to support that balancing act. From the logistical point of view, we were bound to a calendar, co-created by our availabilities, that proved too loose for our co-inquiry in our context. Disruption was so intense in the interval between the meetings — in most cases, of one month — that the co-inquirers' connection and commitment could be easily lost in the pressing challenges of those months. I invited flexibility around our calendar on a few occasions, but the group did not express the willingness to change/add meeting dates. In retrospect, I 
wonder if using a more unilateral approach to the calendar, which I avoided in the spirit of co-creation and as what I thought could be a way to secure maximum participation, would have led us to a different outcome in terms of engagement. I believe meeting every two or three weeks would have been optimal to keep our intentions and our accountability alive. Also, as suggested by Logan and Sam, organizing a form of accountability partnership between meetings could have supported our group's growth in connection and co-creation.

As the convener of the group and the primary researcher, my role in setting the container was fundamental. The balancing act between openness and safety translated for me in a tension between rigor and flexibility, to sustain generativity in the process. I certainly practiced rigor in the preparation of the co-inquiry, clarifying my intentions, the methods and the mutual expectations for the co-inquirers' in the initial documents I shared with the group, including the consent form/memorandum of understanding everyone signed. I continued to hold the logistical space with rigor, punctually reminding dates and deadlines, e.g., for the submission of the MAP assessments, and holding the coinquirers accountable for their personal inquiry and experiments meeting after meeting. Clearly, our planetary challenges cracked those boundaries open in many ways: it became evident that flexibility was key to secure the space and the aliveness of our group. Also, my own experience with disruption, coupled with my immense gratitude for the group's contribution to my dissertation (especially through such difficult times) might have loosened my rigor in favor of flexibility, (also my natural preference), at times - for example, when I opened the inquiry about our engagement in our work, I was with the sense that it did not feel right to add pressure on our already pressurized group. However, 
I kept practicing rigor in my own inquiry and, while managing my expectations, I never stopped inviting co-leadership in the group as a way to hold an open, inclusive, selfamending and regenerating space for us to engage in our co-inquiry work. At the same time, I remained open to whatever emerged in the group, attempting to hold that emergence simultaneously from the methodological, logistical, intellectual, and emotional/spiritual standpoint. I describe that next, in my discussion of my enactment of leadership in our group as another factor of the generativity of the system.

\section{Leadership as "Hosting"}

In my journey from the utopistic ideal of participation in the co-inquiry to embracing the reality of the disruptions permeating our group, unfolded my experience as the leader of our group, which necessarily impacted our generativity as a system.

The very first realization at the basis of my leadership was the shift from the idea of enacting fully shared, co-leadership with my co-inquirers, to assuming the role of leader inviting co-leadership. Even before the pandemic, I noted the hesitation of the group to fully enact shared leadership. At the beginning of the co-inquiry, I attributed that to the uncertainty evoked by our very emergent process, and to the fact that the existence of the group was linked to my dissertation. At the end of our second meeting, Logan shared:

[I am] so thrilled that there's, you know, [our space] is created and I get to join, as opposed to having to create it, myself, and then invite others to join.

Then global chaos precipitated the group's delegating of the authority to hold our space, and steer our processes and content, to me. In a way, the experience of this coinquiry illuminated how we can naturally tend, especially in complex times, to delegate 
responsibility for our own groups to the "designated" authority, and loosen our engagement as co-leaders. However, my inviting co-leadership did not fade, as participation was a constitutive factor of our endeavor, and "power with" a key aspect of my leadership model.

Wheatley and Frieze (2011) suggest that a good metaphor for leadership in complexity is that of the "host" (that they oppose to the "hero," whose "power over" is based on an illusory control over the situation), who enacts "power with" by promoting shared learning from experience, and group visioning/goal setting, reflection, decision making, accountability. I embraced that model as corresponding to the participatory nature of our work, to my commitment to supporting the group through it in any way, and to my awareness of being a "wounded" host, equally needing constant support through the work.

My hosting the group was based on my strategies, choices and practices to hold the space for our experience logistically (securing a generative container, as I described in the previous section), methodologically, intellectually, emotionally, and spiritually.

My methodological hosting is described in detail in Chapter III. Beyond the methodological choices I made to support our development through our work, what I believe was decisive was my commitment to my own inquiry as a co-inquirer. That led me to share: the fruit of my intentions and attention throughout the process, the gifts of my reflection on the path of my different territories of experience (as timely as possible), and my questions about the process and its content—as a way to correct/redirect our work in what seemed the most fertile directions. 
If I enacted the practice of action inquiry throughout the process, I might have further leveraged the theory of action inquiry — and hold the group's space more tightly from the intellectual point of view. I shared several important texts about developmental action inquiry with my co-inquirers, most of whom were familiar with the approach prior to the co-inquiry, and used key concepts throughout the study, yet, I wonder if more formal presentations or explanations would have impacted the generativity of our work. Our space was purposefully open to its own emergence, within the overarching intention of expanding consciousness expressed in the three guiding questions of the co-inquiry, and this unabashed spaciousness might have resonated with the fear of the unknown evoked by the uncertainty of the pandemic, and instill insecurity instead of initiative within the group. Anchoring the co-inquiry to its guiding questions, to concepts (like the ones I operationalized in the prompts for our meetings' activities), and theory had a reassuring influence on the group. Bringing more theory into the meetings, e.g., evoking single-, double-, triple-loop awareness (Torbert \& Associates, 2004) more explicitly, or recommending specific readings throughout the process, might have added rigor to the group's work and engagement, while contributing to enrich our intellectual shared space. That might also have added pressure on an already overwhelmed group. It is true that my focus on learning from our experience, harmonizing mind-heart-body-soul and tempering our shared academic, above-the-neck way of being, knowing, and doing might have translated into my (under)using theory. As I realized I needed to further re-integrate the Expert/Skill-centric action-logic in my own repertoire, it dawned on me that a better integration of theory and practice might have supported the generativity of our group. 
My hosting was particularly alive at the emotional and the spiritual level. I felt extremely connected with the group, and deep care and gratitude for it. My infusing our space with compassion and unconditional acceptance was spontaneously unfolding from my heart in the awareness of our vulnerability, and, at the same time, of our oneness. That was certainly amplified in response to the complexity through which we were evolving. Yet, it was important for me to realize that if I felt safe in the group in spite of its changing membership and the shift to remote meetings, and I was quite comfortable with expressing my vulnerability, it was not necessarily the case for everyone in the same way, depending on our individual factors and on our lived/missed (bonding) experiences with the group. That led me to deliberately focus on strengthening the connection within the group, start private email exchanges with the co-inquirers in addition to my emails to the group, and be more explicit about my transubjective experiences of connection. Operating from an intensified intention to connect, I had another important realization: what we found was extremely significant for our connection was the experience with the sharing of our developmental autobiographies, nevertheless, after focusing on that theme for two consecutive meetings, I decided to pursue the co-inquiry by shifting to another theme for the following session. That precluded the possibility, for the two co-inquirers who had been absent to both of those meetings, to join the rest of the group in the experience. I realized only later, after the end of the co-inquiry, that could have been part of the shadow of what was experienced as an open and inclusive group, and certainly impacted our co-creation. Tending, in some way, to equality in the members' lived experience within the group could have been an important factor of "safety to engage," especially with the group evolving across disruptions, and needing larger doses of "glue" 
to become and function as a whole. A way I supported continuity of inclusion in our group work was sending emails

- after each meeting, to crystallize important aspects of our experience and make them available to those who were absent,

- between meetings, to communicate findings from my own ongoing inquiry,

- and before each meeting, to confirm the topics and the preparation work that was recommended.

Finally, what allowed me to be the host of the group with the constant intention to serve our work in any way I could, was the presence of my mentors, and the space they hold for me to process my own experiences with-in the co-inquiry. With their support, facilitating the group as a wounded host became a precious source of learning and integration.

\section{Co-Leadership}

The instances of joint, shared leadership we experienced in the group were also paramount in terms of the generativity of our system. And at the same time, as I have discussed, outer disruptive circumstances as well as inner and developmental factors impeded our capacity for shared leadership, which Pearce and Conger (2003) define as "a dynamic, interactive influence process among individuals in groups for which the objective is to lead one another to the achievement of group or organizational goals" (p.1).

Presence was the first way in which the co-inquirers did or did not exercise shared leadership, participating in the meeting, engaging wholly in the work of inquiry, and offering more of themselves in service of our mutual and collective growth. With the 
acceptance of the impossibility, for some members, to fully engage in the co-inquiry as agreed, came the realization of the missed opportunities for self and others, as a result of absences and inconsistency in the work.

Presence and engagement, supported by (more or less self- and other-centered) intentionality, vulnerability and accountability, fueled trustworthiness in our group, and safety to engage. The co-inquirers who more actively engaged in co-leadership carefully tended to safety and connection within the group, showing care, gratitude, and celebrating others' successes, strengths and contributions.

If we did not experience co-leadership in terms of co-creating every aspect of our experience, or fully leveraging the generativity of mutual and collective inquiry (Torbert \& Associates, 2004), I could appreciate co-leadership in the clarifying questions posed about my prompts during the meetings, the sharing of reflections/experiences in the intervals (e.g., through the post-meeting questionnaire), and through my own sense of trust, i.e., knowing I could count on the group in case of my temporary failure to support our system and its purpose.

More evidently, on the strength of our experience as coaches, our co-leadership was strong in terms of the co-creation of a developmental space through our capacity for compassion, unconditional positive regard, resonance within the group, neutrality (i.e., non-attachment to outcome)—which Silsbee (2008) identifies as the key aspects of a generative field in coaching. 


\section{The Space Between and Beyond}

I could not emphasize enough how the space between and beyond us co-inquires, in our shaken nested ecologies, was influential in our functioning as a system supporting growth.

The field of our group was strong with presence, compassion, and vulnerability, in the awareness of the challenges of our times.

An important bonding factor in our group was our shared coaching and leadership culture. That allowed us to make space for, and learn from, our differences in making meaning and interpretations, conceptualizations, and practices, in a unifying perspective. Also, that common repertoire, together with our affiliation with the same university, fluidified our conversations preceding and following the meetings.

The pre-existing relationships among some of the co-inquirers generally supported our generativity, nurturing mutual admiration, trust, and inspiration. Yet, even if this was not mentioned during the co-inquiry, previous instructor-student or mentormentee relationships might have activated power dynamics impacting the co-inquirers' experience and engagement. Most of the pre-existing connections became known to the group and me during the co-inquiry.

Apart from my communications to the group via email, and the private exchanges via email or phone with some of the co-inquirers, our relational space became active only during the meetings. Yet, our sessions punctuated an energetic/spiritual relational continuum. Some co-inquirers noted, at the end of the co-inquiry, that their relationship with the other members of the group had been strengthened independently from their actual meeting each other. The transcendent social field (Scharmer, 2009, 2018) we co- 
created made possible the very definition and experience of our changing group as one collective, including and transcending its different configurations through time.

The immanent space between and beyond us (our local and global context), was also at the forefront of the co-inquiry, playing both a disruptive and bonding role for the group. If the challenges we experienced from the outside created absence, disengagement, disconnection, in addition to developmental fallback, they also substantiated our work together. We ended up inquiring into their reflection on our interiority - into our traversing them as a group of persons who were coaches. Because we met and held our contextual difficulties with ample space to process them, they became important sources of learning about ourselves and others, as well as the framing of our shared cognitive, emotional, experiential field.

To conclude, it is my hope that as a system, even if no longer meeting in the physical dimension, we co-inquirers will continue to inspire individual and collective expansion of consciousness through disruption by means of this dissertation. In the next chapter, I discuss three meta-insights catalyzed by the co-inquiry and offer them as the ground for the "actionability" (Bradbury et al., 2019, p. 17) of the experiential knowledge we co-created. 


\section{CHAPTER SIX}

\section{PLANTING FRESH SEEDS}

The experience of the co-inquiry, and the learnings we harvested, catalyzed three meta-insights into collaborative expansion of consciousness in complex, chaotic times. I present these insights here in the spirit of planting seeds that may grow with time and nurturance. The significance of the co-inquiry lied in its being an "experiment in cooperation" (Seigfried, 1996, p. 92) for the expansion of consciousness across disruptions, supporting the simultaneous vertical and horizontal development (Torbert, 2017) of persons whose work implied supporting others' development. It is my hope that the following insights will serve the ongoing expansion of developmental theory and methodologies, and the honing of leadership development practices for our times.

\section{Three Insights From the Co-Inquiry}

The following three insights into the expansion of consciousness through disruption were catalyzed by the experience of the co-inquiry:

- the imperative to dwell within our personal experience of systemic disruptions, and slow down to listen to whatever unfolds on the inside and the outside;

- the importance of growing together with others, leveraging diversity and strengthening human connection for resilience and growth;

- the need for re-training unitive consciousness across the developmental spectrum for personal, mutual and collective growth.

I illustrate these insights in detail in the sections that follow, discussing their contribution and "actionability" (Bradbury et al., 2019, p. 17). 


\section{Dwelling Within Our Lived Experience}

We all are so quick to figure things out, right? We want to do what's next, we want to go onto the next thing. Like right now we don't even, at least for me, I haven't really processed, I guess thinking about it now, like what is really happening? Where is our current society and where is my current path to greater purpose?

With these words Chase captured our (Western) tendency to fast-forward, by-pass, and find quick, illusory solutions to complex, personal and systemic problems. In the midst of the COVID-19 and systemic racism pandemics, the co-inquiry revealed our tendency to look at the future, to hastily figure out a "new way" for ourselves and for humanity at large- - filled with good intentions about co-creating a better world out of crisis, as much as with a desperate search for regaining a sense of control and avoiding the distress of the circumstances. We co-inquirers came to realize how much we needed to slow down, find stillness, and make space for becoming intimate with the outer and inner ravages of our times. Only from their acceptance, understanding, and "recycling," we could let come new possibilities. Rumi wrote: "The hurt you embrace becomes joy. Call it to your arms where it can change." That space for listening into our lived experience, for awareness and attention, at the basis of developmental action inquiry (Torbert \& Associates, 2004) as well as contemplative practices, presencing (Scharmer, 2009, 2018), personal and collective trauma healing (Scharmer \& Hübl, 2020) and presence-based coaching (Silsbee, 2008), was a key feature of our work. That allowed us to find regeneration and infuse our actions with renewed commitment, meaning and purpose. In the current cycle of chaos (Wheatley, 2017), it appears fundamental to create and/or expand the spaces for contemplation and inner processing in our practices as 
action-inquirers and as leadership coaches/developers, and resist the urge to create, accomplish, find solutions and change things rapidly, or prematurely. Deepened awareness and intelligence of the situation can only be uncovered through contemplation inside the abyss (Scharmer, 2018, p.16). As the host of this co-inquiry, in spite of my being mindful of the pace of the process and deliberately making ample time for inquiry at the level of our being, I was confronted with the tension between moving forward, covering new ground, and deeper inquiry and inclusion. As coaches, we all noticed how challenging it was to make the space for difficult emotions to be surfaced in our work, and how that required effort and skillfulness. And we realized, both in our co-inquiry and in our coaching, how illuminating, bonding, and generative it was to create openings to intimately and mutually be with our personal experiences of complex systemic phenomena. As Freinacht (2017) suggests, calling for a "listening society" (p. 1) attuned to the inner dimension of human affairs, slowing down to honestly, humbly, vulnerably relate to our experiences is key to navigating chaos as a society.

\section{Growing Together}

Developmental literature emphasizes that growth unfolds in interdependence with the environment, and that we need good company to develop (Baxter-Magolda, 2009; Kegan, 1982, 1994; Torbert \& Associates, 2004). Through the disruptions that marked the co-inquiry, our recognition of our being "social animals" needing connection and nurturance to live and grow was exasperated by physical and social distancing. It became evident that we could not navigate those unforgiving waters alone. Human connection was paramount to be able to hold and transcend the emotions and the experiences brought about by the COVID-19 pandemic and the collective trauma of systemic racism. The only 
way we could grow through those crises was by making space for self and others to process our experience, be met in our processing, and together, reconnect with our natural resilience. Wheatley and Frieze (2011) write

Collapse always causes terrible suffering. Yet we humans have an enduring capacity not only to survive, but to learn and grow. Resilience is in us, if we look for it. Whatever our material circumstances, we can feel confident that we have what we need, no matter what happens. It's right here in us, not alone, but as community. (p. 127)

In our divided and polarized world (Scharmer 2020), it feels urgent to acknowledge that "we need each other," in Ted's words, to nurture our resilience and our capacity to grow and support development. That forces us, both as scholars and practitioners, to recognize that we need to explore, expand and diversify technologies for collaborative development. Getting together with the deliberate intention to be there for one another, grow personally and mutually, and evolve our systems seems the most urgent responsibility for leaders and leadership developers through the disruptions of our times (Torbert \& Associates, 2004; Wheatley, 2017). Action inquiry, and particularly CDAI with the simultaneous emphasis on first, second, and third person inquiry, provides a fruitful methodology to support that work.

Communities of inquiry appear as ideal spaces to generate knowledge and experience for the expansion of consciousness (Torbert \& Associates, 2004). The individual development we co-inquirers experienced through our collective process confirms findings from other studies based on action inquiry, and particularly CDAI (Torbert \& Associates, 2004; Torbert, 2017). Contemplating her experience with the 
facilitation of a co-inquiry aiming at the expansion of consciousness, Smith (2016) writes: “...doing this developmental work in the company of others is not only theoretically sound but necessary. We are all simultaneously whetstones, arms, and mirrors for each other, in the same way that we are alternately constituted and reconstituted by each other and by ourselves in relation to each other." (p. 270).

Another important aspect of our growing together through this co-inquiry was that everyone, at our different developmental centers of gravity (from the Achiever/Selfdetermining to early Alchemist/Construct-aware), benefited from engaging in the coinquiry. The diversity in terms of meaning-making particularly enriched the experience of the co-inquirers through precious mirroring and inspiration across stages. That had the potential to support those at the Achiever/Self-determining center of gravity in their passage from the conventional to the post-conventional tier, and those at later stages in their continuing integration and enhanced orchestration of previous action-logics.

The co-inquiry also showed us that as coaches, we have the same need for community to illuminate our blind spots, (Scharmer, 2009, 2018), to learn (how to learn) from one another and from our ecologies, and to be (ever more) present to what wants to emerge in our contexts (Torbert \& Associates, 2004). Coaches' commitment to support others primarily through their self as instrument implies the responsibility for ongoing self-care and self-regeneration, and we experienced how the holding environment of the co-inquiry could be nurturing, re-energizing as well as conducive to the stretching of our capacities and skills. 


\section{Re-training Unitive Consciousness}

In the chasm of what Scharmer (2018) defines as the three major divides of our times: the ecological, the social, and the spiritual divides, we can hear more and more loudly, as humanity, the call to awaken to our essential oneness. Throughout the coinquiry, we co-inquirers heard that call as we uncovered aspects of our "being one another," as we experienced heart-to-heart, soul-to-soul, energetic and transubjective connections, as we reignited our calling in life in response to the needs of the world, as we reaffirmed the importance of the spiritual dimension in our life, and whenever we opened to the Field of infinite possibilities. "We are here to awaken from the illusion of our separateness:" in this invitation from Thich Nhat Hanh to rediscover our essential unity, we hear echoes of Bateson's (1972) urgings to re-enchant our relationship with life (Berman, 1981) through the re-connection with one another and with nature as part of a whole mind. This re-connection is evoked as the antidote to the dis-connection from our environment, from one another, and inside ourselves. In this re-connection, we can trust our trans-cognitive, emotional and somatic experiences as natural and valid expressions of our being one with the whole. The co-inquiry offered us the opportunity to honor those aspects of our being and knowing, that we are used to relegating in the background of our rational, cognitive experience of the world, and let them inform our doing. That rekindled meaning and inspiration, and what Scharmer (2018) defines our Self as "highest future potential" (p. 17). Equally important in our developmental endeavor, re-training our unitive consciousness in different ways supported our bringing more of our wholeness into our shared space and into our coaching. My personal felt-sense of deepened and broadened connection with my co-inquirers as well as my clients as a result of my 
attunement with unitive consciousness suggests that what Blackstone (2006) describes as the impact of nondual, unitive awareness in the therapeutic relationship, i.e., deepened empathy and attention to the singularity of each moment, and increased connection, spontaneity and equality, applies to coaching and relationships in general. Re-training our unitive consciousness through meditation and other creative, heart-based and somatic processes fosters our awakening from the illusion of separateness and the expansion of the capacities that naturally come with the awareness of oneness. As Blackstone (2006) puts it:

As our realization of nonduality progresses, all of [the] dynamic aspects of our experience gain their optimal fluidity and freedom. In other words, we are able to allow experiences, such as emotion, thoughts or perceptions, to occur, or to flow, without impeding them. Examples of this unimpeded experience are an increased subtlety and vividness of perception, a greater depth of emotional responsiveness, as well as greater emotional resiliency, and a more spontaneous flow of creativity. For this reason, nondual realization is often referred to as freedom. It is freedom from our own constraints upon ourselves, from our rigid organizations of experience. (p. 33)

The cultivation of unitive consciousness appears decisive in terms of development and of being an instrument of growth. The idea of freedom from our own barriers and rigidities resonates with the intention of bringing "more of who we are" and more of our wholeness into our life, our relationships, and our work, which echoed in the co-inquiry across developmental centers of gravity. Indeed, if developmental literature associates unitive consciousness with the latest stages of development (Anderson \& Adams, 2016; 
Chandler, Alexander \& Heaton, 2005; Cook-Greuter, 2013; Torbert, 1994; Torbert \& Associates, 2004), I argue, with Blackstone (2006), Chen (2019), and Mills et al. (2020), that attunement to unitive consciousness is possible - emotionally, somatically, and spiritually—from earlier stages. Our heart, our body and our soul are portals to our essence as unbounded awareness, and that is true at any stage of our cognitive maturation. Our meaning-making of our experiences with/of unitive consciousness may vary with our complexity of mind, yet the experience itself, in virtue of its being transcognitive, direct, may enrich the life of many people at different developmental stages.

It is true that in the vertical unfolding of our ego through the different stages of development (Cook-Greuter, 2013; Torbert \& Associates, 2004), our essential unity gets lost in the cognitive-based separateness, the individualism and the busyness of our Western cultures. That is why the need emerges, at different developmental stages, to retrain our unitive consciousness, trust our innate faculties as one with the whole, and become skillful at strategically leveraging them in our environments. Building on Wilber's (2003) conceptualization, Scharmer associates the possibility of that experience (namely through presencing) with accessing specific states (and not stages) of consciousness (Scharmer, 2003, as cited in Nicolaides \& McCallum, 2014). Similarly, Baron and Cayer refer to the possibility of "transiently" (2011, p. 358) operating from expanded, post-conventional consciousness based on the access, with practices such as mindfulness meditation, to higher states of consciousness.

In the co-inquiry, we could experiment with unitive consciousness by joining together in stillness and meditative inquiry, sharing and listening about our experiences with aspects of our wholeness, leveraging creativity and creative/artistic languages to 
invite and to describe our experiences and insights. The co-inquiry experience suggests, as the accounts of other practices fostering unitive consciousness (Blackstone, 2006; Scharmer, 2009, 2018; Scharmer \& Kaufer, 2013), that building on that "primary aspect of [our] being" (Mills et al., 2020, p. 3) frees our self's expression, agency and sense of "power with," and opens the space for further levels of connection with others and with our environment.

This has important implications in terms of leadership. At different levels of development, we can aspire to cultivate what Anderson and Adams (2016) define, ascribing it to "the highest stages of awareness" (p. 85), unitive leadership. According to the authors, unitive leadership is rooted in the very real experience, at the same time of a bodily and transcendent nature, of oneness with life itself. They write: "From the perspective of Unity, we are all each other. The children dying in wars on distant shores are our children. There is only one family. The Ecosystem is our body" (Anderson \& Adams, 2016, p. 85). The ecological, social, and spiritual divides of our world seem to desperately call for a leadership that emerges from the awareness of wholeness, interconnectedness, and unity.

(Action) research and leadership development practices should explore, include and foster the grammar, technology and (new) narratives (Scharmer, 2018) of unitive consciousness as potentially conducive to bridging those divides. I now turn to describe the research and practice implications of the three meta-insights and the experiential knowledge generated through the co-inquiry. 


\section{Pursuing (Action) Research Supporting the Expansion of Consciousness Through Disruption}

It seems urgent, in our present times, to develop action research as "a catalyst to

successfully transmute the inexhaustible resource of human creativity in all spaces—self to society—-toward addressing our global problems" (Bradbury et al., 2019, p. 15). The experience of this co-inquiry confirms the potential and the significance of CDAI-based (Torbert \& Associates, 2004) participatory action research to support the expansion of consciousness (Smith, 2016; Torbert, 2017), and attests for its relevance in times when the developmental lines are easily blurred by disruptions. Fostering presence, integration and regeneration, our work supported resilience and allowed us co-inquirers to grow through and from disruption.

The epistemological and methodological framework of CDAI (Torbert \& Associates, 2004) — with its interweaving first, second, third person perspective; its focus on single-, double-, and triple-loop inquiry, feedback, and learning; the alignment and integration of the four territories of experience and more broadly, of being, knowing and doing (McCallum \& Nicolaides, 2015) — supports growth in its complex, emerging, relational and ecological nature. The new paradigm for social science and social action proposed by CDAI (Torbert, 2017) is developing in academic contexts, yet, the complexity and the versatility of the model call for detailed descriptions of CDAI-based action inquiry to support further applications in different fields. This co-inquiry offers an example of how CDAI can be used as an epistemological and methodological foundation and at the same time be enriched by a variety of methods and practices. In this way, this co-inquiry extends an invitation to action inquirers to pursue creative experimentation 
with CDAI-based methods, particularly in service of the expansion of consciousness. Diverse experiences rooted in CDAI would contribute to enrich its theory and methods. In particular, this co-inquiry showed the heightened importance of leveraging first and second person inquiry, and particularly of nurturing mutuality, in our distancing, isolating times. Further research could illuminate (remote) mutuality—its factors, unfolding and impact-in other experiments in cooperation in our disruptive contexts. Similarly, our work and our development were largely supported by triple-loop inquiry at the level of our being. Research is needed to pursue the exploration of the experience and the implications (across developmental stages) of triple-loop inquiry, awareness, and the relationship between the two.

Other important implications of this co-inquiry gravitate around unitive consciousness. This co-inquiry suggests that trans-cognitive experiences of unitive consciousness evoked emotionally, somatically, and transubjectively from the (social) field (Blackstone, 2006; Chen, 2019; Mills et al., 2020; Prendergast, 2019; Scharmer, 2009, 2018) could be nurtured and developmentally beneficial at different stages - and not exclusively at the Unitive/Ironist stage (Cook-Greuter, 2013; Torbert \& Associates, 2004). The developmental impact of nurturing unitive consciousness certainly requires investigation, and more broadly, unitive consciousness needs to be further explored and understood from an interdisciplinary perspective. Similarly, (action) research clearly stemming from the perspective of wholeness and oneness would illuminate the implications - in leadership, coaching, and potentially numerous other areas—of this ontological standpoint. 
The co-inquiry also showed the relevance and the potential of expanding consciousness, capacities and skills for developmental coaches, whose work implies supporting others' (leadership) development. The holding environment of the co-inquiry was particularly beneficial for us co-inquirers in our context, when our consciousness, and our capacities and skills as coaches, were impacted by chaos. This points to the opportunity, particularly in our complex and chaotic times, for further (action) research exploring and scaffolding coaches' growth as instruments of development, joining the call of many others authors (Bachkirova, 2016; Diehl, 2010; Laske, 1999, 2003; Perry, 2014; Scott, 2009; Wildflower, 2006). Further efforts in this direction could also contribute to delineate developmental coaching as a wholeness-based practice (Coughlin, 2015; Silsbee, 2008), and to support coaches' development as catalyzers leveraging multiple channels, (namely mind, heart, body, and soul), and multiple nested systems, in service of their clients. Another possible expansion around this line of inquiry would include coaches' clients and/or mentors in collaborative action research. That would shed light on the developmental factors at play in the parallel processes unfolding between the different actors of the coaching ecology, and more generally, on how the coaches' meaning-making, capacities and skills play out in the coaching relationships and outcomes.

Beyond the specific area of coaching, the co-inquiry invites developmental communities of inquiry to be formed around the expansion of consciousness, capacities and skills in other fields where the self is a primary instrument (e.g., leadership, education, etc.), and, across different fields, among people interested in inquiring into the deepest aspects of their being human. 
To conclude, this co-inquiry represents a minuscule tile in the mosaic that will compose the (action) research of human and systems' development in our times and spaces marked by the impact of the global pandemic(s). Longitudinal studies would be important to document our personal, mutual, and collective evolutions through and from these extraordinary times.

What follows is a discussion of the co-inquiry's implications for practice, and particularly of how our experience could contribute to inform and develop methodologies supporting growth through and from disruption.

\section{Developing Methodologies Supporting Growth Through and From Disruption}

The months of the co-inquiry unequivocally showed that the heightened complexity, separateness, and disruption in our environment had the potential to blur our developmental lines, and ignite growth at least as much as fallback (Livesay, 2013; McCallum, 2008). We could experience firsthand that "there is nothing linear about overall development" (Wilber, 2003, p. 26), and this is especially true in our turbulent times. Also, we were alerted to the fact that we need "islands of sanity" (Wheatley, 2017, p. 4) to support and grow self, others, and our systems through chaos-spaces where we can honestly and vulnerably be with our experience, find connection at deep human levels, reconnect with our wholeness, and restore our natural capacity for resilience and regeneration. Nicolaides and McCallum (2014) highlight that

Through expansion of awareness, increased developmental capacity makes possible an evolving or maturing relationship with phenomena as challenging as complexity, conflict, and ambiguity. [...] Expanded developmental capacity helps us to transcend our anxieties related to the unknown and uncertain, provides us 
tolerance for the discomfort of social conflict, and helps us learn our way through such challenges to discover unforeseen potential and possibility. (p. 57)

The co-inquiry's holding environment and methodology made it possible for us co-inquirers to grow through and from disruption - and potentially to better support others' resilience and growth in our contexts. As I have discussed, we could expand our consciousness, capacities, and skills, and re-train our unitive consciousness, at different stages of development, (specifically from an Achiever/Self-determining to an early Alchemist/Construct-aware center of gravity). That extends the possibility to grow from disruption, traditionally ascribed to later stages of development (Nicolaides \& McCallum, 2014) across the developmental spectrum.

On these bases, the co-inquiry is a modest contribution to the development of wholeness-based methodologies aimed at supporting growth across developmental stages in our times. The indications that emerge from the co-inquiry call for methodologies that are collaborative, and based on the participation and the inclusion of (developmentally) diverse group members; grounded on the ontological premises of oneness and on the intention to contribute with "more of" our wholeness (as beings and systems) to self, others' and systemic development; and built around the development of presence, integration, and re-generation (as shown in Table 7, p. 216).

Ideally, such methodologies would blend developmental coaching and CDAI's (Torbert \& Associates, 2004) shared constitutive aspects such as quality of presence, intention and attention, focus on mutuality and inclusion, practices for awareness creation, ongoing regeneration of self and systems (including processes to navigate, learn and evolve from ambivalences, incongruencies, and conflicts), and accountability. Also, 
triple-loop inquiry, meditative inquiry, somatic inquiry, and other creative methods of inquiry would be invaluable additions to re-train unitive consciousness.

The following features emerge from the co-inquiry as key for CDAI-based methodologies supporting personal, mutual, collective growth through and from disruptions:

- clearly formulated, shared intentionality, to be inquired and reformulated again and again through the process in its evolving context, to sustainably fuel commitment,

- small, diverse group/s of stakeholders,

- an open and secure container, based on a clear agreement on common rules, processes, and mutual expectations, and simultaneously on the acceptance and the opportunity to work with of any interferences as part of the experience,

- an accountability partnership system and a shared space (e.g., Google Drive) to pursue collaborative work and sustain inclusion and connection during the intervals,

- host/s ready and equipped to "enter the fray" (McCallum \& Nicolaides, 2015) of inquiry inviting co-leadership with purpose, humility and (self-)compassion, and to hold the inquiry space from the logistical, methodological, intellectual/theoretical, emotional, and spiritual standpoint,

- a system of support for the hosts outside the group/s,

- focus on first and second person inquiry with pertinent use of third person resources such as theory/concepts, research and assessments in support of the lived experience, meaning-making, and learning of the group, 
- ample spaces for dwelling within, and processing, one's and the system's experience, with a focus on integration,

- emphasis on practices and rituals supporting bonding and leveraging mutuality,

- practices fostering "funneling through systems," exploring and leveraging the connecting patterns across ones' and the system's ecologies,

- practices fostering (re-)connection with the natural world,

- use of specific language and practices fostering and leveraging unitive consciousness, and particularly creative methods combining contemplative, nature-based, symbolic, emotional, and somatic knowing with reflection and action. The expression and the encounter of individual spiritualities could enhance, and complexify, the experience.

Methodologies informed by these principles and ingredients could support development in different contexts:

- (action-research-based) intra- or inter-organizational leadership development programs, especially with an emphasis on navigating change and uncertainty, and fostering diversity and inclusion,

- spaces for communities of developmentally engaged practitioners such as leadership coaches, consultants, and action researchers for transformation (Bradbury et al., 2019) intending to cultivate resilience and grow self, others and systems through disruption,

- leadership coaches' personal and professional development programs as well as coaching training programs deliberately aiming at the vertical development of coaches, in addition to the strengthening of coaching skills - this corresponds to 
the exhortation of scholars/practitioners studying the impact of developmentally oriented curricula and practices in coaching education (Kennedy, 2012; Perry, 2014),

More broadly, the methodological indications evinced from the co-inquiry experience could serve organizational as well as community development through experiments in cooperation among people of different horizons united by the commitment to explore and expand consciousness. By fostering presence, integration, and regeneration, wholeness-based practices could be crucial to nurture resilient leadership in our society at large, bridge our dramatic divides, and continue to grow as humanity through complexity and chaos.

\section{Epilogue}

The journey of this dissertation, from its conception to its completion, evokes the transforming character of Rumi’s "Guest House” (Barks \& Moyne, 1995):

This being human is a guest house. Every morning a new arrival.

A joy, a depression, a meanness, some momentary awareness comes as an unexpected visitor.

Welcome and entertain them all! Even if they're a crowd of sorrows, who violently sweep your house empty of its furniture, still, treat each guest honorably. He may be clearing you out for some new delight. 
The dark thought, the shame, the malice, meet them at the door laughing, and invite them in.

Be grateful for whoever comes, because each has been sent

as a guide from beyond. (p. 109)

As I conclude this journey, I am in awe of the power of vulnerable living inquiry conducted together with people committed to evolve self, others, and the world. And I am with the warmth of deep gratitude for those who joined their arms with mine to hold such complex work in such extraordinary times. We endured the messiness, the falls, the uneasiness, the fluctuations and the breakthroughs of development, and grew together.

It is possible, and necessary, to expand our consciousness through disruption. I am with the strength of a renewed commitment to support resilience and development as a personal, relational, social, and ecological practice. As a work of love.

I am with the energy of the creative power that comes from the awareness of wholeness, interconnectedness and unity in our divided world.

I am with humility and wonder, facing the mysteries of life.

I am with insatiable curiosity to explore and experience more of what it means to be human beings. Together. 


\section{REFERENCES}

Anderson, R. J., \& Adams, W. A. (2016). Mastering leadership: An integrated framework for breakthrough performance and extraordinary business results. Hoboken, NJ: John Wiley \& Sons.

Anderson, R. J., \& Adams, W. A. (2018). Scaling leadership: Building organizational capability and capacity to create outcomes that matter most. Hoboken, NJ: John Wiley \& Sons.

Argyris, C., \& Schön, D. A. (1974). Theory in practice: Increasing professional effectiveness. San Francisco, CA: Jossey-Bass.

Assagioli, R. (2010). The act of will. Amherst, MA: Synthesis Center Press.

Astorino, D. M. (2002). Executive coaching and adult development: An integration of perspectives (Doctoral dissertation). Retrieved from ProQuest Dissertations and Theses Global. (3132363)

Bachkirova, T. (2009). Cognitive-developmental approach to coaching: an interview with Robert Kegan. Coaching: An International Journal of Theory Research and Practice, 2(1), 10-22.

Bachkirova, T. (2011). Developmental coaching: Working with the self. Maidenhead, United Kingdom: Open University Press-McGraw-Hill Education.

Bachkirova, T. (2016). The self of the coach: Conceptualization, issues and opportunities for practitioner development. Consulting Psychology Journal: Practice and Research, 68(2), 143-156. 
Bachkirova, T., \& Smith, C. L. (2015). From competencies to capabilities in the assessment and accreditation of coaches. International Journal of Evidence Based Coaching and Mentoring, 13(2), 123-140.

Balogh, R., \& Getz, C. (2019). Dreaming across continents: A collaborative inquiry into dream sharing as a resource for action researchers. Action Research, $0(0), 1-17$.

Barks, C. \& Moyne, J. (1995). The essential Rumi. New York, NY: HarperCollins.

Baron, C., \& Cayer, M. (2011). Fostering post-conventional consciousness in leaders: why and how? Journal of Management Development, 30(4), 344-365.

Basseches, M. (1984). Dialectical thinking and adult development (Vol. 3). Norwood, NJ: Ablex Pub. Corp.

Bateson, G. (1972). Steps to an ecology of mind. San Francisco, CA: Chandler.

Bateson, G. (2002). Mind and nature: A necessary unity. New York, NY: Hampton Press.

Bateson, N. (2016). Small arcs of larger circles. Charmouth, United Kingdom: Triarchy Press. [Kindle version]. Retrieved from https://www.amazon.com

Baxter Magolda, M. B. (2009). Authoring your life: Developing an internal voice to navigate life's challenges. Sterling, VA: Stylus Publishing, LLC.

Berger, J. G. (2003). A summary of the Constructive-Developmental Theory of Robert Kegan. Retrieved from https://wiki.canterbury.ac.nz/download/attachments/6358104/berger+on+kegan+n arrative.doc

Berger, J. G. (2012). Changing on the job: Developing leaders for a complex world. Stanford, CA: Stanford University Press. 
Berger, J. G., \& Fitzgerald, C. (2002). Leadership and complexity of mind: The role of executive coaching. In C. Fitzgerald, \& J. G. Berger (Eds.), Executive coaching: Practices and perspectives (pp. 27-57). Palo Alto, CA: Davies-Black.

Berger, J. G., \& Fitzgerald, C. (2019). Coaching for an increasingly complex world. In S. English, J. Manzi Sabatine, \& P. Brownell (Eds.), Professional coaching: Principles and practice (pp. 293-303). New York, NY: Springer Publishing Company.

Berger, J. G., \& Johnston, K. (2012). Cultivating leadership. In J. G. Berger, Changing on the job: Developing leaders for a complex world. Stanford, CA: Stanford University Press.

Berman, M. (1981). The re-enchantment of the world. Ithaca, NY: Cornell University Press.

Blackstone, J. (2006). Intersubjectivity and nonduality in the psychotherapeutic relationship. Journal of Transpersonal Psychology, 38(1), 25-40.

Blackstone, J. (2012, May 31). Embodied nonduality. Retrieved from https://undividedjournal.com/2012/05/31/embodied-nonduality/

Bohm, D. (2002). Wholeness and the implicate order. London, United Kingdom: Routledge.

Boyd, R. D. (1991). Personal transformations in small groups: A Jungian perspective. London, United Kingdom: Routledge.

Bradbury, H., Glenzer, K., Ku, B., Columbia, D., Kjellström, S., Ortiz Aragón, A., ... Gray, P. (2019). What is good action research: Quality choice points with a refreshed urgency. Action Research, 17(1), 14-18. 
Bradbury, H., \& Lichtenstein, B. M. B. (2000). Relationality in organizational research: Exploring the space between. Organization Science, 11(5), 551-564.

Bradbury, H., Waddell, S., O’ Brien, K., Apgar, M., Teehankee, B., \& Fazey, I. (2019). A call to action research for transformations: The times demand it. Action Research, 17(1), 3-10.

Brown, B. C. (2012). Leading complex change with post-conventional consciousness. Journal of Organizational Change Management, 25(4), 560-577.

Bruce, A., \& Davies, B. (2005). Mindfulness in hospice care: Practicing meditation-inaction. Qualitative Health Research, 15, 1329-1344.

Center of Action Research (2018, August 20). VUCA leadership and action research Center of Action Research webinar series [Video file]. Retrieved from https://www.youtube.com/watch?v=oUMDhgQJmi4

Chandler, H. M., Alexander, C. N., \& Heaton, D. P. (2005). The transcendental meditation program and postconventional self-development: A 10-year longitudinal study. Journal of Social Behavior and Personality, 17, 93-121.

Chen, S. (2019, August 5). Evolution toward wholeness: Integrating a holistic paradigm into adult development [web log comment]. Retrieved from https://resonancepath.com/evolution-toward-wholeness/

Chopra, D., \& Kafatos, M. C. (2017). You are the universe: Discovering your cosmic self and why it matters. New York, NY: Harmony Books.

Coghlan, D. (2005). Ignatian spirituality as transformational social science. Action Research, 3(1), 89-107.

Commons, M. L., Trudeau, E. J., Stein, S. A., Richards, F. A., \& Krause, S. R. (1998). 
Hierarchical complexity of tasks shows the existence of developmental stages. Developmental Review, 18(3), 237-278.

Cook-Greuter, S. R. (1999). Postautonomous ego development: A study of its nature and measurement (Doctoral dissertation). Retrieved from ProQuest Dissertations \& Theses Global. (9933122)

Cook-Greuter, S. R. (2002). A detailed description of the development of nine action logics adapted from ego development theory for the leadership development framework. Retrieved from http://www.cook-greuter.com

Cook-Greuter, S. R. (2004). Making the case for a developmental perspective. Industrial \& Commercial Training, 36(6), 275-281.

Cook-Greuter, S. R. (2011). A Report from the Scoring Trenches. In A. H. Pfaffenberger, P. W. Marko, \& A. Combs (Eds.), The postconventional personality: Assessing, researching, and theorizing higher development. (pp. 57-71). Albany, NY: SUNY Press.

Cook-Greuter, S. R. (2013). Nine levels of increasing embrace in ego development: A full-spectrum theory of vertical growth and meaning making. Retrieved from http://www.cook-greuter.com

Cook-Greuter, S. R., \& Soulen, J. (2007). The developmental perspective in integral counseling. Counseling \& Values, 51(3), 180-192.

Coughlin, C. (2015). Developmental coaching to support the transition to selfauthorship. New directions for adult and continuing education, 2015(148), 17-25. 
Cox, E. \& Jackson, P. (2010). Developmental coaching. In E. Cox, T. Bachkirova, D. Clutterbuck (Eds.), The Complete Handbook of Coaching (1st ed.) (pp. 217-230). London, United Kingdom: Sage.

Crenshaw, K., (1991). Mapping the margins: Intersectionality, identity politics, and violence against women of color. Stanford Law Review, 43(6), 1241-1299.

Csikszentmihalyi, M. (2008). Flow: The psychology of optimal experience. New York, NY: HarperCollins.

Diehl, F. (2010). Eutopiagraphies: Narratives of preferred-future selves with implications for developmental coaching (Doctoral dissertation). Retrieved from ProQuest Dissertations and Theses Global. (3417072)

Distefano, I. (2019). Developmental coaches making meaning of their work. Unpublished manuscript.

Drago-Severson, E. (2009). Leading adult learning: Supporting adult development in our schools. Thousand Oaks, CA: Corwin (a joint publication with the National Staff Development Council).

Ellingson, L. L. (2017). Embodiment in qualitative research. Abingdon, United Kingdom: Routledge.

Eriksen, K. (2006). The constructive developmental theory of Robert Kegan. The Family Journal: Counseling and Therapy for Couples and Families, 14(3), 290-298.

Fischer, K. W., \& Rose, S. P. (1998). Growth cycles of brain and mind. Educational Leadership, 56(3), 56-60.

Fisher, D., Rooke, D., \& Torbert, W. R. (2000). Personal and organisational transformations: Through action inquiry. Boston, MA: EdgelWork Press. 
Flaherty, J. (2010). Coaching: Evoking excellence in others. New York, NY: Routledge.

Focht, A. \& Ponton, M. (2015). Identifying primary characteristics of servant leadership: Delphi study. International Journal of Leadership Studies, 9(1), 44-61.

Foster, P. (2014). Collaborative developmental action inquiry. In D. Coughlan \& M. Brydon-Miller (Eds.), Sage encyclopedia of action research management, (pp. 124-128). London, United Kingdom: Sage.

Frankl, V. (2000). Man's search for ultimate meaning. New York, NY: Basic Books. Freinacht, H. (2017). The listening society: A metamodern guide to politics. Metamoderna ApS. [Kindle version]. Retrieved from http://www.amazon.com Freire, P. (1982). Pedagogy of the oppressed. New York, NY: Continuum.

Gendlin, E. (1982). Focusing (2nd ed.). New York, NY: Bantam Books.

Ghosh, R., Haynes, R. K., \& Kram, K. E. (2013). Developmental networks at work: Holding environments for leader development. Career Development International, 18(3), 232-256.

Greenleaf, R. (1977). The servant as leader. Indianapolis, IN: Greenleaf Center.

Harris, L. S., \& Kuhnert, K. W. (2008). Looking through the lens of leadership: a constructive developmental approach. Leadership \& Organization Development Journal, 29(1), 47-67.

Hawkins, P. \& Smith, N. (2006). Coaching, mentoring, and organizational consultancy: supervision and development. Maidenhead, United Kingdom: Open University Press.

Hayashi, A. (2018). Social presencing theatre. Retrieved from: https://arawanahayashi.com/origins/ 
Heifetz, R. A., Grashow, A., \& Linsky, M. (2009). The practice of adaptive leadership: Tools and tactics for changing your organization and the world. Boston, MA: Harvard Business Press.

Herdman-Barker, E., \& Torbert, W. R., (2011). Generating and measuring practical differences in leadership performance at postconventional action-logics:

Developing the Harthill Leadership Development Profile. In A. H. Pfaffenberger, P. W. Marko, \& A. Combs (Eds.), The postconventional personality: Assessing, researching, and theorizing higher development. (pp. 39-56). Albany, NY: SUNY Press.

Heron, J. (1996). Co-operative Inquiry. London, United Kingdom: Sage.

Heron, J. (1998). Sacred science. Person-centred inquiry into the spiritual and the subtle. Ross-on-Wye, United Kingdom: PCCS Books.

Heron, J. (2008). Notes on spiritual leadership and relational spirituality. Retrieved from http://www.human-inquiry.com/slrs.htm

Heron, J., \& Reason, P. (2008). Extending epistemology within a co-operative inquiry. In P. Reason \& H. Bradbury (Eds.), The Sage handbook of action research: Participative inquiry and practice, (pp. 366-380). London, United Kingdom: Sage.

Herr, K., \& Anderson, G. L. (2014). The action research dissertation: A guide for students and faculty. Thousand Oaks, CA: Sage publications.

Hewlett, D. C. (2004). A qualitative study of postautonomous ego development: The bridge between postconventional and transcendent ways of being (Doctoral 
dissertation). Retrieved from ProQuest Dissertations \& Theses Global. (305049436).

Hosking, D. M. (2011). Moving relationality: Meditations on a relational approach to leadership. In A. Bryman, D. L. Collinson, K. Grint, B. Jackson, \& M. Uhl-Bien (Eds.), The Sage handbook of leadership (pp. 455-467). Thousand Oaks, CA: Sage.

Inglis, J., \& Steele, M. (2005). Complexity intelligence and cultural coaching: Navigating the gap between our societal challenges and our capacities. Integral Review, 1, $35-46$.

Knights, J., Grant, D., Young, G. (Eds.). (2018). Leading beyond the ego: How to become a transpersonal leader. New York, NY: Routledge.

Jironet, K., \& Stein, M. (2013). A psycho-spiritual model for leadership development. Retrieved from http://inclaritas.com/wpcontent/uploads/2013/07/Transformational-...-2012.pdf

Joiner, B. (2011). Leadership at postconventional stages of adult development. In A. H. Pfaffenberger, P. W. Marko, \& A. Combs (Eds.), The postconventional personality: Assessing, researching, and theorizing higher development. (pp. 133149). Albany, NY: SUNY Press.

Joiner, B. (2013). Leadership agility: a global imperative. Dialogue. Duke University, 4853.

Joiner, B., \& Josephs, S. (2007). Leadership agility: Five levels of mastery for anticipating and initiating change (1st ed.). San Francisco, CA: Jossey-Bass. 
Jones, S., \& Woglom, J. F. (2015). Behind the body-filled scenes: Methodologies at work on the body in graphica. In M. Perry \& C. L. Medina (Eds.), Methodologies of Embodiment: Inscribing bodies in qualitative research. (pp. 116-137). New York, NY: Routledge.

Jung, C. G. (1975). Collected Works. Princeton, NJ: Princeton University Press.

Kegan, R. (1980). Making meaning: The constructive-developmental approach to persons and practice. The Personnel and Guidance Journal, 58, 373-380.

Kegan, R. (1982). The evolving self. Cambridge, MA: Harvard University Press.

Kegan, R. (1994). In over our heads: The mental demands of modern life. Cambridge, MA: Harvard University Press.

Kegan, R., \& Lahey, L. L. (2009). Immunity to change: How to overcome it and unlock potential in yourself and your organization. Boston, MA: Harvard Business Press.

Kegan, R., \& Lahey, L. L. (2016). An everyone culture: Becoming a deliberately developmental organization. Boston, MA: Harvard Business Press.

Kelly, E. (2013). Warren Buffet's transformation in leadership, part 2. Integral Leadership Review. Retrieved from http://integralleadershipreview.com/8992transformation-in-leadership-part-2/

Kennedy, D. L. (2012). The impact of development on coaches' use of self as instrument (Doctoral dissertation). Retrieved from ProQuest Dissertations and Theses Global. (3503054)

King, L. A. (2011). The challenge of ego development. Intentional versus active development. In A. H. Pfaffenberger, P. W. Marko, \& A. Combs (Eds.), The 
postconventional personality: Assessing, researching, and theorizing higher development. (pp. 163-174). Albany, NY: SUNY Press.

Ladkin, D. (2010). Rethinking leadership: A new look at old leadership questions. Northampton, MA: Edward Elgar.

Lahey, L., Souvaine, E., Kegan, R., Goodman, R., \& Felix, S. (2011). A guide to the subject-object interview: Its administration and interpretation. Cambridge, MA: Minds at Work.

Laske, O. E. (1999). An integrated model of developmental coaching. Consulting Psychology Journal: Practice and Research, 51, 139-159.

Laske, O. E. (2003). An integrated model of developmental coaching: Researching new ways of coaching and coach education. In Proceedings of the First ICF Coaching Research Symposium (52-61).

Laske, O. E. (2006). From coach training to coach education: Teaching coaching within a comprehensively evidence based framework. International Journal of Evidence Based Coaching and Mentoring 4(1), 45-57.

Ledwith, M. (2017). Emancipatory action research as a critical living praxis: From dominant narratives to counternarrative. In L. L. Rowell, C. D. Bruce, J. M. Shosh, \& M. M. Riel (Eds.), The Palgrave international handbook of action research (pp. 49-62). New York, NY: Palgrave Macmillan.

Legault, M. (2010). Becoming an ethical leader: An exploratory study of the developmental process (Doctoral dissertation). Retrieved from ProQuest Dissertations \& Theses Global. (305249881). 
Lichtenstein, B. \& Plowman, D. (2009). The leadership of emergence: a complex systems leadership theory of emergence at successive organizational levels. The Leadership Quarterly, 20(4), 617-630.

Lin, J., Oxford, R. L., \& Culham, T. E. (Eds.). (2016). Toward a spiritual research paradigm: Exploring new ways of knowing, researching and being. Charlotte, NC: Information Age Publishing.

Livesay, V. T. (2013). Exploring the paradoxical role and the experience of fallback in developmental theory (Doctoral dissertation). Retrieved from ProQuest Dissertations \& Theses Global. (1433819874)

Loevinger, J. (1976). Ego development: Conceptions and theories. San Francisco, CA: Jossey Bass.

Marshall, J. (1999). Living life as inquiry. Systematic Practice and Action Research, $12(2), 155-171$.

Maslow, A. H. (1971). The farther reaches of human nature. New York, NY: Viking Press.

McCallum, D. C. (2008). Exploring the implications of a hidden diversity in Group Relations Conference learning: A developmental perspective (Doctoral dissertation). Retrieved from ProQuest Social Sciences Premium Collection. (304625846)

McCallum, D. C., \& Nicolaides, A. (2015). Cultivating intention (as we enter the fray): The skillful practice of embodying presence, awareness, and purpose as action researchers. In H. Bradbury (Ed.), The SAGE Handbook of Action Research. (pp. 643-652). London, United Kingdom: Sage. 
McCaslin, M. (2008). The nature of transpersonal leadership: Building potentiating relationships. Retrieved from http://integralleadershipreview.com/5058-featurearticle-the-nature-of-transpersonal-leadership-building-potentiating-relationships/

McCauley, C. D., Drath, W. H., Palus, C. J., O'Connor, P. M. G., \& Baker, B. A. (2006). The use of constructive-developmental theory to advance the understanding of leadership. The Leadership Quarterly, 17(6), 634-653.

Merron, K., Fisher, D., \& Torbert, W. R. (1987). Meaning making and management action. Group \& Organization Studies, 12(3), 274-286.

Miller, M. E., \& Cook-Greuter, S. R. (1994). Transcendence and mature thought in adulthood: The further reaches of adult development. Lanham, MD: Rowman \& Littlefield.

Mills, P. J., Barsotti, T. J., Blackstone, J., Chopra, D., \& Josipovic Z. (2020). Nondual awareness and the whole person. Global Advances in Health and Medicine, 9, 14.

Molenkamp, R. (2012). The field. Retrieved from https://www.grouprelations.org Nicolaides, A. (2008). Learning their way through ambiguity: Explorations of how nine developmentally mature adults make sense of ambiguity (Doctoral dissertation). Retrieved from ProQuest Social Sciences Premium Collection. (304625192)

Nicolaides, A., \& McCallum, D. C. (2013). Inquiry in action for leadership in turbulent times: Exploring the connections between transformative learning and adaptive leadership. Journal of Transformative Education, 11(4), 246-260.

Nicolaides, A., \& McCallum, D. C. (2014). Accessing the blind spot: The U process as seen through the lens of developmental action inquiry. In O. Gunnlaugson, C. 
Baron, \& M. Cayer (Eds.), Perspectives on Theory U: Insights from the field. (pp. 48-60). Hershey, PA: IGI Global.

Palmer, P. (2004). A hidden wholeness: The journey toward an undivided life. San Francisco, CA: Jossey-Bass.

Palmer, W. (2008). The intuitive body. Berkeley, CA: Blue Snake Books.

Palus, C. J., \& Drath, W. H. (1995). Evolving leaders: A model for promoting leadership development in programs. Greensboro, NC: Center for Creative Leadership.

Patton, M. (2015). Qualitative research \& evaluation methods (4th ed.). Thousand Oaks, CA: Sage.

Pearce, C. L., \& Conger, J. A. (2003). All those years ago. The historical underpinnings of shared leadership. In C. L. Pearce \& J. A. Conger (Eds.), Shared leadership: Reframing the hows and whys of leadership. (pp. 1-18). Thousand Oaks, CA: Sage.

Perry, K. A. (2014). Coach, know thyself: The developmental consciousness of professional coaches (Doctoral dissertation). Retrieved from ProQuest Dissertations \& Theses Global. (3631514).

Perry, M., \& Medina, C. L. (2015). Introduction: Working through the contradictory terrain of the body in qualitative research. In M. Perry \& C. L. Medina (Eds.), Methodologies of embodiment: Inscribing bodies in qualitative research. (pp. 113). New York, NY: Routledge.

Petrie, N. (2011). Future trends in leadership development. Center for Creative Leadership white paper, 5(5). Retrieved from http://law.scu.edu/wpcontent/uploads/leadership/Future-Trends-in-Leadership-Development.pdf 
Petrie, N. (2015). The how-to of vertical leadership development-Part 2. 30 experts, 3 conditions, and 15 approaches. White Paper. Greensboro, NC: Center for Creative Leadership.

Pfaffenberger, A. (2005). Optimal adult development: An inquiry into the dynamics of growth. Journal of Humanistic Psychology, 45(3), 279-301.

Pfaffenberger, A. H. (2011). Assessing postconventional personality. How valid and reliable is the sentence completion test? In A. H. Pfaffenberger, P. W. Marko, \& A. Combs (Eds.), The postconventional personality: Assessing, researching, and theorizing higher development. (pp. 9-22). Albany, NY: SUNY Press.

Potter, P. (2017). Becoming a coach: Transformative learning and hierarchical complexity of coaching students (Doctoral dissertation). Retrieved from ProQuest Dissertations \& Theses Global. (10258038)

Prendergast, J. J. (2019). The deep heart: Our portal to presence. Boulder, CO: Sounds True.

Presley, S. P. (2014). How leaders engage in complexity leadership: Do action-logics make a difference? (Doctoral dissertation). Retrieved from ProQuest Dissertations \& Theses Global. (1502794919).

Reams, J. (2015). The heart and soul of leadership: A transpersonally oriented examination of how quality of presence impacts leadership. Retrieved from https://www.researchgate.net/publication/265324228_The_Heart_and_Soul_of_L eadership_A_Transpersonally_Oriented_Examination_of_How_Quality_of_Prese nce_Impacts_Leadership 
Reams, J., Gunnlaugson, O., \& Reams, J. (2014). Cultivating leadership through deep presencing and awareness based practices. In K. G. Schuyler, J. E. Baugher, K. Jironet, \& L. Lid-Falkman (Eds.). Leading with spirit, presence, and authenticity: A volume in the International Leadership Association series, Building Leadership Bridges (pp. 39-58). San Francisco, CA: Jossey-Bass.

Reason, P. (1994). Three approaches to participative inquiry. In N. K. Denzin \& Y. Lincoln (Eds.), Handbook of Qualitative Research (pp. 324-339). Thousand Oaks, CA: Sage.

Reason, P. (2000). Action research as spiritual practice. Learning Community Conference. University of Surrey. Retrieved from http://www.peterreason.eu/Papers/AR_as_spiritual_practice.pdf

Reason, P., \& Bradbury, H. (2008). The Sage handbook of action research. Participative inquiry and practice. London, United Kingdom: Sage.

Reason, P., \& Rowan, J. (Eds.). (1981). Human inquiry: A sourcebook of new paradigm research. Chichester, United Kingdom: Wiley.

Rooke, D., \& Torbert, W. R. (1998). Organizational transformation as a function of CEO's developmental stage. Organization Development Journal, 16(1), 11-28.

Rooke, D., \& Torbert, W. R. (2005). Seven transformations of leadership. Harvard Business Review, 83(4), 67-75.

Saldaña, J. (2016). The coding manual for qualitative researchers. London, United Kingdom: Sage Publications.

Scharmer, C. O. (2009). Theory U: Leading from the future as it emerges. Oakland, CA: Berrett-Koehler Publishers. 
Scharmer, C. O. (2018). The essentials of Theory U: Core principles and applications. Oakland, CA: Berrett-Koehler Publishers.

Scharmer, C. O. (2020, June 28). Turning toward our blind spot: Seeing the shadow as a source for transformation. Retrieved from: https://medium.com/presencinginstitute-blog/turning-toward-our-blind-spot-seeing-the-shadow-as-a-source-fortransformation-aff23d480a55

Scharmer, C. O., \& Hübl, T. (2020, March 31). Otto Scharmer in dialogue with Thomas Hübl: Global social witnessing and the current crisis [Video file]. Retrieved from https://thomashuebl.com/global-social-witnessing-and-current-crisis-ottoscharmer-thomas-huebl/

Scharmer, C. O., \& Kaeufer, K. (2013). Leading from the emerging future: From egosystem to eco-system economies. San Francisco, CA: Berrett-Koehler Publishers.

Schein, E. (2013). Humble inquiry: The gentle art of asking instead of telling. Thousand Oaks, CA: Berrett-Koehler.

Schön, D. (1983). The reflective practitioner: How professionals think in action. New York, NY: Basic Books.

Scott, S. A. (2009). The effects of personal growth activities on individuals in postconventional stages of ego development (Doctoral dissertation). Retrieved from ProQuest Dissertations and Theses database. (3343849)

Seigfried, C. H. (1996). Pragmatism and feminism: reweaving the social fabric. Chicago, IL: University of Chicago Press.

Sendjaya, S. (2005). Leading with the heart. Monash Business Review, 1(2), 34-40. 
Senge, P. M., Scharmer, C. O., Jaworski, J., \& Flowers, B. S. (2004). Presence: Human purpose and the field of the future. Cambridge, MA: SoL.

Sharma, B. (2019). Maturity coaching: Enabling vertical development in leaders. In S. English, J. Manzi Sabatine, \& P. Brownell (Eds.), Professional coaching: Principles and practice (pp. 247-260). New York, NY: Springer Publishing Company.

Sharma, B., \& Cook-Greuter, S. R. (2015). Polarities and ego development: Polarity thinking in ego development theory and developmental coaching. Retrieved from https://www.cook-greuter.com/Sharma\%20CookGreuter\%20paper\%20EAIF\%20SUNY.pdf

Silsbee, D. K. (2008). Presence-based coaching: Cultivating self-generative leaders through mind, body, and heart. San Francisco, CA: Jossey-Bass.

Silsbee, D. K. (2010). The mindful coach: Seven roles for helping people grow. San Francisco, CA: Jossey-Bass.

Silsbee, D. (2018). Presence-based leadership: Complexity practices for clarity, resilience, and results that matter. Asheville, NC: Yes! Global.

Smith, S. (2016). Growing together: The evolution of consciousness using collaborative developmental action inquiry (Doctoral dissertation). Retrieved from http://www.williamrtorbert.com/wpcontent/uploads/2013/09/Smith_Shakiyla_FIN AL.pdf

Smith, K. K., \& Berg, D. N. (1987). Paradoxes of group life: Understanding conflict, paralysis, and movement in group dynamics. San Francisco, CA: Jossey-Bass. 
Souvaine, E., Lahey, L. L., \& Kegan, R. (1990). Life after formal operations: Implications for a psychology of the self. In C. N. Alexander \& E. Langer (Eds.), Higher stages of human development: Perspectives on adult growth, (pp. 229257). New York, NY: Oxford University Press.

Stevens-Long, J. (2011). The prism self revisited: The matter of integrity. In A. H. Pfaffenberger, P. W. Marko, \& A. Combs (Eds.), The postconventional personality: Assessing, researching, and theorizing higher development. (pp. 221232). Albany, NY: SUNY Press.

Strozzi-Heckler, R. (2007). The leadership dojo. Build your foundation as an exemplary leader. Berkeley, CA: Frog Books.

Torbert, W. R. (1987). Managing the corporate dream: Restructuring for long-term success. Homewood, IL: Dow Jones-Irwin.

Torbert, W. R., (1994). Cultivating postformal adult development: Higher stages and contrasting interventions. In M. E. Miller \& S. R. Cook-Greuter (Eds.), Transcendence and mature thought in adulthood: The further reaches of adult development (pp. 181-203). Lanham, MD: Rowman \& Littlefield.

Torbert, W. R. (1996). The 'chaotic' action awareness of transformational leaders. International Journal of Public Administration, 19(6), 911-939.

Torbert, B. (2003). Personal and organizational transformations though action inquiry. London, United Kingdom: The Cromwell Press.

Torbert, W. R. (2013). Listening into the dark: An essay testing the validity and efficacy of collaborative developmental action inquiry for describing and encouraging 
transformations of self, society, and scientific inquiry. Integral Review, 9(2), 264299.

Torbert, W. R., (2014). Brief comparison of five developmental measures: the GLP, the LDP, the MAP, the SOI, and the WUSCT. Retrieved from http://www.williamrtorbert.com/wpcontent/uploads/2012/03/DevMeasuresCompa red4714.pdf

Torbert, W. R., (2017). The pragmatic impact on leaders \& organizations of interventions based in the collaborative developmental action inquiry approach. Integral Leadership review. Retrieved from: http://integralleadershipreview.com/15836collaborative-developmental-action-inquiry/

Torbert, W. R. \& Associates (2004). Action inquiry: The secret of timely and transforming leadership. San Francisco, CA: Berrett-Koehler.

Torbert, W. R. \& Erfan, A., (2019, September). Possible mistakes of late action-logic actors in a polarized world [Paper presentation]. Growth Edge Network Conference, Marriottsville, MD.

Travis, F., \& Brown, S. (2011). My brain made me do it: Brain maturation and levels of self-development. In A. H. Pfaffenberger, P. W. Marko, \& A. Combs (Eds.), The postconventional personality: Assessing, researching, and theorizing higher development (pp. 23-38). Albany, NY: SUNY Press.

Uhl-Bien, M., \& Marion, R. (2011). Complexity leadership theory. In A. Bryman, D. L. Collinson, K. Grint, B. Jackson, \& M. Uhl-Bien (Eds.), The Sage handbook of leadership (pp. 468-482). Thousand Oaks, CA: Sage.

Western, S. (2013). Leadership: A critical text (2nd ed.). Thousand Oaks, CA: Sage. 
Wheatley, M. J. (1992). Leadership and the new science: Learning about organization from an orderly universe. San Francisco, CA: Berrett-Koehler.

Wheatley, M. J. (2017). Who do we choose to be? Oakland, CA: Berrett-Koehler.

Wheatley, M. J., \& Frieze, D. (2011). Walk out walk on: A learning journey into communities daring to live the future now. San Francisco, CA: Berrett-Koehler.

Wilber, K. (1979). No boundaries: Eastern and Western approaches to personal growth. Boston, MA: Shambhala.

Wilber, K. (2000). A theory of everything: An integral vision for business, politics, science and spirituality. Boston, MA: Shambhala.

Wilber, K. (2003). Waves, streams, states, and self: An outline of an integral psychology. The Humanistic Psychologist, 31(2-3), 22-49.

Wildflower, L. (Ed.). (2006). Researched theories: Origins and applications of coaching. Santa Barbara, CA: Fielding Graduate University.

Winnicott, D. W. (1965). The maturational process and the facilitating environment: Studies in the theory of emotional development. London, United Kingdom: Karnac Books.

Yeyinmen, C. (2016). Uses of complex thinking in higher education adaptive leadership practice: A multiple-case study (Doctoral dissertation). Retrieved from https://dash.harvard.edu/bitstream/handle/1/27112707/YEYINMENDISSERTATION-2016.pdf?sequence=1\&isAllowed=y. 


\section{APPENDIX A}

\section{Co-inquiry map}

The co-inquiry map served as an illustration of its spiraling, emergent movement, and of the key factors substantiating the group's inquiry work.

\section{Individual internal factors}

Thoughts and mental processes

Emotions and emotional intelligence

Physical sensations

Awareness and intentionality

Identities, cultures and intersectionalities

Personality

Purpose

Values and beliefs

Developmental story

Developmental readiness

Meaning-making and growth edge

Cognitive complexity

Symbolic development

Inner state

Depth

Intuitions and other unconscious material

Collective internal factors

Group's shared meaning, values, rules

Group developmental trajectory

Intersubjective dynamics

Unconscious collective dynamics

\section{Individual external factors}

Aspect

Presence

Voice (and silence)

Verbal expression

Non-verbal communication

Skills

Initiatives, actions and contributions

Personal ecologies

Professional ecologies

Source,

Spirit,

the Field

\section{Collective external factors}

Group characteristics

Group's actions, processes, rituals, and outcomes Interpersonal dynamics Power dynamics Contextual culture and political and social agenda 


\section{APPENDIX B}

Post-meeting Questionnaire

The following questionnaire was posted in a shared Google Drive and sent via email after each group meeting, in order to gather the co-inquirers' thoughts after our experiences together.

1) What is (still) with you after the experience of the meeting? (describe any observations, thoughts, insights, questions, feelings, sensations that emerged during or in relation to the meeting)

2) What did you observe/learn about yourself? (describe any learnings about your assumptions, your way of being with others, your capacities and skills, your approach of your growth edge...)

3) What did you notice in and about the group during the meeting?

4) What did you notice in the other members of the group?

5) Anything else you would like to share about the meeting and/or your experience? 


\section{APPENDIX C}

\section{Post-co-inquiry Interview Guide}

The following interview guide informed the individual interviews that I conducted with the co-inquirers after the last group meeting. It allowed them to reflect on their experience and their evolution during the months of the co-inquiry, and myself to gather their concluding and emerging thoughts at the completion of our work together.

Prior to the interview, I asked each co-inquirer to send me the following elements via email:

- How do you identify yourself in terms of gender and race?

- How old are you?

- What is your MAP scoring as assessed by Suzanne Cook-Greuter?

- How many years of experience in coaching do you have?

- Do you currently hold a coaching certification? if yes, which one?

- What pseudonym would you like me to use to refer to you in my dissertation?

\section{Developmental reflexivity}

$\underline{\text { Self }}$

- At the completion of our co-inquiry, how are you different from when it began?

What has shifted in your awareness, intentions and behaviors?

- What have you learned about yourself (as a coach) from the co-inquiry?

- How has your understanding and experience of your growth edge evolved?

Others and the group

- How did you grow with the group? In what ways the other members served as mirrors and/or inspiration? 
- How would you describe the group's dynamic and how it has evolved over time?

- What did you observe in terms of co-creation?

\section{Experience of the co-inquiry process}

- What aspects of our work together supported your development?

- What aspects of our work were most challenging/natural for you?

- How could our work together have been more supportive of your development? And of the group as a system generating development?

- What have you learned about the expansion of consciousness through our work? 


\section{APPENDIX D}

\section{Trees}

Examples of "trees" that supported my analysis serving as organic, living structures to organize my evolving thoughts and insights.

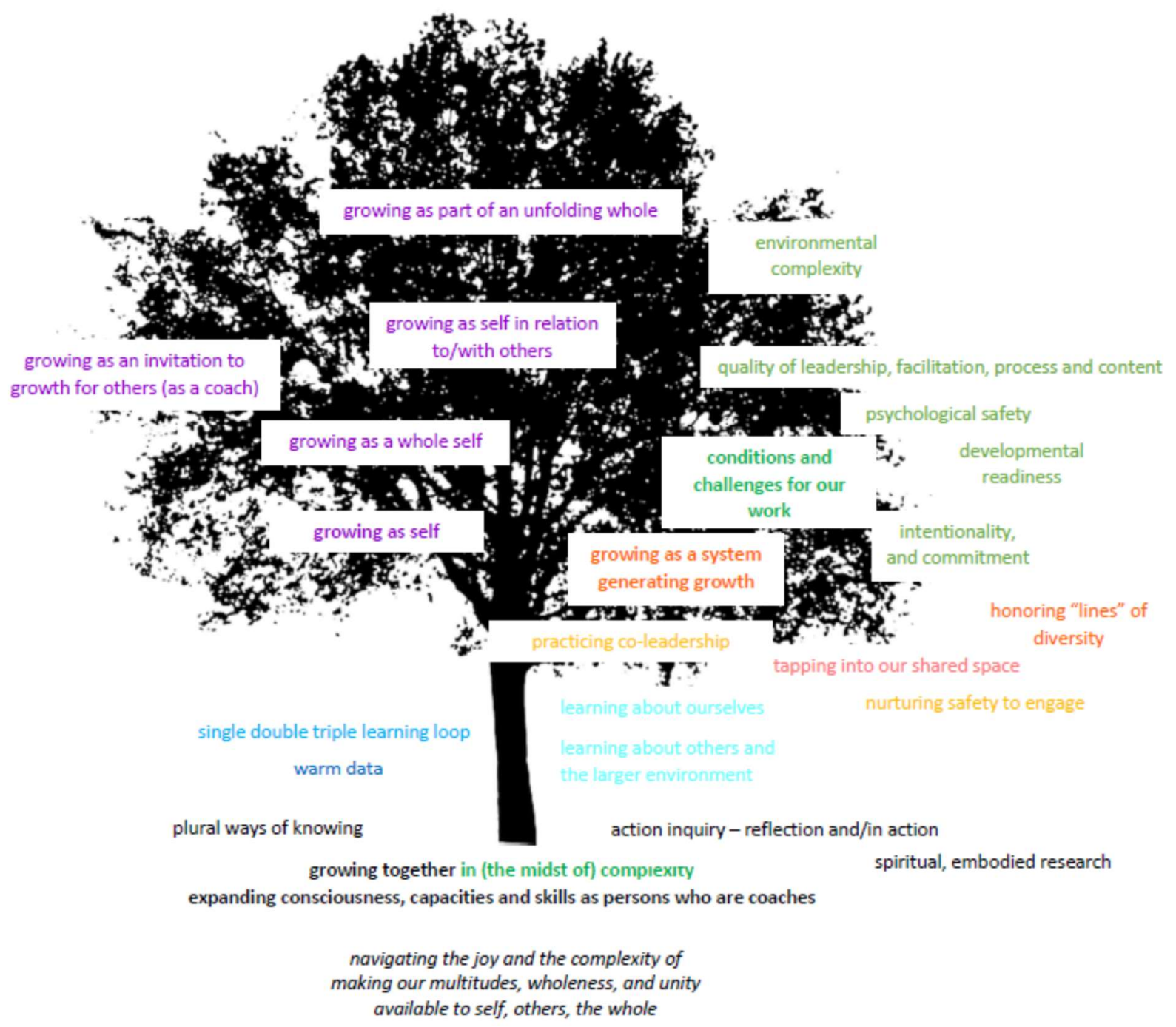




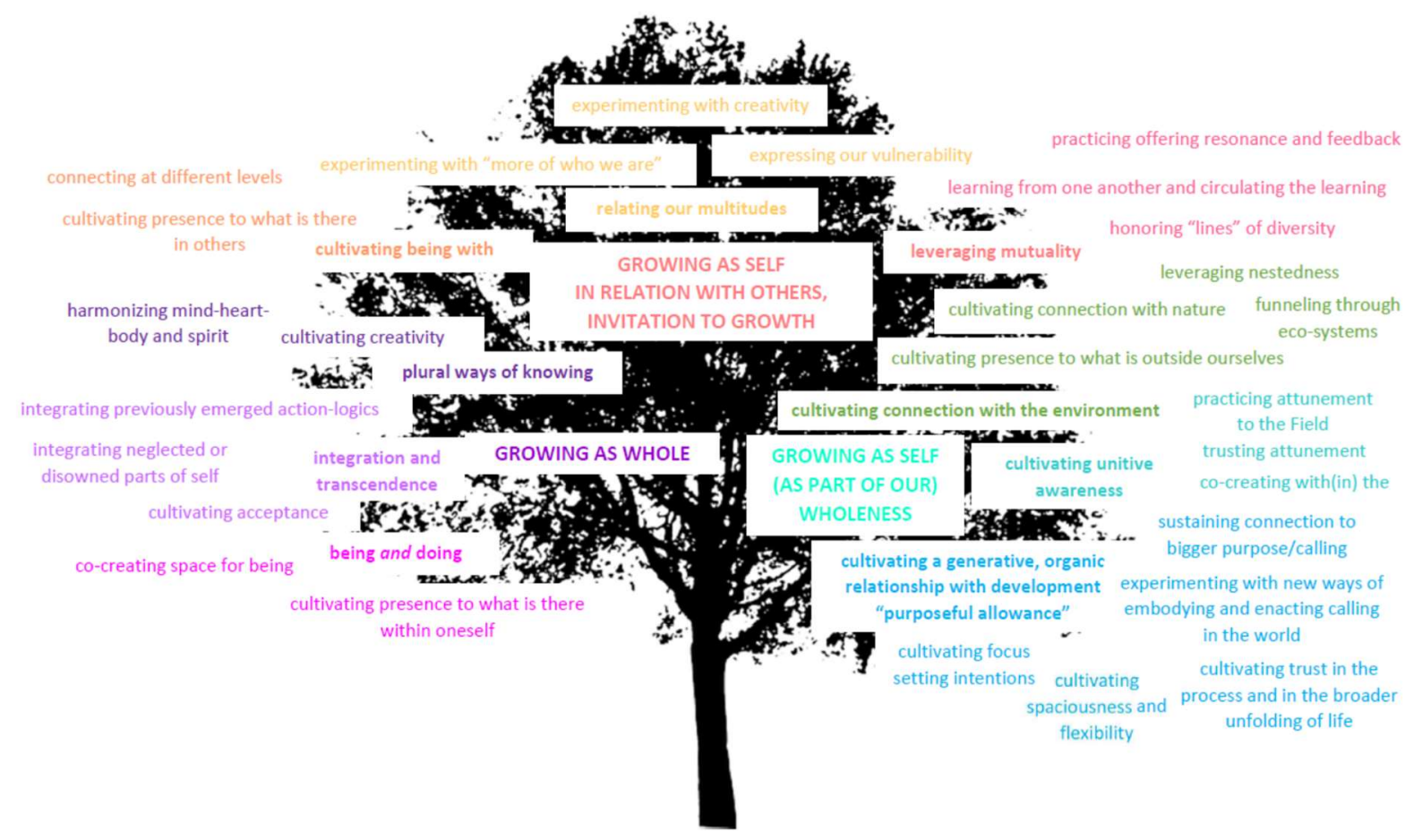

growing together in the midst of complexity as instruments for growth

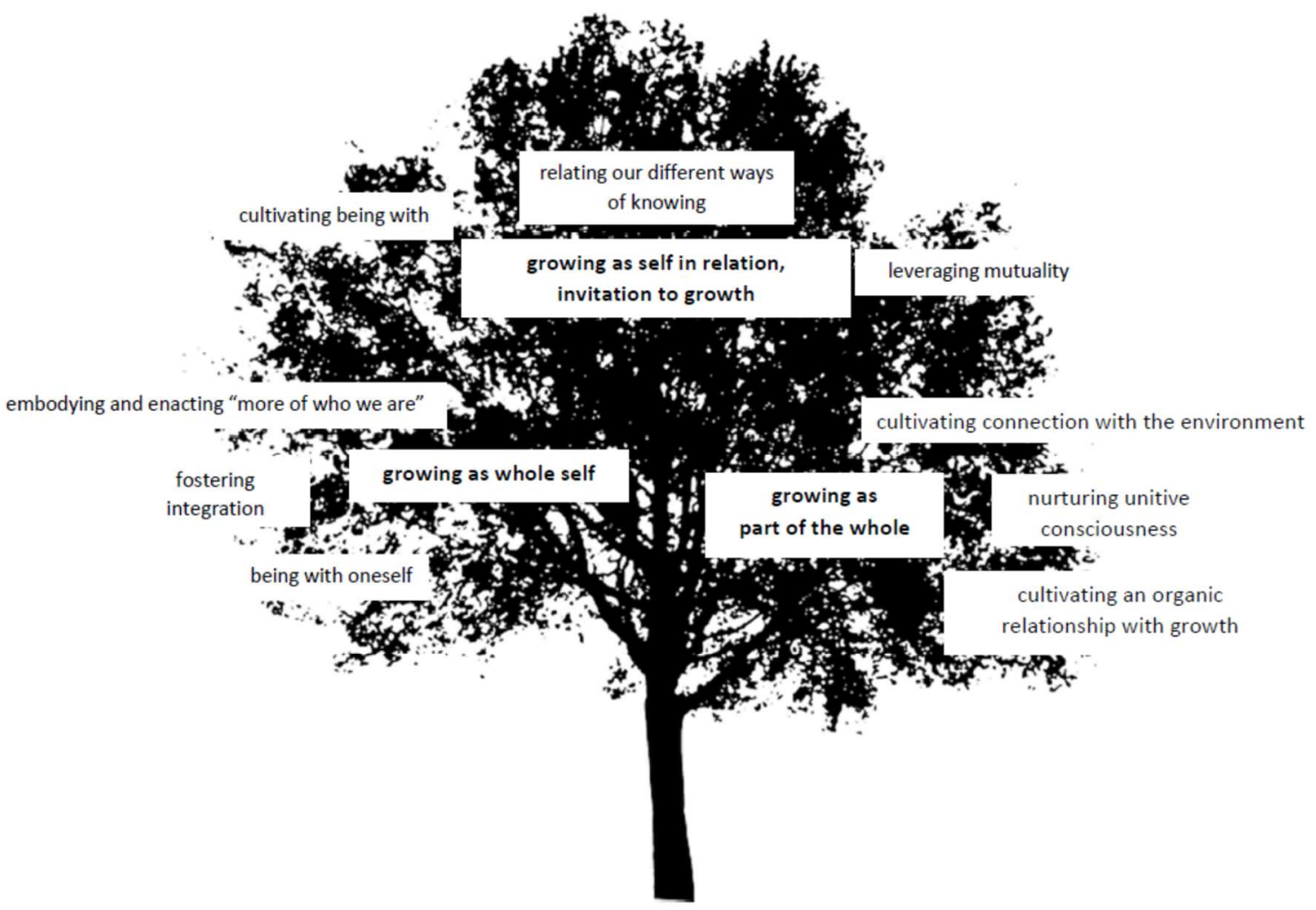

growing together as instruments for growth in the midst of complexity 
IRB \#: IRB-2020-101

Title: The Consciousness of Developmental Coaches: Generating Knowledge and Growth through Action Inquiry Creation Date: 11-25-2019

End Date: 12-1-2020

Status: Approved

Principal Investigator: Ilaria Distefano

Review Board: USD IRB

Sponsor:

\section{Study History}

\begin{tabular}{lll}
\hline Submission Type Initial & Review Type Expedited & Decision Approved \\
\hline Submission Type Modification & Review Type Expedited & Decision Approved \\
\hline
\end{tabular}

\section{Key Study Contacts}

\begin{tabular}{lll}
\hline Member Ilaria Distefano & Role Principal Investigator & $\begin{array}{l}\text { Contact } \\
\text { idistefano@sandiego.edu }\end{array}$ \\
\hline Member Cheryl Getz & Role Primary Contact & Contact cgetz@SanDiego.edu
\end{tabular}

